\title{
A Typology of Practice: The Archaeological Ceramics from Mahurjhari
}

\author{
Coline Lefrancq, Jason Hawkes, Jaseera C.M. and R.K. Mohanty
}

1. Institute Français de Pondichéry, 11 Saint Louis Street, Pondicherry 605001, India / Research Centre in Archaeology and Heritage, Université libre de Bruxelles, Brussels, Belgium / Research Centre HiSoMA, CNRS, Maison de l'Orient et de la Méditerranée, Lyon, France

2. Department of Asia, The British Museum, Great Russell Street, London, WC1B 3DG

3. Department of Epigraphy and Archaeology, Tamil University, Tanjore, Tamil Nadu, India

4. Deccan College Post Graduate and Research Institute, Pune 411006, Maharashtra, India

All hyperlinks in this PDF document link back to the original published version of this article online.

This article presents the results of the analysis of the pottery from the recently excavated site at Mahurjhari in central India. In doing so, it also proposes a new way of looking at archaeological ceramics in South Asia. Here, archaeological ceramics are traditionally defined on the basis of their visual appearance (their colour and texture), which results in a great deal of ambiguity, limits intra- and inter-regional comparison, and impedes a more material culture-based approach to their study. Indeed, there is no established pottery typology for the region in which this site is located, and despite the fact that ceramics invariably account for the majority of excavated assemblages they frequently remain unreported. Addressing this, we suggest that recording and analysing archaeological ceramics on the basis of how they were made (essentially, implementing a chaîne opératoire approach) might be a useful way to proceed. Given that such approaches are new in this area, we explain what this entails, and then present the results of the analysis of this pottery assemblage using these methods-defining classes of pottery on the basis of traces left by the ways they were made. With a typology thus defined on the basis on the practice of pottery manufacture, we then seriate the assemblage with reference to recent AMS dates obtained from the site and suggest a chronological sequence for the pots from this site. These results are then framed within a wider discussion of the potential value of the application of new ways of looking at archaeological ceramics in South Asia.

Keywords: archaeology, pottery analysis, ceramics, Mahurjhari, early historic, typologies, chaîne opératoire, South Asia, Vidarbha This open access publication was funded by the European Research Council, grant agreement no. 609823.

(c) Author(s). Except where otherwise noted, content from this work may be used under the terms of the Creative Commons Attribution 3.0 Unported licence, which permits unrestricted use, distribution, and reproduction in any medium, provided that attribution to the author(s), the title of the work, the Internet Archaeology journal and the relevant URL/DOI is given. 


\section{List of Figures}

Figure 1: Map illustrating the geographical parameters of the Vidarbha region, and the location of the site at Mahurjhari in relation to modern cities. Image credit: Authors.

Figure 2: The habitation site at Mahurjhari as it appears today. Image credit: Riza Abbas (Indian Numismatic Historical and Cultural Research Foundation).

Figure 3: Archaeological remains, including potsherds, bead-making debitage and carnelian bead rough-outs visible on the surface at the site. Image credit: Authors.

Figure 4: Plan of the archaeological site at Mahurjhari, showing areas of archaeological investigation. Image credit: Authors.

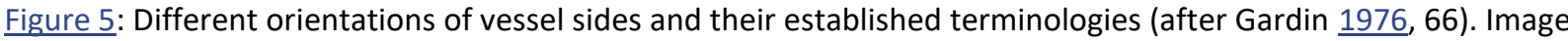
credit: Authors.

Figure 6: Upper left: rims and bases, Class 1 variant 1-type 1, MHR2002.A1; upper right: bases, Class 1 variant 1type 1 and base type 1, MHR2002.A4; lower left: external and internal sides of rim, Class 1 variant 1-type 1, MHR2002.A4.1; lower right: external and internal sides of rim, Class 1 variant 1-type 2, MHR2002.B4.53. Image credit: Authors.

Figure 7: External and internal sides of base, Class 1 variant 2-base type 1, MHR2002.A8.3. Image credit: Authors.

Figure 8: Left: external and internal sides of incised bodysherds, Class 1 variant 3, MHR2002.B4.29/59. Image credit: Authors.

Figure 9: Left: external side of shoulder, neck and bodysherds, Class 2, MHR2002.A6; right: internal side of shoulder, neck and bodysherds, Class 2, MHR2002.A6. Image credit: Authors.

Figure 10: Above: external and internal sides of bodysherds, Class 2 variant 1, MHR2002.A1; below: external and internal side of shoulders, Class 2 variant 1, MHR2002.A6, with the coil making the junction between the shoulder and the neck visible on the interior surface. Image credit: Authors.

Figure 11: External and internal sides of rims and bodysherds, Class 2 variant 2-type 5, MHR2002.A8. Image credit: Authors.

Figure 12: Above: external and internal sides of bodysherd with red slip and incised decoration, Class 2 variant 3, MHR2002.A10.10; middle: external and internal sides of bodysherd with red slip and appliqué decoration, Class 2 variant 3, MHR2002.A9. 29; below: external side of bodysherds with red slip and impressed (possibly twisted cord) decoration, Class 2 variant 3, MHR2002.B4.50/57. Image credit: Authors.

Figure 13: External and internal sides of necks with red and mica slip, Class 2 variant 4, MHR2002.A11.8/21/16. Image credit: Authors.

Figure 14: External sides of bodysherd with impressed decoration, Class 2 variant 5, including MHR2002.A4.30 (left), and MHR2002.A1.14/22 (right). Image credit: Authors.

Figure 15: External and internal sides of bodysherd with mud decoration, Class 2 variant 6, MHR2002.A7.7. Image credit: Authors.

Figure 16: External and internal sides of base, Class 3 variant 1-base type 1, MHR2002.A2.7. Image credit: Authors.

Figure 17: Above: external and internal sides of rim, Class 3 variant 2-type 2, MHR2002.A11.6; below: external and internal sides of rim, Class 3 variant 2-type 3, MHR2002.F-NE.16.no number. Image credit: Authors.

Figure 18: External and internal sides of rim, Class 4, MHR2002.B9.1-type 1. Image credit: Authors. 
Figure 19: Above: external and internal sides of rims, Class 5 variant 1, MHR2002.A4-type 9; middle: external and internal sides of rims, Class 5 variant 1- mix of types, MHR2002.C7; below: external and internal sides of base, Class 5 variant 1-base type 1, MHR2002.F-NW.150.69. Image credit: Authors.

Figure 20: External and internal sides of bowl, Class 5 variant 2-type 2, MHR2002.C8.19-53. Image credit: Authors.

Figure 21: Above: external and internal sides of rim, Class 5 variant 3-type 2 variant 1, MHR2002.F-SW.6.1; middle left: external side of rim, Class 5 variant 3-type 8, MHR2002.F-NW.124.1; middle right: external side of rim, Class 5 variant 3-type 8, MHR2002.F-NW.120.1; below: external and internal sides of bodysherds with incision and stamped decoration with 'sun-flower', Class 5 variant 3, MHR2002.B1.20/35. Image credit: Authors.

Figure 22: Above: external and internal sides of rim, Class 5 variant 4-type 4, MHR2002.E5.1; below: external side of a neck (left) and of a rim (right), Class 5 variant 4-type 2, MHR2002.D1.5/2. Image credit: Authors.

Figure 23: Above: external and internal sides of rim, Class 6 variant 1-type 2, MHR2002.C1.13; below: external and internal sides of rim, Class 6 variant 3-type 1, MHR2002.E5.2. Image credit: Authors.

Figure 24: Above: external and internal sides of rim, Class 6 variant 2-type 9, MHR2002.E6.26; below: external and internal sides of rim, Class 6 variant 2-type 2, MHR2002.E9.5. Image credit: Authors.

Figure 25: External and internal sides of rim, Class 6 variant 3-type 1, MHR2002.E11.9.

Figure 26: External and internal sides of bodysherd, Class 7 variant 1, MHR2002.B11.12. Image credit: Authors.

Figure 27: Above: external and internal sides of bodysherd with red slip, Class 7 variant 2, MHR2002.A5.4; below: external side of bodysherd with red slip and incision, Class 7 variant 2, MHR2002.A3.3. Image credit: Authors.

Figure 28: External and internal sides of bodysherd, Class 8, MHR2002.A3.5. Image credit: Authors.

Figure 29: Upper left: external and internal sides of a neck, Class 9, MHR2002.A4.14; upper right and lower centre: external and internal sides of bodysherd, Class 9, MHR2002.A5. Image credit: Authors.

Figure 30: External and internal sides of rim with impressed decoration, Class 10 variant 1-type 3, MHR2002.E6.3. Image credit: Authors.

Figure 31: External and internal sides of rim, Class 10 variant 2-type 4, MHR2002.E15.10. Image credit: Authors.

Figure 32: External and internal sides of bodysherd, Unidentified 1, MHR2002.D2.no number. Image credit: Authors.

Figure 33: Upper left: external and internal sides of bodysherd, Unidentified 2, MHR2002.D2.1; upper right: external and internal sides of bodysherd, Unidentified 2, MHR2002.D12.20; lower centre: external and internal sides of bodysherd, Unidentified 2, MHR2002.E11.no number. Image credit: Authors.

Figure 34: External and internal sides of bodysherd, Unidentified 3, MHR2002.C5. Image credit: Authors.

Figure 35: Chart illustrating the distribution of pottery classes and variants in Trench C, layers 1 to 6 . Image credit: Authors.

Figure 36: Chart illustrating the distribution of pottery classes and variants in Trench F, layers 1 to 8. Image credit: Authors.

Figure 37: Common vessel shapes in each phase, Trenches C and F. Image credit: Authors.

Figure 38: Chart illustrating the distribution of pottery classes and variants in Trench A, layers 1 to 6 . Image credit: Authors. 
Figure 39: Chart illustrating the distribution of pottery classes and variants in Trench B, layers 1 to 5 . Image credit: Authors.

Figure 40: Chart illustrating the distribution of pottery classes and variants in Trench D, layers 1 to 5 . Image credit: Authors.

Figure 41: Diagram illustrating the different vessel parts as discussed in this study. Image credit: Authors.

Figure 42: Diagram illustrating the different rim forms and their corresponding names as discussed in this study. Image credit: Authors.

\section{List of Tables}

Table 1: Quantities of retained potsherds according to the trenches

Table 2: Technological and morphological categories used in the recording of archaeological ceramics from Mahurjhari

Table 3: Synthetic table illustrating the criteria used to define each class of pottery and its variants in the assemblage (as described in detail above)

Table 4: Dig numbers, depths, and brief descriptions of the layers pertaining to Trenches A-D and $\mathrm{F}$ at Mahurjhari, together with an indication of the presence or absence of different categories of archaeological material found during excavation. $\mathrm{PT}=$ pottery, $\mathrm{BD}=$ bead, $\mathrm{BD}-\mathrm{d}=$ =bead debitage, $\mathrm{BR}=$ brick, $\mathrm{BN}=$ bone, $\mathrm{SH}=$ shell, $\mathrm{MT}=\mathrm{metal}$,

$\mathrm{TC}=$ terracotta, $\mathrm{ST}=$ stone, and $\mathrm{WS}=$ worked stone

Table 5: Number of sherds of each class/variant recorded in the archaeological layers of Trench C

Table 6: Number of sherds of each class/variant recorded in the archaeological layers of Trench F

Table 7: Reconstructed chronological sequence for Trenches $\mathrm{C}$ and $\mathrm{F}$, based on radiocarbon dates and relative dating (after Mohanty et al. in press)

Table 8: Distribution of classes and variants from dated layers in Trenches C and F

Table 9: Number of sherds of each class/variant recorded in the archaeological layers of Trench A

Table 10: Reconstructed chronological sequence for Trench A, based on relative dating

Table 11: Number of sherds of each class/variant recorded in the archaeological layers of Trench B

Table 12: Reconstructed chronological sequence for Trench B, based on relative dating

Table 13: Number of sherds of each class/variant recorded in the archaeological layers of Trench D

Table 14: Reconstructed chronological sequence for Trench D, based on relative dating 


\section{Introduction}

The archaeological site at Mahurjhari is located $15 \mathrm{~km}$ north-west of Nagpur on the Nagpur-Katol road, Nagpur District, Maharashtra, India (79.006637 ${ }^{\circ}$ East, $21.221162^{\circ}$ North), in the region of Vidarbha (Figure 1). The region is defined topographically by broad alluvial plains bordered by large hill ranges to the north, east and south. These plains are irrigated by a number of rivers, chief among which are the Purna and the Wainganga, together with its major tributaries: the Wardha, Kanhan and Painganga. Geologically, the entire region lies within the Deccan Traps, an igneous province of flood basalt, with large areas of lateritic rock and clay soils covering residual hills and river basins. Mahurjhari is situated in the north-eastern part of the region, within the Kanhan river basin, approximately $50 \mathrm{~km}$ to the south of the Satpura Mountains. The immediate area, as with much of the region, features a wide variety of minerals including: manganese, coal, dolomite, white clay, yellow and red ochres, sand (stowing), quartz and quartzite. Indeed, the archaeological site at Mahurjhari is close to a particularly rich source of manganese, which is currently being mined (Mohanty $\underline{2003}$ ).

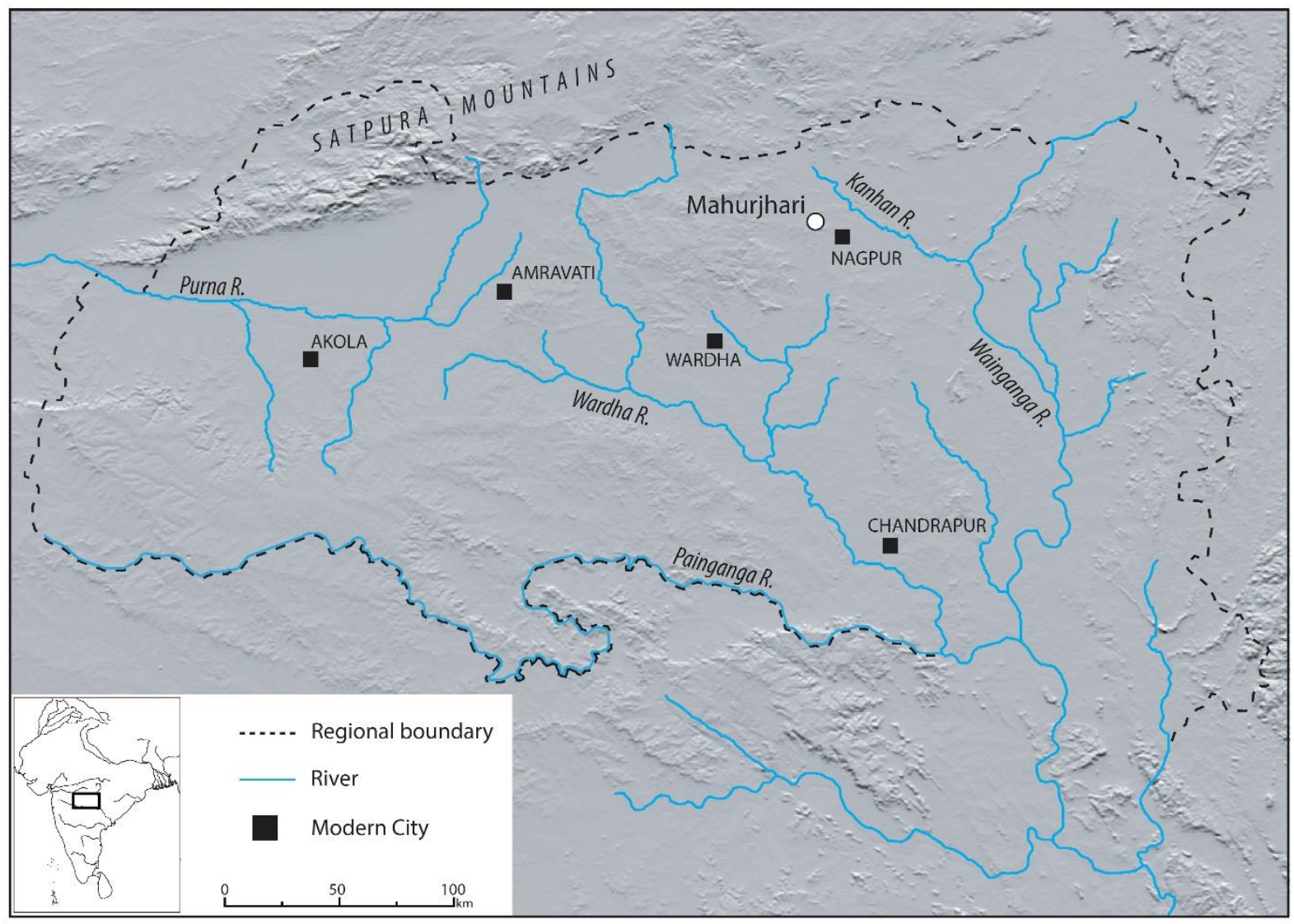

Figure 1: Map illustrating the geographical parameters of the Vidarbha region, and the location of the site at Mahurjhari in relation to modern cities. Image credit: Authors.

Discovered in the 1930 s by G.A.P. Hunter (Hunter $\underline{1933}$ ), the site is characterised by a number of stone circles spread across a wide $\left(c .6 \mathrm{~km}^{2}\right)$ area, which in its broadest sense also encompasses the neighbouring site at Junapani (Rivett-Carnac 1879; Ghosh 1964, 32-33); a large (c. 20 ha) and conspicuous habitation mound located adjacent to the modern village of Mahurjhari, and a smaller (c. $10 \mathrm{ha}$ ) area of habitation located $500 \mathrm{~m}$ to the south (Figure 2). Archaeological remains including potsherds, brick fragments, metalwork, sculptures and a large concentration of semi-precious stone-bead manufacturing debris are visible across the surface of the entire area (Figure 3). The site has been surveyed and excavated a number of times, notably by S.B. Deo who excavated a series of the stone circles and associated burials at the site between 1970-1972 (Deo 1973). Between 2001-2004, R.K. Mohanty excavated the area of historical habitation to investigate the bead-manufacturing industry (Mohanty 1999; 2003; 2004; 2005; 2006; Mohanty and Thakuria 2014; Thakuria and Mohanty 2009; Vaidya and Mohanty 2015). Together, the results of these investigations have revealed a complex sequence of activity and 
occupation at the site from at least the mid-first millennium BCE to the mid-first millennium CE and beyond what, in India, is known as the Megalithic period or early Iron Age to the early historic period. For further discussion of the notation of periods in this region, see Shete and Kantikumar (2017), Shete (2018) and Sawant (2010; 2012). Those activities appear to have changed over time, with megalithic mortuary practices giving way to urban settlement and bead manufacturing at some point during the early centuries CE. During this time, the site and the bead manufacturing that took place there appear to have become increasingly important in wider regional economic dynamics (Sawant 2008-2009).

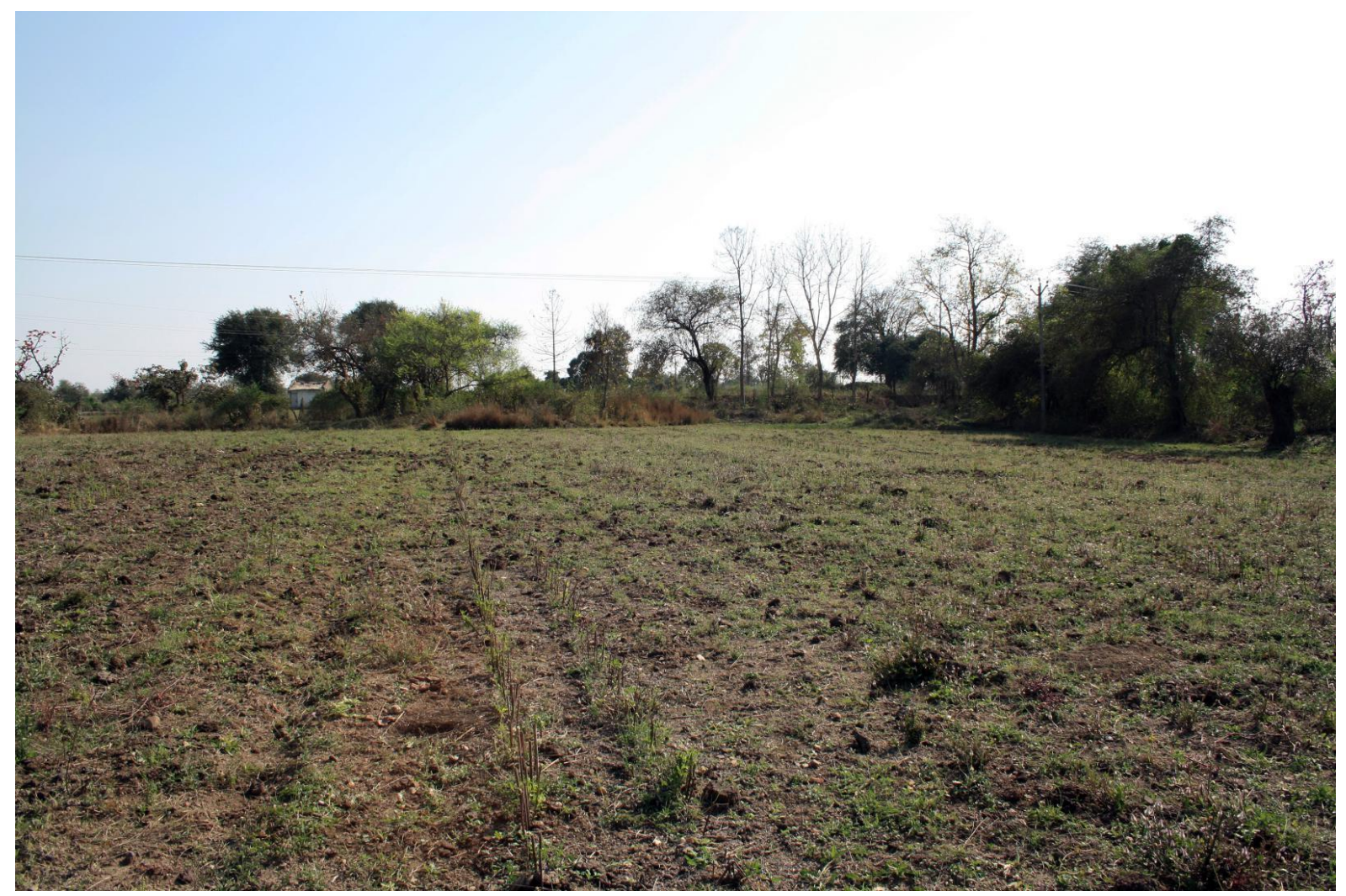

Figure 2: The habitation site at Mahurjhari as it appears today. Image credit: Riza Abbas (Indian Numismatic Historical and Cultural Research Foundation)

Unfortunately, our further understanding of the site has been hampered by a lack of chronological resolution in the dating of the main settlement, and a concomitantly poor understanding of the archaeological remains from the settlement. Addressing this, recent work has involved AMS dating of surviving radiocarbon samples that were collected during the most recent 2001-2004 phases of excavation (Mohanty et al. in press), as well as a re-analysis of the excavated pottery from the site. This article presents the results of the analyses of ceramics from the areas of historical settlement. We hope that the publication of the details of this pottery will provide a useful benchmark dataset for future investigations in the region. Moreover, in the presentation of our results we also suggest an alternative way of looking at and engaging with archaeological ceramics in India - one that is based on the analysis of the operational sequences, or chaîne opératoire, used in their production - in an attempt to move beyond certain traditional modes of practice. 


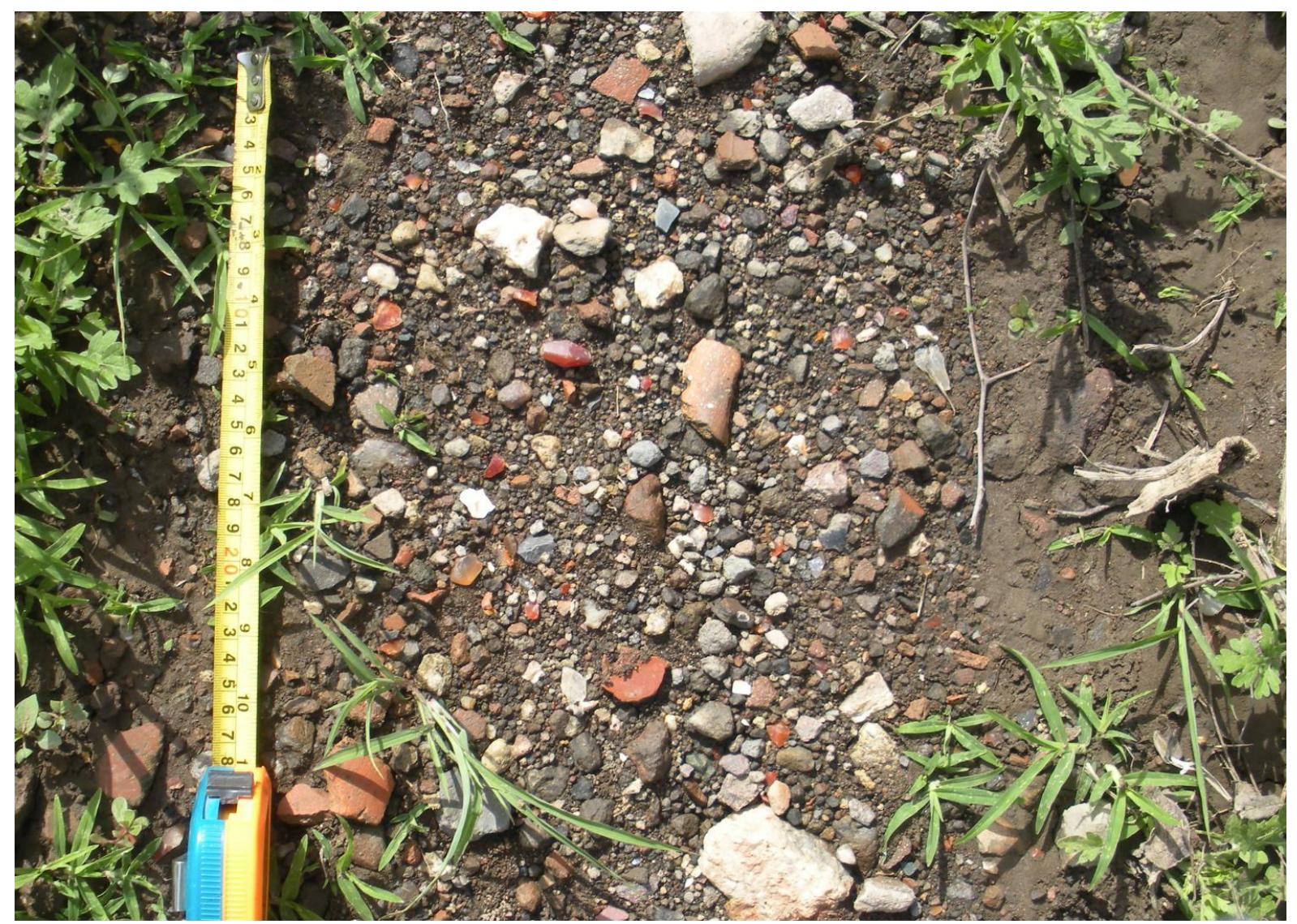

Figure 3: Archaeological remains, including potsherds, bead-making debitage and carnelian bead rough-outs visible on the surface at the site. Image credit: Authors.

Following a brief review of standard approaches to the study of archaeological ceramics from historical periods in South Asia, and the potential benefits that other analyses can bring, we turn to the assemblage from Mahurjhari and describe the methods that we have used to analyse it. This is followed by the presentation of our results, in two parts: first, a detailed description of the ceramic classes and variants that we were able to define and, second, their distribution across the excavated trenches and their seriation over time.

\section{Background}

In the archaeology of South Asia, pottery has been studied mainly to establish chronological and cultural typologies. Different pottery 'wares', have been identified in order to mark periods of time and (sometimes) the existence of particular cultural groupings in particular areas at those times. To this end, classifications have been based primarily on the most predominant formal technological and decorative characteristics of the potsherds themselves. In the pottery reports of excavation monographs dating from the 19th century to the present day, we find wares being defined on the basis of four main visible characteristics: the colour of the potsherd, the texture of the clay, the firing mode, and its surface treatment (for further discussion, see Sinopoli 1991). Through the combination of these descriptive terms and technological traits, the complexity of the variety of ceramics made by different people in different ways and at different scales of production across South Asia are reduced to broad (pan-Indian) categories, such as: 'Red Coarse Ware', 'Black Slipped Ware', 'Fine Red Ware' and so on. Such categories are useful and convenient. They can be used to categorise excavated potsherds on site by members of the excavation team, irrespective of whether they have any specialist training in the recording and analysis of archaeological ceramics. As such, their use facilitates a relatively quick and easy overview of the excavated material, which (depending on the scale of excavations) can often comprise many hundreds of thousands of individual sherds and weigh many tonnes. 
However, at the same time, much as this general approach might provide a good overview of the material on site, this is where the analyses of ceramics in South Asia often ends. Following their initial sorting, morphologically diagnostic sherds (usually rim sherds) are retained and the vast majority of the assemblage is discarded at the end of an excavation and added to the backfill. This being the case, only recording the most visible characteristics of the pots and reducing an entire assemblage to these main wares is extremely problematic. In not being sensitive to or recording more information about the ways individual pots were made or decorated, what they might have been used for, and how they are seriated and distributed within and between assemblages we end up missing a great deal of information about the archaeological ceramics - often the single largest category of archaeological remains at any site. Not having this information affects our archaeological understanding in four main ways. First, and most immediately, it limits the amount of variation (inherent in any material assemblage) that we can accommodate in our pottery typologies, which become somewhat crude and simplistic. Second, the simple ways in which 'wares' are defined creates a great deal of misunderstanding regarding whether the pottery found at one site is the same as that found elsewhere, not least because the terms used to define 'wares' are inherently subjective (one archaeologist's definition of 'coarse' may be the same as another's 'plain'). This in turn further limits the usefulness of existing typologies for relative dating, and means that archaeologists across South Asia frequently end up having to rely on a few very distinctive key 'fossil types' as 'chronological markers'. However, because these fossil types often account for only a very small proportion of a total pottery assemblage, when they are absent it becomes extremely difficult to date phases of occupation (and sometimes entire sites) with any degree of precision. Third, without full and complete information about a complete assemblage, we remove a great deal of archaeological information that can help interpret site formation processes and the deposits in which they were found. For instance, clues as to the nature of the deposit in which potsherds are found (whether it was a domestic space, a rubbish dump, or agricultural field) can sometimes be provided by features of the pottery assemblage found within it (its uniformity, level of fragmentation and abrasion, and so on). Fourth, and even more fundamentally, defining pots in these ways ignores all of the information that they can provide about the ways people made them, decorated them and used them, which in turn provide important clues about craft production, value systems and life-ways (see Rice 1987; Sinopoli 1993; Shepard 1965; Orton et al. 1993).

It was precisely this type of traditional framework that was used during the recent (2001-2004) excavation and initial post-excavation analyses at Mahurjhari. Here, ten trenches were excavated across the wider area of the site during all three seasons of fieldwork, six of which (A-F) related to the area of early historic settlement (see Figure 4). Ceramics were sorted and classified on site, with 'wares' defined on the basis of: broad colour ranges of the surface of individual potsherds (red, black, grey, and so on); their relative feel (fine, plain or coarse); and any other distinguishing visual characteristics (e.g. whether they were slipped or polished). This resulted in the categorisation of the entire assemblage into four main wares (Red Ware, Red Micaceous Ware, Black Ware, and Black Micaceous Ware). Unfortunately, however, excavations did not yield any of the key fossil types that would normally be used for relative dating. This meant that there were no clear chronological indicators to help date the archaeological contexts (or 'units') and thus identify the phases of activity within a settlement that was home to such a large and important bead-manufacturing industry. Equally, because so few details were recorded about the pottery, it was difficult to say very much about the ways they were made and used. These limitations were further exacerbated by the fact that the majority of the excavated assemblage was discarded on site prior to postexcavation analyses. On-site tallies of the quantities of excavated artefacts were made for the majority of excavation trenches, but unfortunately not for Trench $\mathrm{F}$ - the largest. Then, only sherds that were deemed to be in some way diagnostic of the original vessel shape (rims, bases, handles, spouts, and lids) as well as decorated bodysherds were retained. This practice is common throughout South Asia for several reasons, not least inadequate funding, expertise and provision of suitable facilities for storage and analyses. 


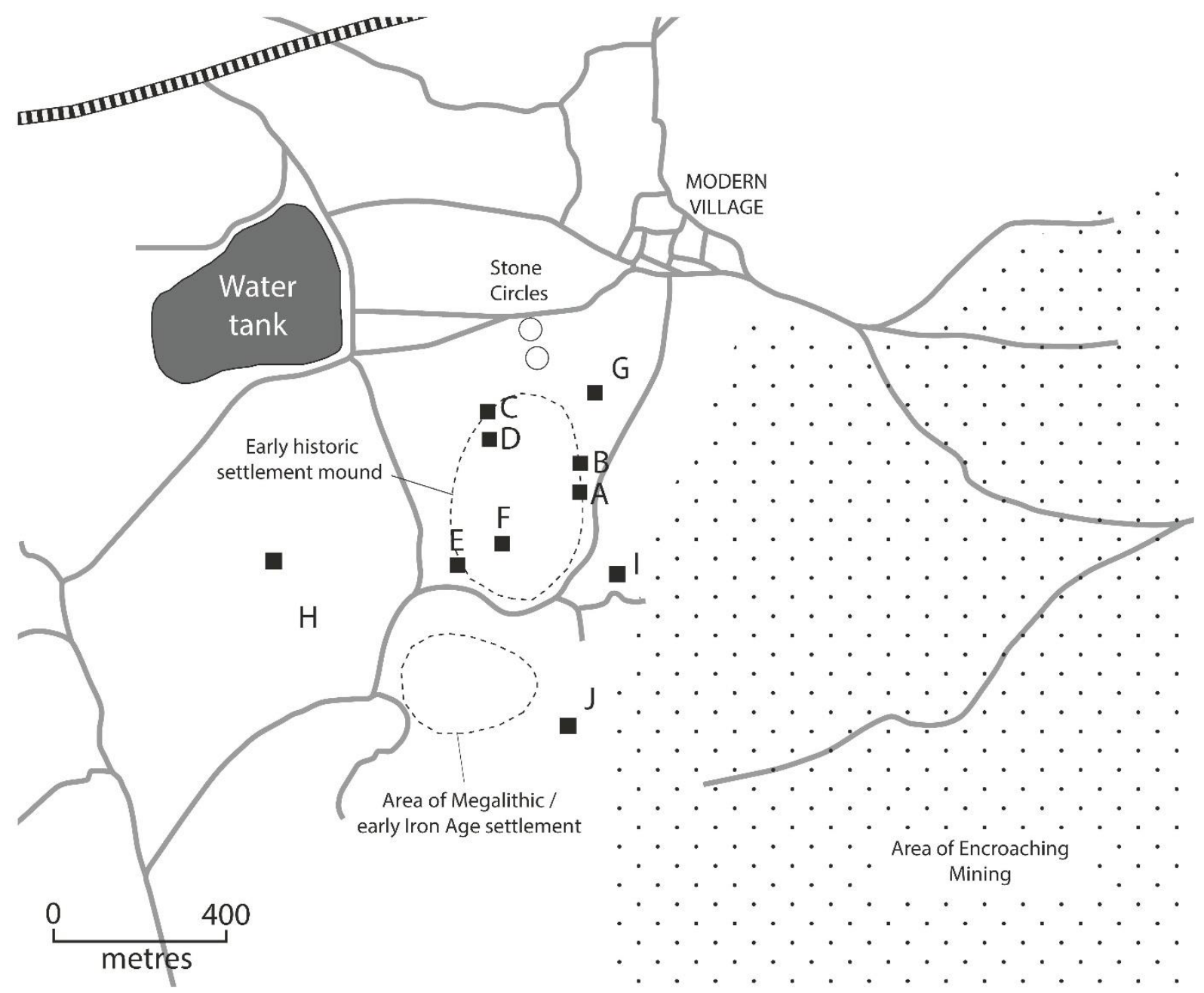

Figure 4: Plan of the archaeological site at Mahurjhari, showing areas of archaeological investigation. Image credit: Authors.

\section{This Study}

Addressing this situation, we have recently dated stratigraphic layers from two trenches ( $C$ and $F$ ) in the area of historic settlement (Mohanty et al. in press). The results indicate that this area of settlement dates from the 4th century CE to at least the 10th century CE. These dates provide us with a useful benchmark against which to relate the remaining pottery assemblage and changes in the material. Further, we have re-analysed the remaining assemblage with the explicit aims of: (1) retrieving as much information as possible from the remains; (2) using the ceramics from Trenches $\mathrm{C}$ and $\mathrm{F}$ to help date those from other trenches and the stratigraphic layers in which they are found; and (3) exploring the potential of the application of alternative approaches to the examination and interpretation of archaeological ceramics in South Asia.

What this means in practice is that we have focused on pots from Trenches A-F, which correspond most closely to the area of early historic settlement. Due to the discard and retention policy implemented on site, we are left with an assemblage comprising a total of 5317 potsherds, which amounts to a minimum number (MNI) of 2034 individual vessels that together weigh $753.24 \mathrm{~kg}$ (see Table 1). 
Table 1: Quantities of retained potsherds according to the trenches

\begin{tabular}{|l|l|l|l|}
\hline \multicolumn{1}{|c|}{ Trench } & \multicolumn{1}{|c|}{ No. of potsherds } & Total MNI & Total weight (g) \\
\hline Trench A & 390 & 189 & 8060.98 \\
\hline Trench B & 443 & 224 & 5832 \\
\hline Trench C & 1097 & 523 & 17337.7 \\
\hline Trench D & 330 & 96 & 3400 \\
\hline Trench E & 327 & 123 & 5585.9 \\
\hline $\begin{array}{l}\text { Trench F- } \\
\text { SW }\end{array}$ & 2730 & 879 & 35107.4 \\
\hline Total & 5317 & 2034 & 75323.98 \\
\hline
\end{tabular}

As we allude to above, a wide range of approaches can be applied to the examination of archaeological ceramics, depending on the questions being asked. All ceramics, whether a single sherd or complete vessel, contain an extraordinary amount of information. The composition, colour and other physical characteristics of the clay fabric, their shape, function and decoration combine to tell us about various aspects of the methods used in their manufacture, who made them, for whom, how they were used, and (together with other archaeological information) what these practices may have meant in terms of wider social, cultural and economic dynamics. There are also a series of well-established methods and techniques that can be applied to extract, measure and record these data. These range from relatively simple methods of visual inspection, to more specialised forms of microscopic examination and scientific analyses. For further discussion see Shepard (1965), Rye and Evans (1976), Rice (1987), Lemonnier (1993), Orton et al. (1993), and Livingstone-Smith (2001). Central to all of these approaches is an awareness that archaeological ceramics are not just tools for dating or cultural indicators, but are also archaeological objects that were made and used in specific ways for specific reasons. A common goal in these approaches is thus to achieve both a cultural and sociological reading of an assemblage.

Responding to the need to retrieve more detail from the pottery, and being aware of various approaches that can be brought to bear, we have decided to use an approach that incorporates the sequence of events that took place during manufacture of the pots as the basis for classification of different 'classes' of pottery. In essence, classifying them first on the basis of how they were made and then on the basis of what was being made, rather than only on the way they might appear (subjectively) to the observer. The central premise here is that traces of the various steps involved in the course of transforming natural clay into a finished pot are preserved in the pot during the firing process. We recognise that recording these traces does require a certain level of knowledge and expertise beyond that which is needed for simply on-site sorting by colour and texture. However, this is not impossible. Indeed, we hope that as awareness grows of the value of looking at and thinking about pots in a more detailed way, so too will the number of ceramic specialists in the South Asian archaeological community. Through the identification and analysis of these traces of production, we will define categories or classes of ceramics. Then, once classified, they can be further categorised by addressing a range of other dimensions of ceramic variability (i.e. morphology, surface colour, paste, etc.). The result will be: (1) a more refined subset of ceramic categories (variants of classes) that will accommodate the variation that exists within the manufacture of any given class of ceramics; and (2) the identification of the different vessel forms that were made using each ceramic class and variant. From the vessel forms we can also infer the function (or range of possible functions) of the pots that were made, with reference to the size of the different parts of the pots (the diameter of the rim for instance) and their general shape and form (the presence of a neck, or a handle, and so on). Doing so will allow consideration of the various motivating factors that lay behind the choices that were made in the production of pots.

While the concept of the chaine opératoire was developed during the mid-20th century (Leroi-Gourhan 1964; $\underline{1965}$; 1971), it was not adapted and applied to analyses of archaeological ceramics internationally until the 1970s 
and 1980s (Balfet 1965; 1966; Rye and Evans 1976; Van der Leeuw 1976; Rye 1981; Lemonnier 1993; LivingstoneSmith 2001; Gosselain 2002; Roux 2007; 2011; Roux and Courty 2016). In South Asia, there have been very few attempts to apply this methodology, and these have mainly been in the field of ethnoarchaeology (Saraswati and Behura 1966; Mahias 1993; Kramer 1997; Choksi 1998; Degoy 2005). However, it is worth highlighting a small number of studies being piloted in scholarship on the Indus civilisation that incorporate these methods (Parikh and Petrie 2015; Ceccarelli and Petrie 2017).

The application of this techno-morphological approach, informed by attention to the chaîne opératoire, has the potential to be able to tell us significantly more than traditional approaches alone. This is because this way of classifying pots has to engage, at a fundamental level, with the various social, cultural and technological decisionmaking processes and material constituents that lay behind their manufacture and decoration, as well as the types of vessel forms and implied functions of the forms that were made. In engaging with the material remains in this way we can not only suggest what people were doing with their pots, but also retrieve valuable information about the potters who made them - their relationships with the available environmental sources, the evolution or permanence of their production techniques, the cultural choices that informed some of the decisions they made - and by extension the social and economic meanings of the pots as either commodities of trade or expressions of identity. Given what has been summarised above about standard approaches to ceramics in this area, it is arguably the case that there is a great deal of potential in applying this approach in South Asia.

\section{Methods}

In order to classify the ceramic assemblage from Mahurjhari primarily on the basis of the techniques used in their manufacture, first it is necessary to define each stage of the manufacturing process and understand the relevant variables we will record for those stages. It is worth noting here that all of these variables and attributes can be recorded visually without the use of more scientific techniques (such as microscopy or chemical sourcing). While such techniques can undoubtedly provide even more valuable information, their application was beyond the means of the present study. Several stages of production are common in the manufacture of all pots. These include the selection and preparation of the clay and other raw materials, the forming and shaping of the vessel, the pre-firing finishing of the vessel surfaces, which can sometimes include various methods of decoration, the drying of the vessel, the firing process, and, finally, any post-firing treatment that might be applied, which again can include various forms of decoration. For an overview, see Orton et al. (1993).

Other than the pre-firing drying, all of these stages of production leave visible and discernible traces on the pots and pottery fragments. These traces can be translated into technical attributes that can be recorded and described. Stages of production and traces of the manufacturing process that can be discerned visually are as follows:

1. Raw material acquisition, selection and preparation: To document the selection and preparation of the clay, we can observe the composition of the paste (texture and colour of the matrix; types of inclusions, their size, shape, frequency, sorting, and colour). These data inform on aspects of the choices potters made in material selection and techniques of clay preparation.

2. Primary and secondary shaping techniques: We can identify traces of the forming and shaping processes that were employed to form ceramic vessels. These are often the most difficult to discern, as we need to recognise the macro-traces left by multiple techniques that were often combined in the shaping of a single vessel. These include (but are by no means limited to) the use of a fast wheel for the entire shaping process (in such cases a lump of clay is centred on a wheel and transformed into a vessel by the use of rotative kinetic energy), the use of a slow wheel combined with other shaping techniques, hand moulding, coiling, beating and stretching of various different parts of a vessel. It is also important to be aware that some techniques may obscure previous production steps (for example, paddling may smooth over wheel marks).

3. Finishing and surface treatment: Prior to firing, both internal and external surfaces can be shaved, trimmed, smoothed, burnished, left rough or have a slurry, slip or glaze applied. Then, decorative techniques can also be employed, such as impressing, incising, stamping, and/or the use of appliqué and painting.

4. Firing: Differences in the firing atmosphere can be identified through the colour of the surfaces of the pot, as well as of its internal fabric visible in section made by clean breaks in any individual sherd.

5. Post-firing treatments: Post-firing treatments such as the application of further decorative treatments or the smoking of a vesse can also be discerned. For instance, when the external surface of the pot is uniformly grey but this is not visible in the section, we can suggest smoking as a last step in the firing process. However, it is recognised that in such cases this could also be considered as a last 'reduced' phase of the firing process. Distinguishing between the two can sometimes be difficult. 
Equipped with an awareness of the manufacturing sequence, the first stage in our analyses of the assemblage from Mahurjhari was to record these attributes for all individual sherds. Pre-defined metrics with reference to commonly agreed 'standard' frames of references, such as Munsell colours and inclusion sorting charts (detailed below), were used in order to ensure that data were recorded as systematically and consistently as possible. This is, of course, with the caveat that human error and the subjectivity of visual inspection mean that some data will inevitably be missed. We also recognise that there are many additional variables that could be recorded, and various different scales of resolution at which this could be carried out. The variables and the quantitative and qualitative attributes used in this study are summarised in Table 2. Coding sheets and detailed descriptions of the attributes and variables that we recorded are presented in the Appendix. This detailed Appendix has been created initially in order to allow a non-specialist to use the table. It was conceived as a fairly exhaustive list of attributes and variables, together with descriptions that can function as a check list to ensure that every potsherd was recorded in as much detail as possible. Indeed, the first stage in the recording of the assemblage was undertaken by Namrita Biswas, a PhD student at the Deccan College of Pune, a non-specialist with no formal training in pottery analyses.

Table 2: Technological and morphological categories used in the recording of archaeological ceramics from Mahurjhari

\begin{tabular}{|c|c|}
\hline Categories of recording & Details of individual features recorded \\
\hline ID Sherd no. & Individual identification number applied to each sherd \\
\hline Context information & $\begin{array}{l}\text { Details of the trench, square, context/layer, and/or feature in } \\
\text { which the individual sherd was found }\end{array}$ \\
\hline Fabric colour & $\begin{array}{l}\text { Details of the sherd core as it appears after a fresh break (its } \\
\text { Munsell colour, whether there are different coloured margins, } \\
\text { whether these are diffuse), details of any margins towards the } \\
\text { exterior surface of the sherd (Munsell colour, whether or not they } \\
\text { are diffuse), details of any margins towards the interior surface of } \\
\text { the sherd (Munsell colour, whether or not they are diffuse), } \\
\text { details of the exterior surface (Munsell colour, whether the colour } \\
\text { is patchy, whether it is visible in section), details of the interior } \\
\text { surface (Munsell colour, whether the colour is patchy, whether it } \\
\text { is visible in section) }\end{array}$ \\
\hline Fabric texture and feel & $\begin{array}{l}\text { The hardness, ease of fracture, firing environment, feel of both } \\
\text { the exterior and interior surfaces measured how, and level of } \\
\text { compaction }\end{array}$ \\
\hline Fabric inclusions & $\begin{array}{l}\text { Details of each inclusion type visible in section (its type, colour, } \\
\text { size, shape, sorting, and frequency) }\end{array}$ \\
\hline Surface finish & $\begin{array}{l}\text { Details of both the exterior and interior surface finish (coating } \\
\text { type, colour, treatment, treatment type, treatment description) }\end{array}$ \\
\hline Surface decoration & $\begin{array}{l}\text { Details of the exterior and interior decoration (decoration type, } \\
\text { and decoration description) }\end{array}$ \\
\hline Description & Sherd type, vessel form, manufacturing technique(s) \\
\hline Vessel size and sherd dimensions & $\begin{array}{l}\text { Measurements and characteristics of the rim (type, shape, } \\
\text { diameter, \% surviving), base (type, diameter, \% surviving), } \\
\text { thickness (body thickness, rim thickness, neck thickness, shoulder } \\
\text { thickness, base thickness), and sherd dimensions (sherd height, } \\
\text { sherd width) }\end{array}$ \\
\hline
\end{tabular}


Having recorded this information, the sherds were spread out on a table and grouped according to the repeating combinations of attributes that had been noted during the detailed recording process. In doing so, the potsherds were organised into distinct classes and variants of those classes on the basis of the criteria evident through visual inspection, the most apparent of which were deemed by us to be the most relevant. Groupings (and resulting definitions of classes) were not made on the basis of statistical analyses, though such techniques are, of course, available. Grouping the sherds in this way resulted in the identification of ten ceramic production classes subdivided into twenty-three variants (described in detail below). The main classes were established on the basis of observations made of the paste, shaping, finishing and firing, which were all considered at the same time, while the variants of a class were set up on the basis of the surface treatment and/or the firing mode. The goal here was to identify meaningful variations in the production of pots in order to use these as the bases of our classification - essentially, defining technical pottery groups that attest to 'ways of doing'. As we did not find any complete vessels, we could not identify all the techniques that were used in the manufacture of any single pot. We also defined variants within each major class of production to express the variations that are visible and readily identifiable in terms of treatment of surfaces or firing mode. It is perhaps worth pointing out here that this system does not correspond stricto sensu to that used by earlier ceramic specialists in the development of classificatory systems within the original chaîne opératoire approach. Roux (Roux 2011; Roux and Courty 2016), for instance, suggests organising potsherds first according to their shaping techniques and then according to the fabric groups and the other technical features such as the surface treatment. This was not possible in this study, as the entire shaping process could not be reconstructed for most of the sherds in the assemblage (one of many unfortunate consequences of the discard policy employed on site). Consequently, we opted for a combination of different technical criteria instead of a purely and strictly 'linear' system.

In addition to the definition of chaîne opératoire classes of pottery, the detailed documentation of fabric colour, texture, feel, and inclusions that emerged from the recording of the variables was used to identify and define the different types of fabric that were used to manufacture the Mahurjhari ceramics. These 'Fabric Groups' were identified on the basis of the different compositions of the clay 'paste' used to make the pots, as visible to the naked eye and with the assistance of $a \times 10$ hand lens. To estimate the density and distribution of visible nonplastic inclusions, we used the inclusion sorting chart published by Barraclough (1992), and reproduced by Orton et al. (1993).

We took a hierarchical approach to our definition of Fabric Groups, identifying major groups and a number of variants using principles similar to those used in the definition of pottery classes. Given the nature of previous approaches, it is important here to make clear the distinction between classes of pottery and Fabric Groups. Classes are defined on the basis of the entire process of manufacture, not simply on the basis of the Fabric Groups. They are then subdivided by variations within this overall process (such as similarly formed vessels that differ only in surface treatment or decorative techniques), and are thus, by definition, not the same as the types of clay mixtures that were used in those manufacturing processes. That is not to say that the ways in which different clays were processed to make pots (defined here as Fabric Groups) were not a central part of manufacturing processes. Quite the opposite is true. Rather, it is simply that defining them separately allows for the consideration of pots that were made using similar methods but with clays that were sourced from different places or processed in different ways by different people. Or, to phrase things another way, a class of pottery can be defined on the basis of shared technical attributes linked to steps of the chaîne opératoire (e.g. coarse texture, organic temper, coil made, red slip on exterior surface, polishing, oxidised firing), even if they were made using a variety of different fabrics at the same time. By the same degree, and as we know from wider archaeological contexts, clay from the same source can be used to make pots belonging to several different classes depending on the intent of the potter, potters or workshop; and the preparation of that clay can differ notably with the addition of specific tempers. A useful example of this can be seen in the Near East. Here, a specific type of pottery known as 'Brittle Ware' is found in contexts dating from the Roman to the Abbassid periods. It is characterised by thinwalled cooking vessels produced with an iron-rich sandy clay, with red or black coloured sections and surfaces depending on the firing atmosphere. In terms of its manufacture, this is one single identifiable 'Class' of pottery. However, recent petrographic and chemical analyses have shown that several fabric groups were used in its manufacture (Vokaer 2011). This realisation has, in turn, led to the identification of several workshops spread throughout North Syria. 
As a third stage of analysis, we organised the potsherds within each class-variant into different morphological categories to develop an open and flexible typology of form that can incorporate new types as future discoveries are made. To this end, we make a distinction between restricted or 'closed' shapes (e.g. pots, and jars) and unrestricted or 'open' shapes (plates, dishes, cups/lids, bowls), both of which indicate very different functional uses. In distinguishing between these shapes, we make reference to the system of metrics and proportions presented by Balfet et al. (1983) and Shepard (1965). According to these definitions, 'open' or unrestricted shapes can be defined if the diameter at the opening (or mouth) of the vessel is equal or higher to the utmost/maximum diameter of the body. They are wider than they are tall. Their diameter equals or exceeds their height. In 'closed' or restricted shapes the diameter of the body of the pot narrows between its maximum diameter and its opening. Even if the opening of this type of pot flares out above this smaller diameter, we define it as a 'closed shape' as it is taller than it is wide.

Nevertheless, and despite the existence of such established frames of reference, it has not been possible to categorise some vessel shapes because we did not encounter any complete profiles. Our categories ('vessel types') have thus been defined on the basis of a various morphological characteristics. These include: the presence or absence of a neck, the orientation of the sides of the vessel using definitions established by Gardin (1976) (Figure 5), and the shape and orientation of the rim. Rim types were recognised as a significant diagnostic feature that we used to define additional variants with each morphological 'type' of vessel.

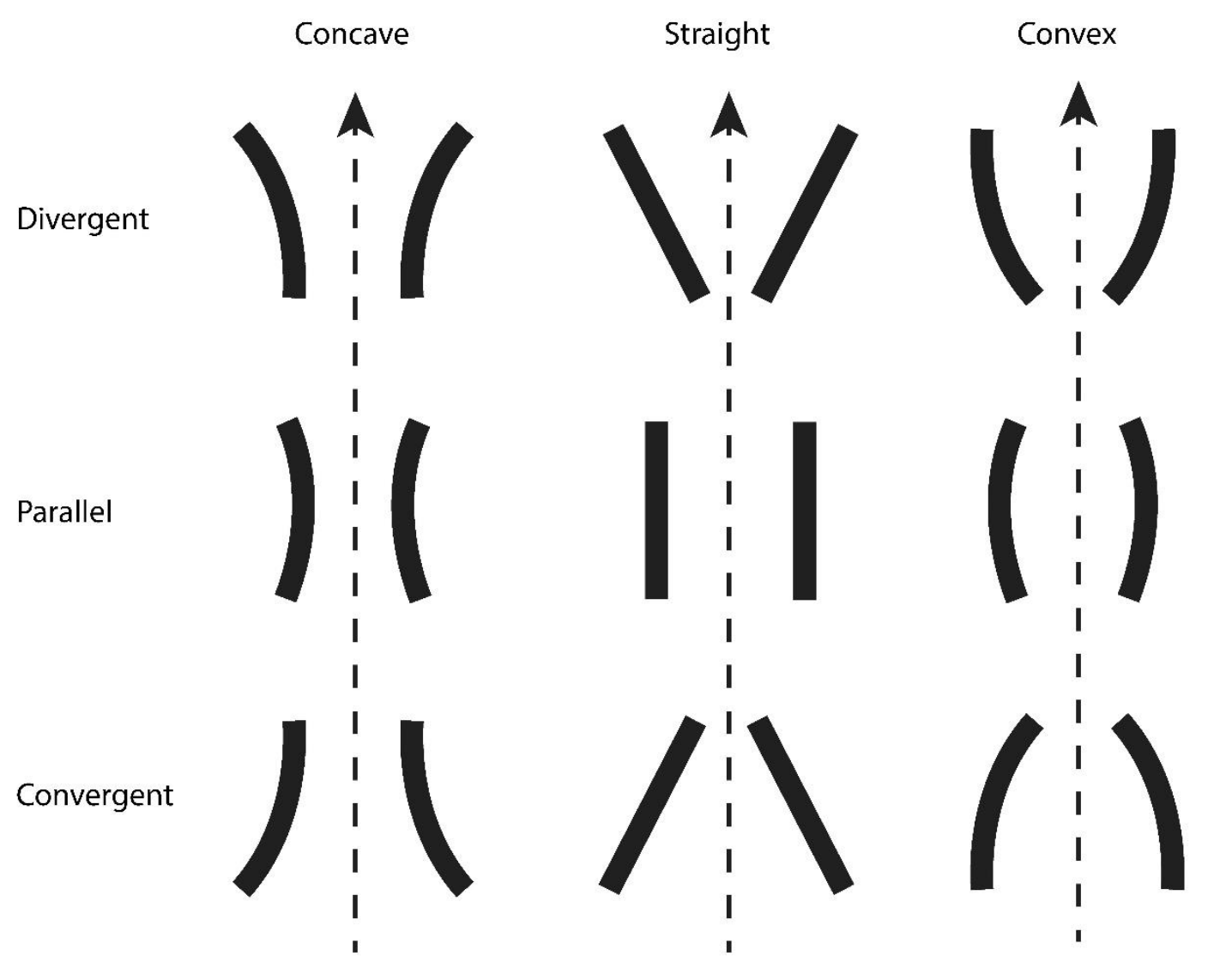

Figure 5: Different orientations of vessel sides and their established terminologies (after Gardin $\underline{1976}, 66$ ). Image credit: Authors.

Having defined the different ceramic classes in this way, the final stages of analyses were to assess the numbers of each class in relation to each other stratigraphically in each trench. This began with the ceramics from Trenches $\mathrm{C}$ and $\mathrm{F}$ because they had already been dated. It was then possible to use the seriated pottery from Trenches $C$ and $F$ as a relative means to date the ceramics found in other trenches and, by extension, establish the chronological sequence of those trenches. With chronology thus established, the seriation of the ceramics in each trench opened up the possibility of looking at how methods and modes of ceramic production varied and changed over time across the site. Of course, it is recognised that the level of results, and what we can say on the basis of this 
analysis, is directly affected by the size of the assemblage and the quality of our understanding of the depositional contexts in which the ceramics were found. It is with these constraints in mind that we present the results below.

Note, as established above (Table 1), ceramics were encountered in all trenches. However, due to various issues relating to the excavation and recording of Trench $E$, the ceramics from that trench have been omitted from this study. Sherd counts and associated data are provided in datasets that can be accessed online (Lefrancq and Hawkes 2019c; 2019d) should further study be carried out.

\section{Results: Chaîne Opératoire Classes and Variants}

Using the approaches described above, a total of ten classes, twenty-three variants of classes and one group of unidentified pottery have been categorised within the assemblage. Each of these classes and its variants is described below, including an account of the main shapes that were made using these classes. In addition, a synthetic table (Table 3 ) reviews the main criteria used to define each class and its variants. Extensive details of the Fabric Groups and illustrations of the morphological types of vessel shapes are provided in appendices that can be accessed online (Lefrancq and Hawkes 2019a; 2019b). The stratigraphic distribution of each class and its variants in each trench together with the chronological sequence with reference to the recently derived AMS dates and comparative material from Trenches $\mathrm{C}$ and $\mathrm{F}$ are also discussed.

\subsection{Class 1}

This class of pottery was made predominantly using Fabric Group 1, and is characterised by a paste of medium texture and the presence of sand-like temper. String-cut marks at the external surface of the annular plain base and parallel horizontal striations on both the interior and external surfaces of bodysherds suggest use of a fast wheel to manufacture this class of pottery. However, surviving sides and bases also exhibit a number of irregularities on the surfaces and slight distortion of the whole vessel. As has been demonstrated in other archaeological contexts in Greece (Rückl and Jacobs 2016) and north-east India (Sharma et al. 2017) the usual signatures of fast-wheel production can also be indicative of wheel-coiled techniques that use a slow wheel to finish the shape. The size of potsherds in this assemblage did not allow us to solve the question of which techniques were used in the production of this class.

This class of pottery was fired in an oxidising atmosphere, evidenced by the red colour of the fabric visible in section, while the presence of a slightly darker core indicates that this firing process was not well controlled. Interior and exterior surfaces are reddish in colour (Munsell 5YR-6/4, 5YR-5/6, 10R-6/4, 10R-5/6, 2.5YR-6/6) with slight variations evident in the treatment of the surface (see below). In addition, some sherds display small white concretions (possibly fragments of chalk) on both surfaces. This may be due to post-depositional effects. Three variants were identified on the basis of decorative techniques.

\section{Class 1 variant 1 ( $n=527)$ (Figure 6)}

This variant comprises the majority of the potsherds belonging to Class 1. Other than occasional white concretions on both surfaces, no surface treatment is evident. Only one distinct vessel form has been identified (the majority of sherds being undiagnostic bodysherds). Vessels are bowls or cups characterised by divergent and straight or convex sides (see Lefrancq and Hawkes 2019b). The rim is thinned and round. Both surfaces exhibit corrugations owing to the wheel-thrown or wheel-coiled techniques used. For vessel forms, see Lefrancq and Hawkes (2019b, plate 1). 


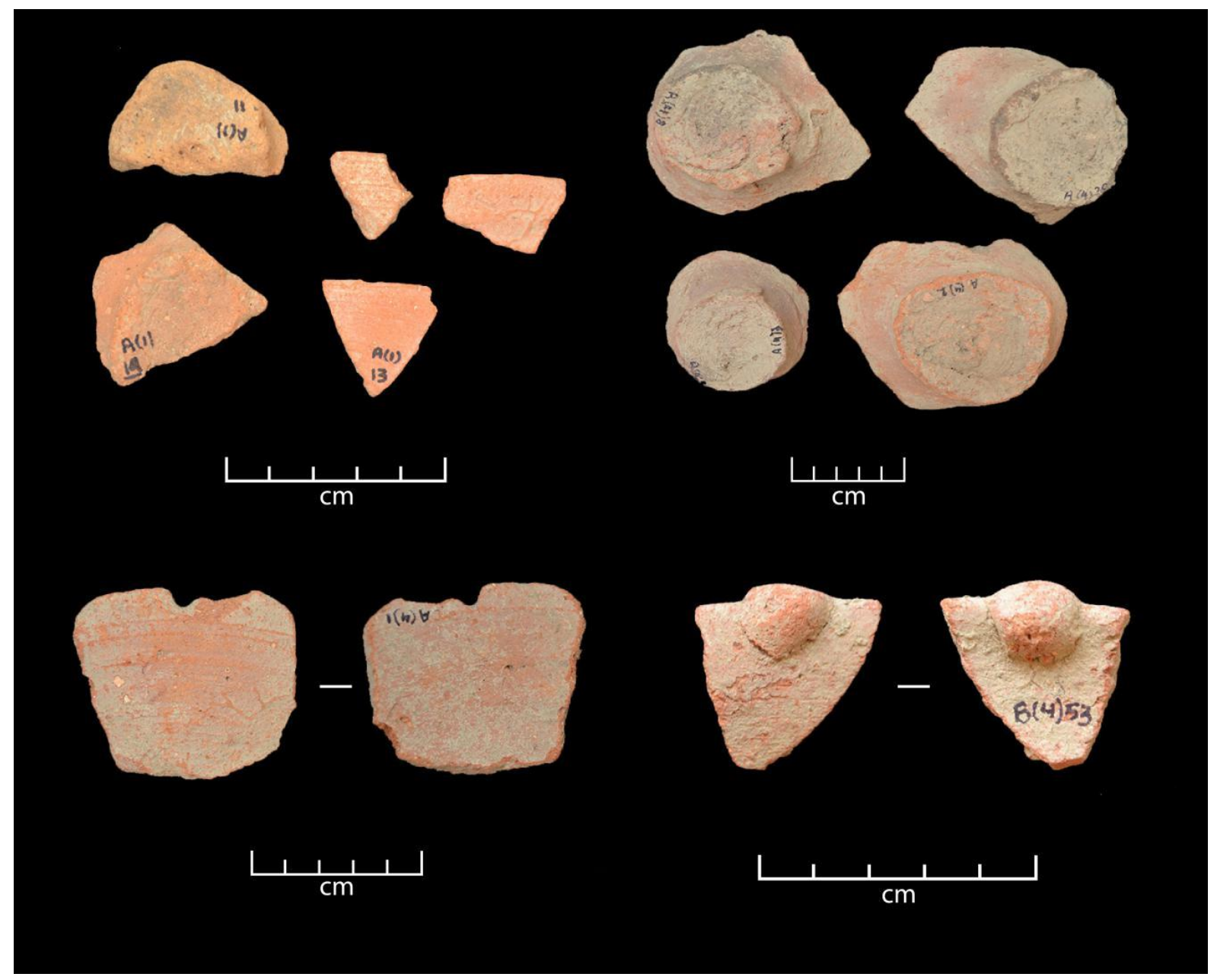

Figure 6: Upper left: rims and bases, Class 1 variant 1-type 1, MHR2002.A1; upper right: bases, Class 1 variant 1-type 1 and base type 1, MHR2002.A4; lower left: external and internal sides of rim, Class 1 variant 1-type 1, MHR2002.A4.1; lower right: external and internal sides of rim, Class 1 variant 1-type 2, MHR2002.B4.53. Image credit: Authors.

\section{Class 1 variant $2(n=2)$ (Figure 7)}

Only two sherds belong to variant 2: a rim-sherd of a jar with an undetermined diameter, divergent and straight sides and a round rim; and a highly eroded fragment of an annular, or ring-shaped, base. Both are characterised by the use of a different fabric (Fabric Group 2) than those belonging to Class 1 variant 1. Fabric Group 2 has a finer matrix (see Lefrancq and Hawkes 2019a). However, some horizontal voids typical of organic tempers are visible on surfaces. This could suggest the addition of organic material such as straw during the firing process. As was the case with variant 1 , the surfaces are irregular with occasional white concretions. No other decoration is noticed. For vessel forms, see Lefrancq and Hawkes (2019b, plate 1). 


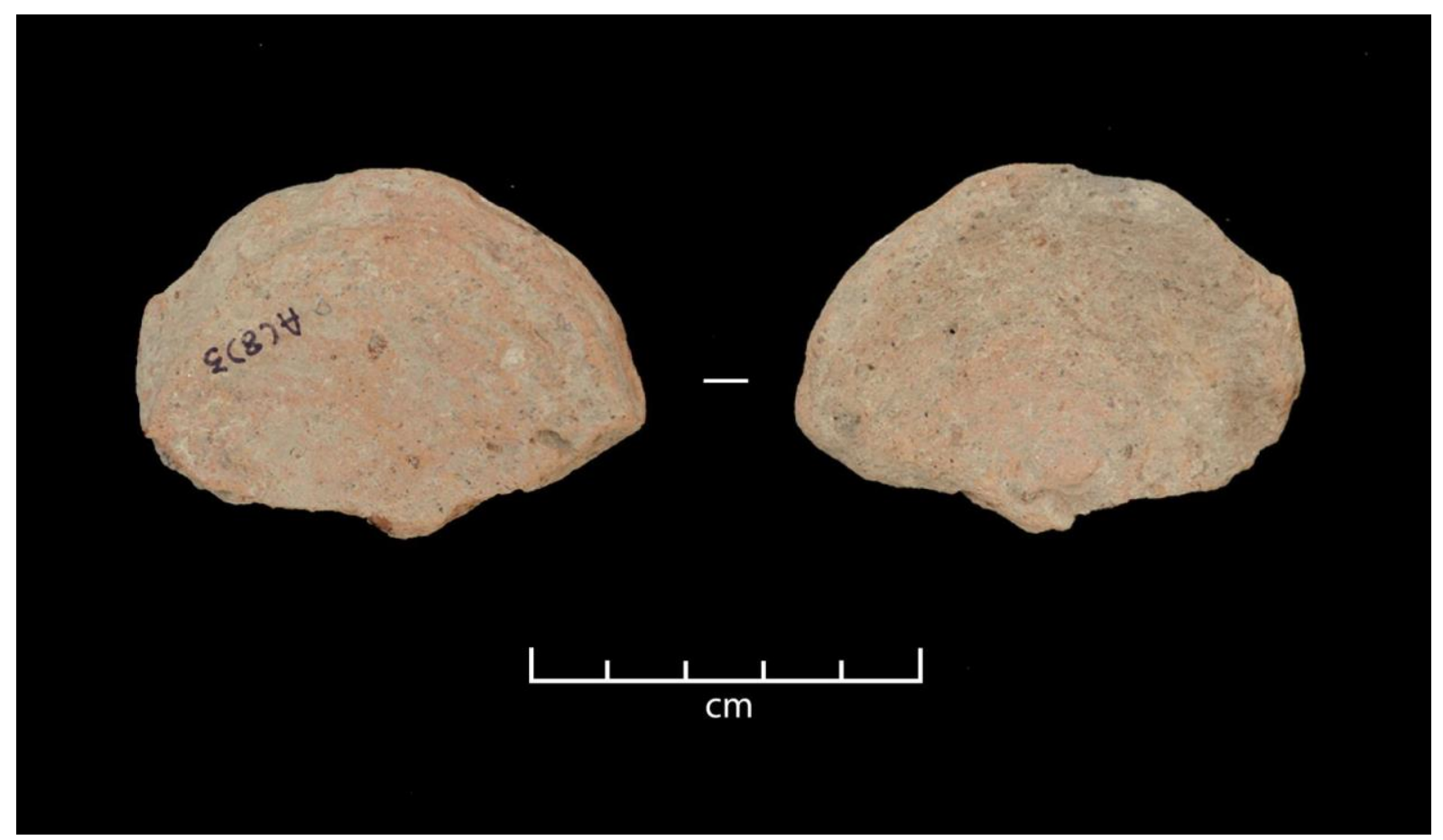

Figure 7: External and internal sides of base, Class 1 variant 2-base type 1, MHR2002.A8.3. Image credit: Authors.

\section{Class 1 variant 3 ( $n=6)$ (Figure 8)}

The fabric and fashioning techniques used to make vessels belonging to this variant are the same as those noted for variant 1 . Only a few bodysherds were found. The main differences between this variant and variants 1 and 2 occur during later stages of the chaîne opératoire (see stage 3 of the manufacturing process, as described above) in the presence of an incised decoration (parallel lines combined or not with oblique lines) on the external surface, and the application of light whitish slip (7.5YR-7/2 pinkish grey, 7.5YR-8/2 pinkish white) on both surfaces. This slip is better preserved on the external surface. No rim sherds have been found but the orientation of the sides of these bodysherds suggest a restricted shape. This contrasts with examples of Class 1 variant 1, where unrestricted shapes predominate. For vessel forms, see Lefrancq and Hawkes (2019b, plate 1).

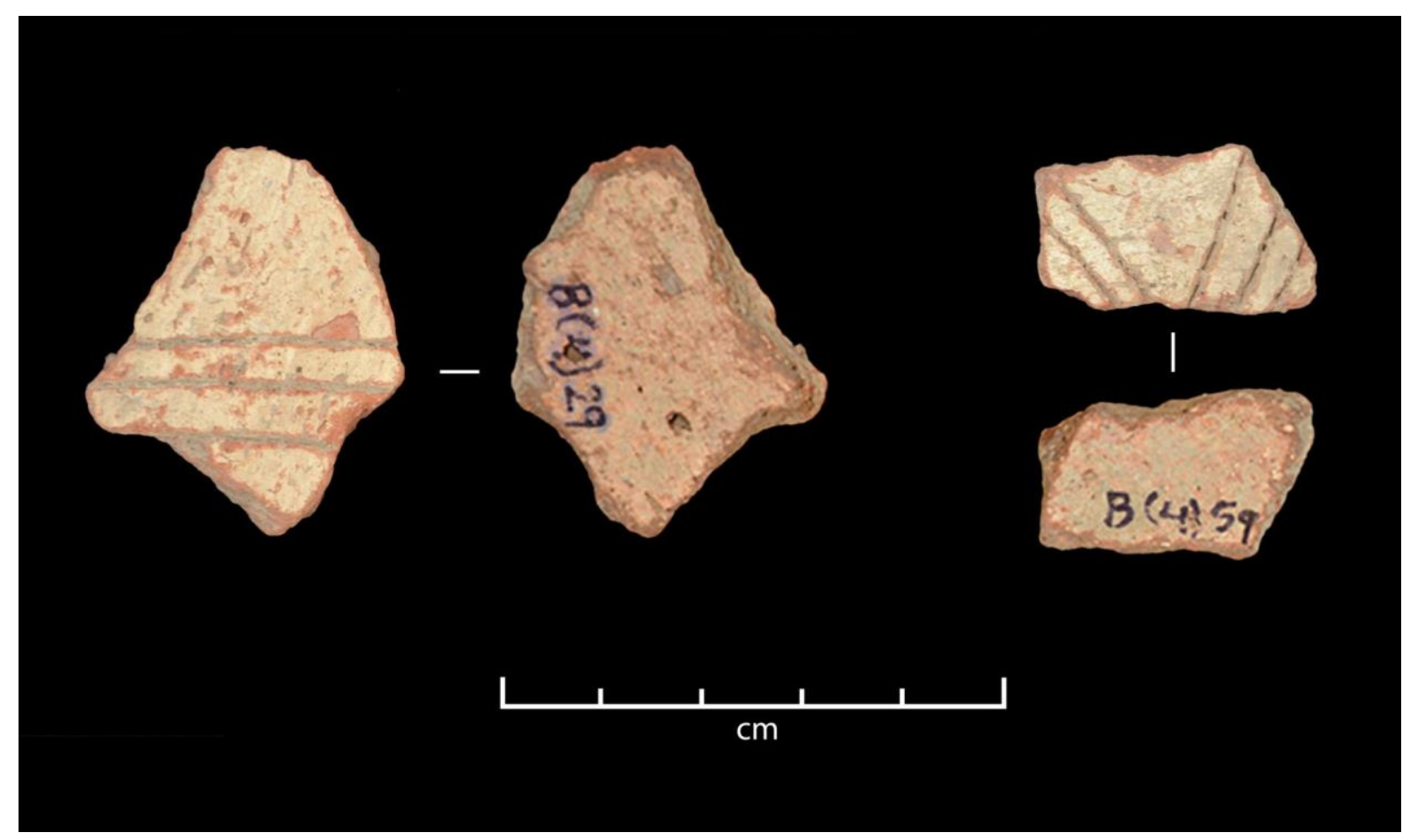




\subsection{Class 2 (Figure 9)}

The clay used to produce this class of pottery belongs mainly to Fabric Group 2, which is fine to medium in texture, medium compact, with grey and white inclusions. However, other Fabric Groups (in order of predominance: $3,1,7,4,9,8,10,6$ ) are also represented. A number of shaping techniques are evident, which enables us to identify these as composite pots. For restrictive shaped vessels, the upper part of the body and the rim are made with coils. The traces of their junction (indicated by internal thickening) are clearly visible on the internal surface of the vase. A slow wheel has been used to join and thin all parts of the pots. The external surfaces of vessels are particularly regular. The lower part of the body might have been shaped using another technique such as a convex mould, but the size of the bodysherds is too small to ascertain this for certain. In the majority of examples, smoothing lines are visible on the internal and/or external sides (colours of surfaces $2.5 Y R$ 6/6 light red, 2.5 YR-6/8 light red; 7.5YR-8/4 pink). A red slip is applied on the external surface of the vessels and on the upper internal surfaces of restricted shapes. Surfaces are often polished or burnished. On some potsherds, a white slip identified as a layer of preparation for the red slip is visible. The neck and the upper part of the body of restrictive shapes often show incised parallel lines. Vessels were fired in a well-controlled oxidising environment, as suggested by the full buff or light red core of potsherds.

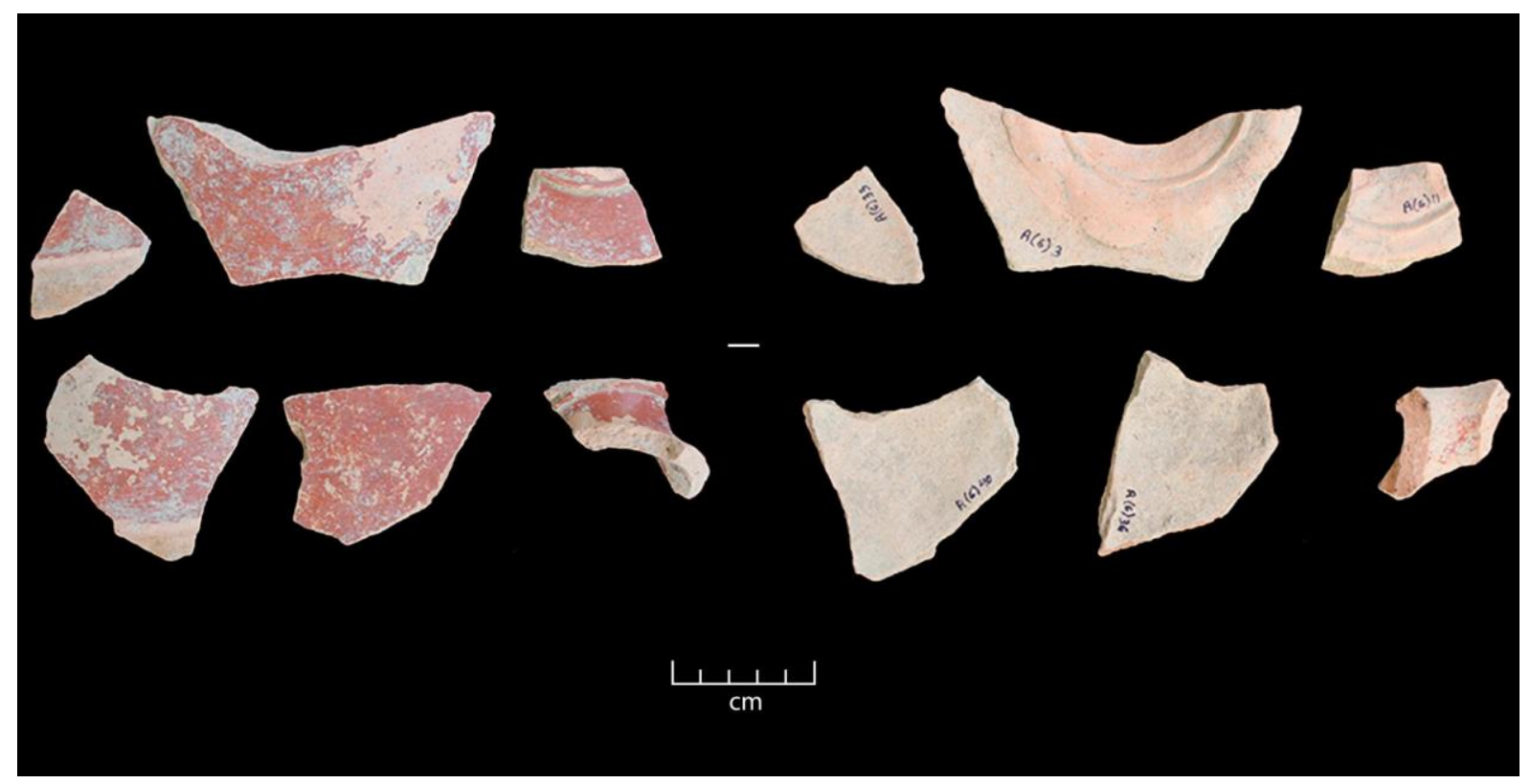

Figure 9: Left: external side of shoulder, neck and bodysherds, Class 2, MHR2002.A6; right: internal side of shoulder, neck and bodysherds, Class 2, MHR2002.A6. Image credit: Authors.

We have established the variants of Class 2 mainly on the basis of the types of decoration (red slip of good quality, red slip of bad quality, incised/appliqué/impressed decorations, red mix with micaceous slip, impressed decoration, added decoration). A small number of potsherds employ several decorative techniques simultaneously (red slip, red mix with micaceous slip, incised decoration and possibly impressed decoration). We accept that many of the distinctions between variants are arbitrary, and these could easily be collapsed into fewer divisions. Yet because we have such a small sample size we have decided to maintain these distinctions until such time as we can incorporate more pots into our analyses.

\section{Class 2 variant $1(n=544)$ (Figure 10)}

This variant includes potsherds with a red slip of good quality that is sometimes lightly burnished (10R-4/8 red, 10R-5/8 red, 10R-4/6 red, 2.5YR-5/8 red). Most of the shapes are restrictive such as jars with or without neck and mainly out-turned rims. But a few unrestrictive shapes have also been found. These include bowls with slightly inturned rim and bowls with ribbed/bifoliate rim. For vessel forms, see Lefrancq and Hawkes (2019b, plates 2-5). 


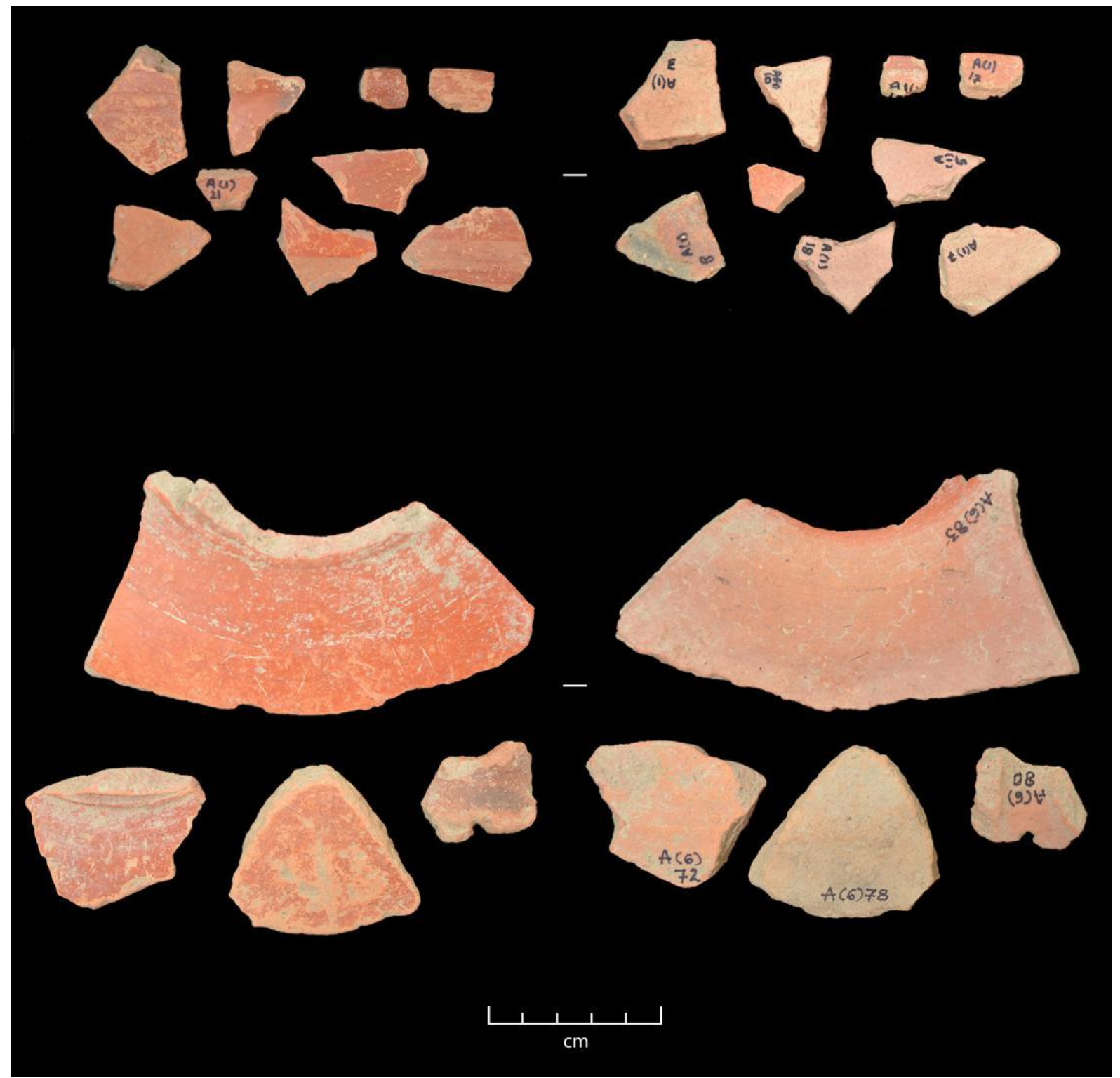

Figure 10: Above: external and internal sides of bodysherds, Class 2 variant 1, MHR2002.A1; below: external and internal side of shoulders, Class 2 variant 1, MHR2002.A6, with the coil making the junction between the shoulder and the neck visible on the interior surface. Image credit: Authors.

Class 2 variant 2 ( $n=287$ ) (Figure 11)

Class 2 variant 2 sherds display a red slip that is of a medium or poor quality (2.5YR-6/6 light red, 10R-6/4 pale red) in comparison with those of Class 2 variant 1 . The slip may have degraded due to post-depositional effects, which might also explain the 'soapier' feel to the surfaces. Shapes are similar to those of Class 2 variant 1, i.e. mainly jars with neck and out-turned rim and a few bowls with in-turned rim, but they offer less diversity in types and variants of types. For vessel forms, see Lefrancq and Hawkes (2019b, plates 5, 6). 


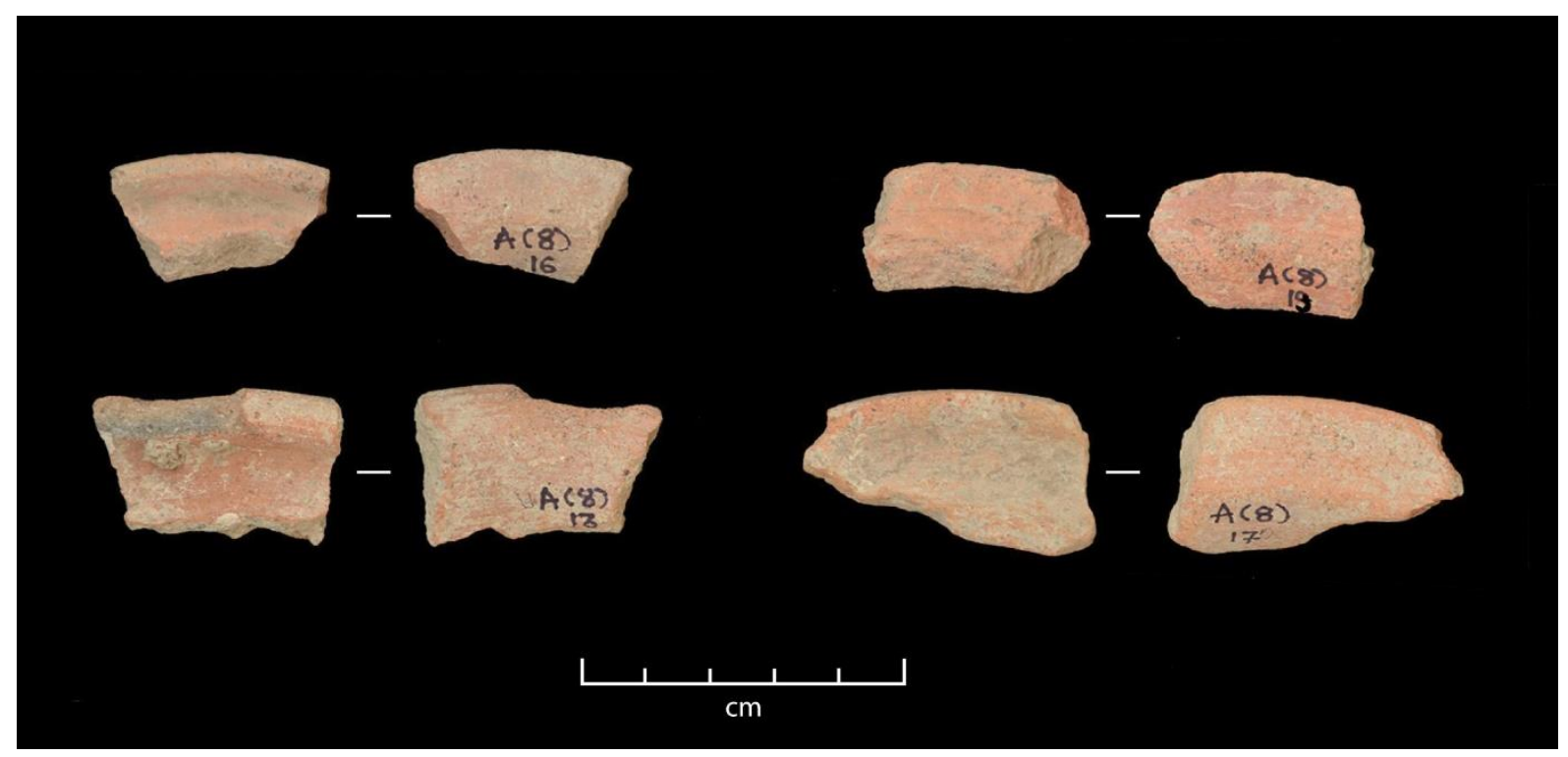

Figure 11: External and internal sides of rims and bodysherds, Class 2 variant 2-type 5, MHR2002.A8. Image credit: Authors.

\section{Class 2 variant 3 ( $n=79)$ (Figure 12)}

This variant could be a sub-variant of the Class 2 variants 1 and 2 in the sense that the potsherds have a red slip of good (variant 1), medium or poor (variant 2) quality on the external surface, along with an incised decoration, an 'appliqué' decoration and/or an impressed decoration made probably with a rope. The incised decorations consist of horizontal and parallel lines and/or oblique lines forming a triangle, while the applied decoration corresponds to a coil on which finger-prints have been impressed. As for the impressed decoration, a twisted rope might have been used to make a kind of 'engraved' pattern. Only bodysherds probably belonging to restrictive shapes were

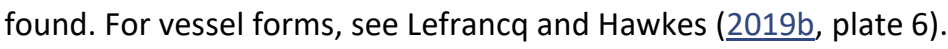




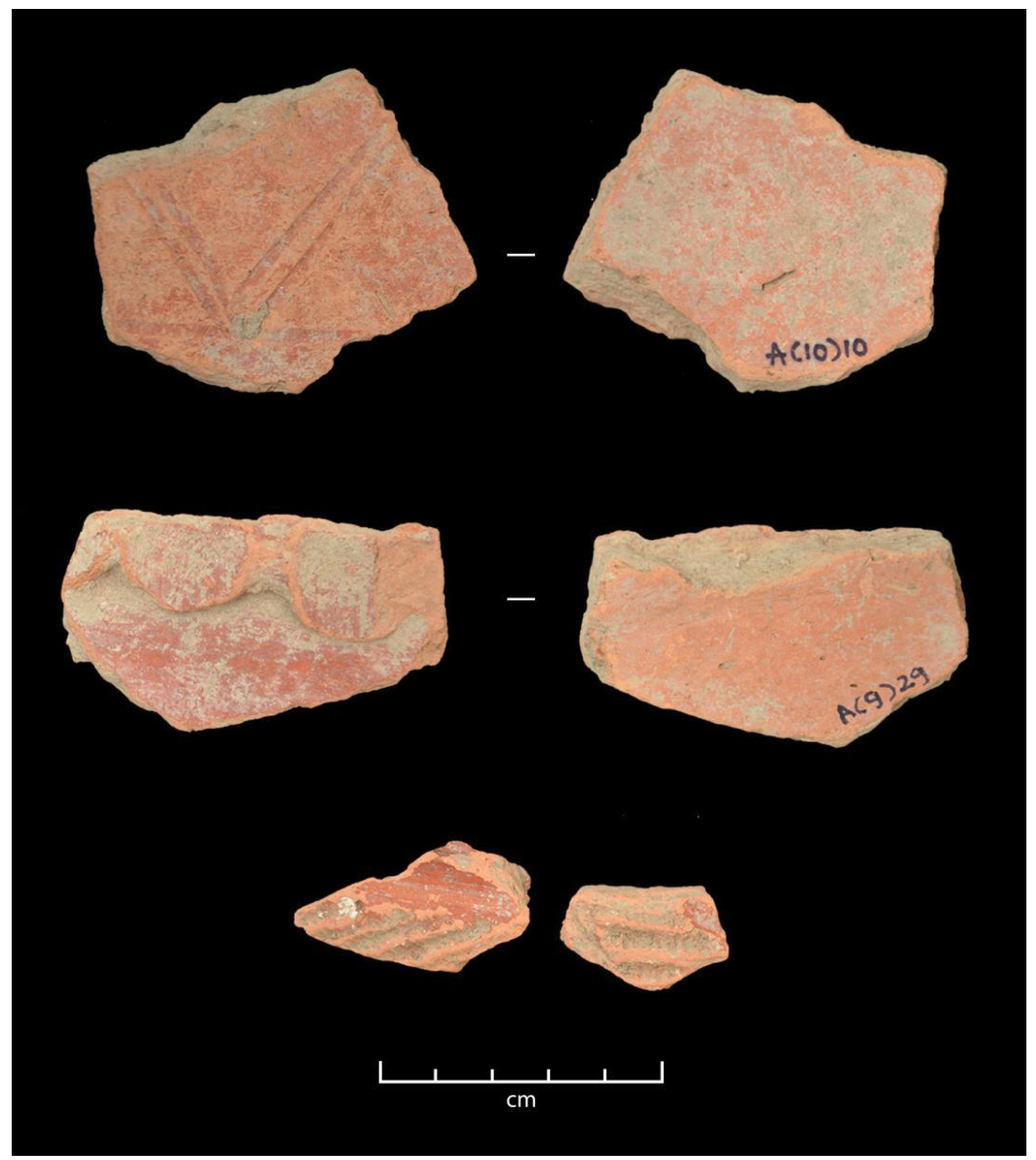

Figure 12: Above: external and internal sides of bodysherd with red slip and incised decoration, Class 2 variant 3 ,

MHR2002.A10.10; middle: external and internal sides of bodysherd with red slip and appliqué decoration, Class 2 variant 3 , MHR2002.A9. 29; below: external side of bodysherds with red slip and impressed (possibly twisted cord) decoration, Class 2 variant 3, MHR2002.B4.50/57. Image credit: Authors.

\section{Class 2 variant 4 ( $n=437)$ (Figure 13)}

This variant is characterised by a red slip (10R-4/8 red, 10R-5/8 red) that is mixed with mica powder (small mica specks are visible). This has been applied on the external surface of restrictive-shaped vessels, and on the internal surface of unrestrictive shapes. It is clear that the mica has been added deliberately during the preparation of the slip, because the fabric of the pot visible in section does not contain mica. Vessel shapes are the same as those made with Class 2 variants 1 and 2: bowls with thick or featureless rim, jars without neck and out-turned rim and jars with neck and out-turned and thick rim. For vessel forms, see Lefrancq and Hawkes (2019b, plates 7-9). 


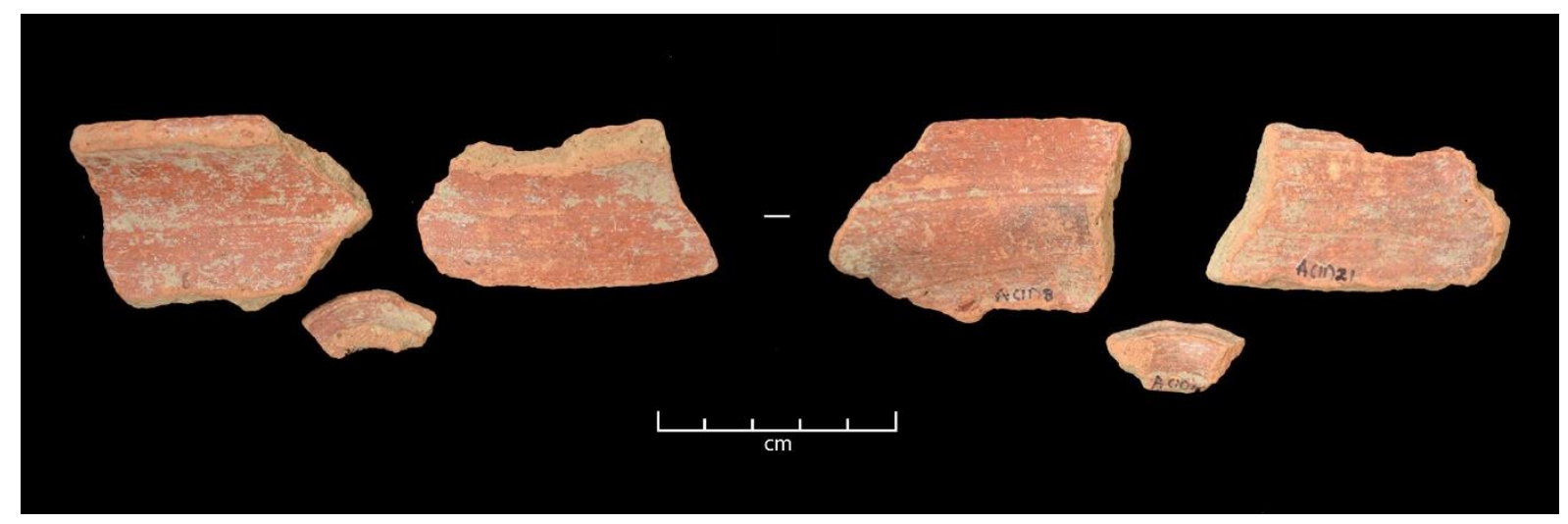

Figure 13: External and internal sides of necks with red and mica slip, Class 2 variant 4, MHR2002.A11.8/21/16. Image credit: Authors.

\section{Class 2 variant $5(n=32)$ (Figure 14)}

Pots belonging to this variant are decorated with impressed motifs on the external surface of the vessel body. Patterns include horizontal registers of impressed dots or triangles, as well as lines impressed using a twisted cord. The factor that defines this variant as distinct from variant 3 is the absence of red slip. However, as mentioned in the general description of the overall class, the slip might have degraded as a result of post-depositional process. Only bodysherds corresponding to restrictive shapes were found. For vessel forms, see Lefrancq and Hawkes (2019b, plate 9).

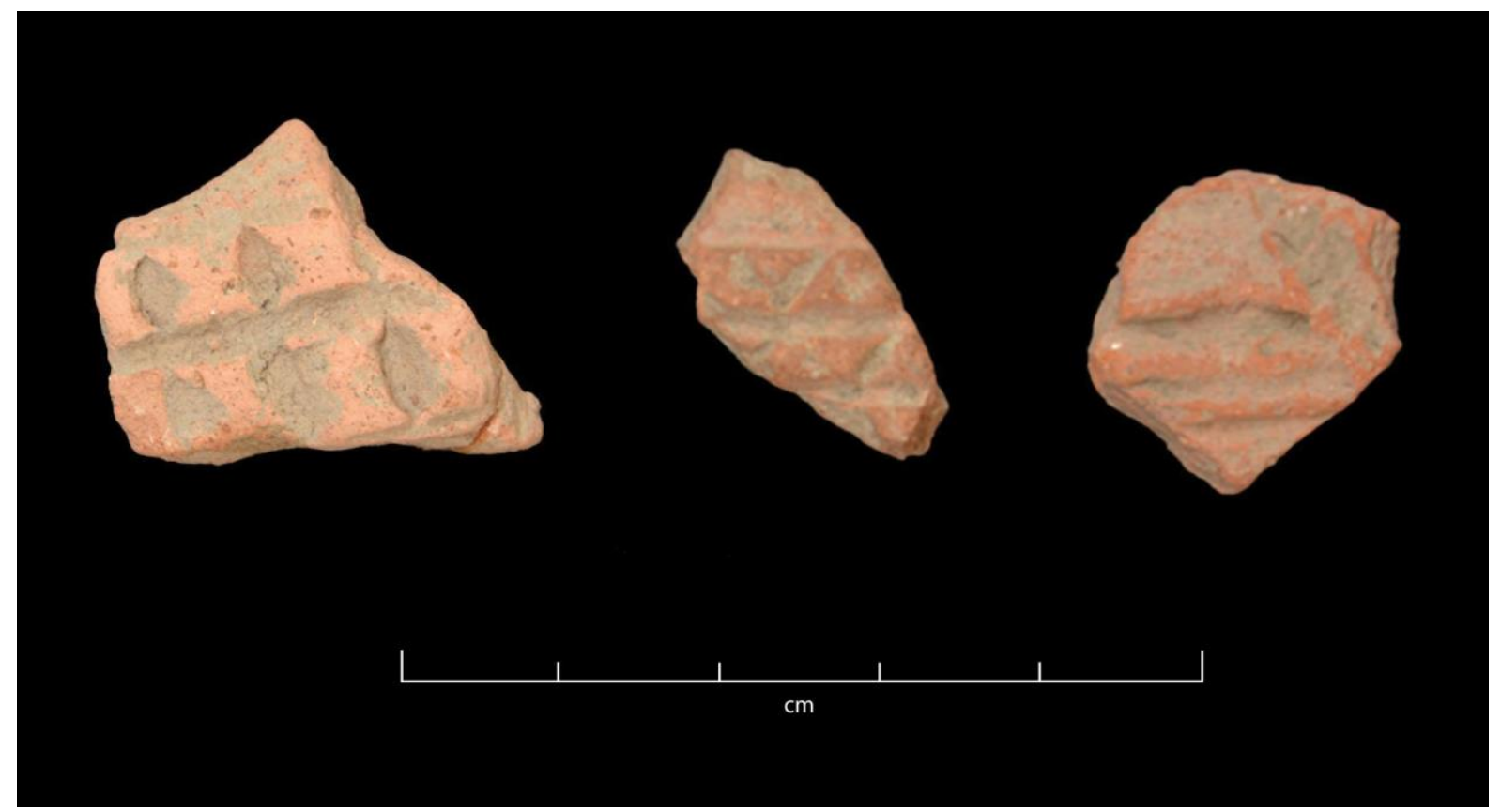

Figure 14: External sides of bodysherd with impressed decoration, Class 2 variant 5, including MHR2002.A4.30 (left), and MHR2002.A1.14/22 (right). Image credit: Authors.

\section{Class 2 variant 6 ( $n=16)$ (Figure 15)}

The last variant of this class is characterised by the application of a preparation of mud-clay on the external surface of the pots (colour of external surface 2.5YR-6/6 light red, colour of internal surface 5YR-7/3 pink, 5YR-6/4 light reddish brown, colour of mud decoration: $2.5 Y R-6 / 8$ light red). Sometimes, this mixture is mixed with mica. 
The most common fabric used in the production of these pots is Fabric Group 3, but a few pots were made using Fabric Groups 2 and 1 as well. For vessel forms, see Lefrancq and Hawkes (2019b, plate 9).

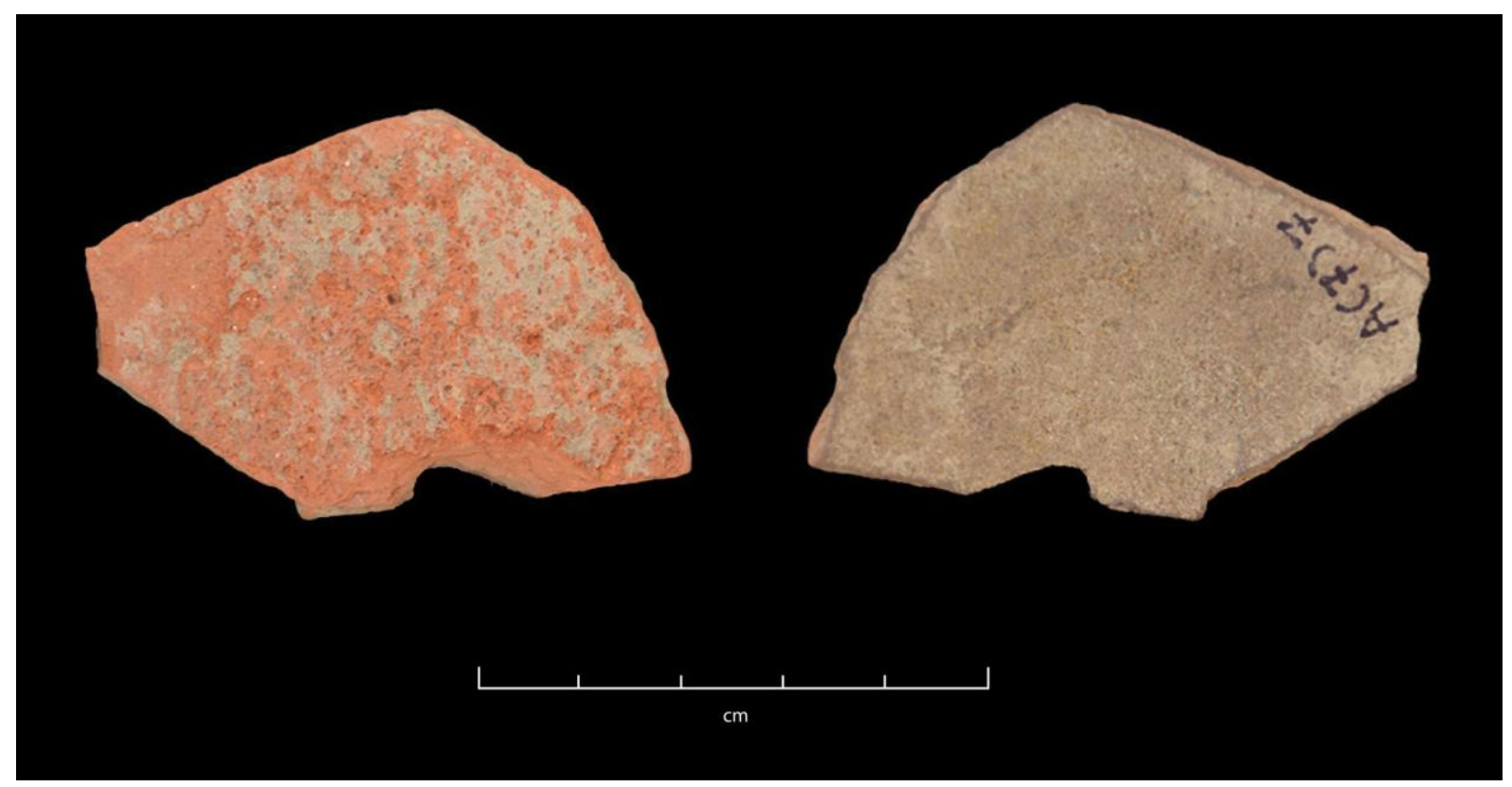

Figure 15: External and internal sides of bodysherd with mud decoration, Class 2 variant 6, MHR2002.A7.7. Image credit: Authors.

\subsection{Class 3}

The technical features of potsherds attributed to Classes 3 and 2 are similar. The distinguishing criterion is the presence of a micaceous slip. The majority of vessels belonging to Class 3 are made using Fabric Groups 2 and 3, though in a few instances Fabric Groups 1, 6 and 7 are used. Some vessels are wheel-thrown but most are made using composite techniques. As such, in instances where there are no complete profiles it can be difficult to identify all of the techniques used. However, as we saw with Class 2, the technique of coiling combined with a slow wheel to achieve regular surfaces is evident in the production of bowls with ribbed/bifoliate rim and annular bases.

Traces of smoothing are often visible on both sides. The main defining characteristic of the class is the presence of a slip made of a low proportion of small mica flakes and of a high proportion of mica particles. This was applied on the external surface of the restrictive shapes and on the internal surface of the unrestrictive shapes. In some vessels, such as those belonging to Class 3 variant 2 type 3 (see Lefrancq and Hawkes 2019b), the micaceous slip is visible on both surfaces. Two variants have been defined according to the texture and the hardness of the paste.

\section{Class 3 variant $1(n=3)$ (Figure 16)}

Only three potsherds belong to this variant (two bodysherds and one base sherd). The paste is compact and hard. This can be due to a higher temperature and longer firing process, as indicated by the colour of the surfaces (10R7/4 pale red, 10R-7/6 light red, 10R-6/3 pale red). Two potsherds are from Fabric Group 2 and the third is from Fabric Group 4. Clear smoothing circular lines are visible on the internal part of the base sherd. For vessel forms, see Lefrancq and Hawkes (2019b, plate 10). 


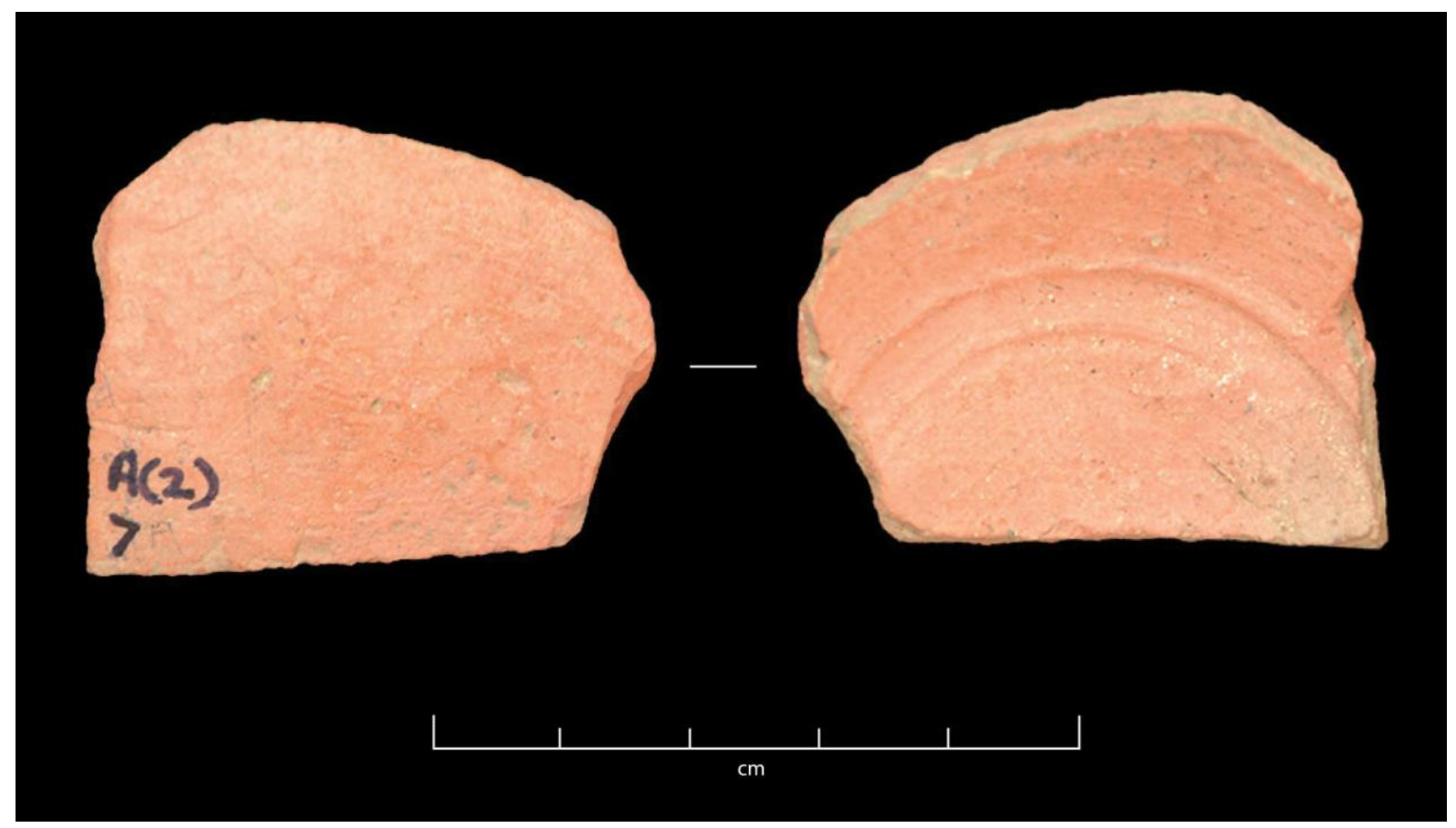

Figure 16: External and internal sides of base, Class 3 variant 1-base type 1, MHR2002.A2.7. Image credit: Authors.

Class 3 variant 2 ( $n=123)$ (Figure 17)

This variant is the most frequent of this class. It is made with Fabric Groups 2 and 3, but in comparison with those of Class 3 variant 1 the texture of the paste is less compact and surfaces are buff-brown rather than red-pink (7.5YR-6/2 pinkish gray, 5YR-6/4 light reddish brown, 10YR-7/3 very pale brown). Traces of smoothing are noticeable on both surfaces.

Mica flakes are visible on the surfaces but not in section. Vessel shapes include: bowls with ribbed/bifoliate rim, pots with in-turned rim and corrugations on the external side of the rim, small pots with an out-turned and round rim, jars with an out-turned rim. For vessel forms, see Lefrancq and Hawkes (2019b, plate 10). 


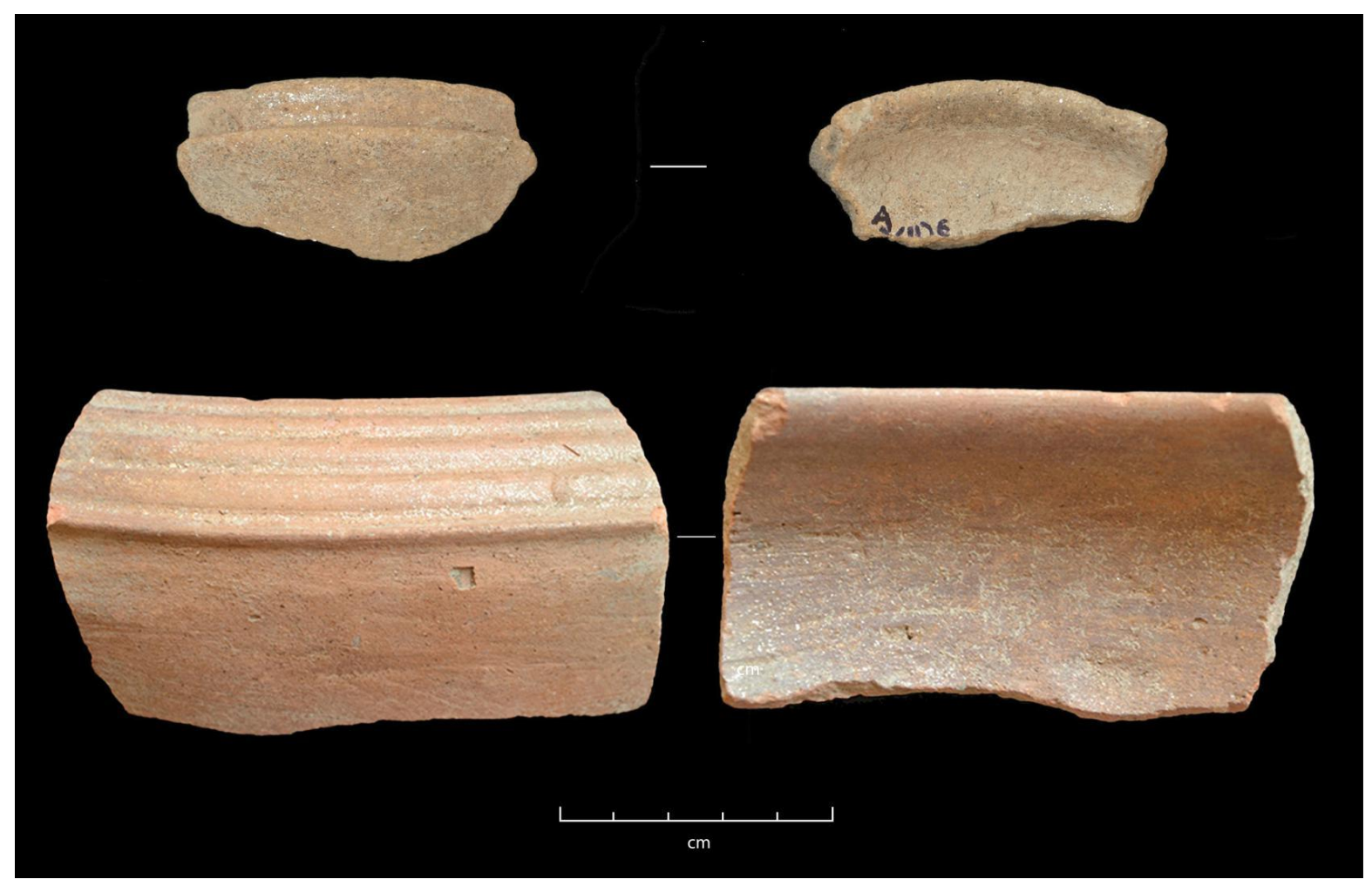

Figure 17: Above: external and internal sides of rim, Class 3 variant 2-type 2, MHR2002.A11.6; below: external and internal sides of rim, Class 3 variant 2-type 3, MHR2002.F-NE.16.no number. Image credit: Authors.

\subsection{Class $4(n=1)$}

Only one distinctive rim-sherd (a necked-jar with an out-turned and featureless rim) was classified as belonging to Class 4 (Figure 18). It is made using a fabric belonging to Fabric Group 12, characterised by a very fine sandy paste, with a few whitish inclusions and mica. The fabric is very hard. The colour of the fabric visible in section is redorange (5YR-6/6 reddish yellow, 2.5YR-7/8 light red). Owing to the small size and heavily eroded condition of the rim sherd, it is difficult to identify the fashioning technique but the piece is of uniform thickness. The surfaces are soapy and rough to the touch. The vessel most probably has a restrictive shape. Taken together, the different manufacturing processes visible in this sherd suggest that it could have been non-locally made. For vessel forms, see Lefrancq and Hawkes (2019b, plate 11). 


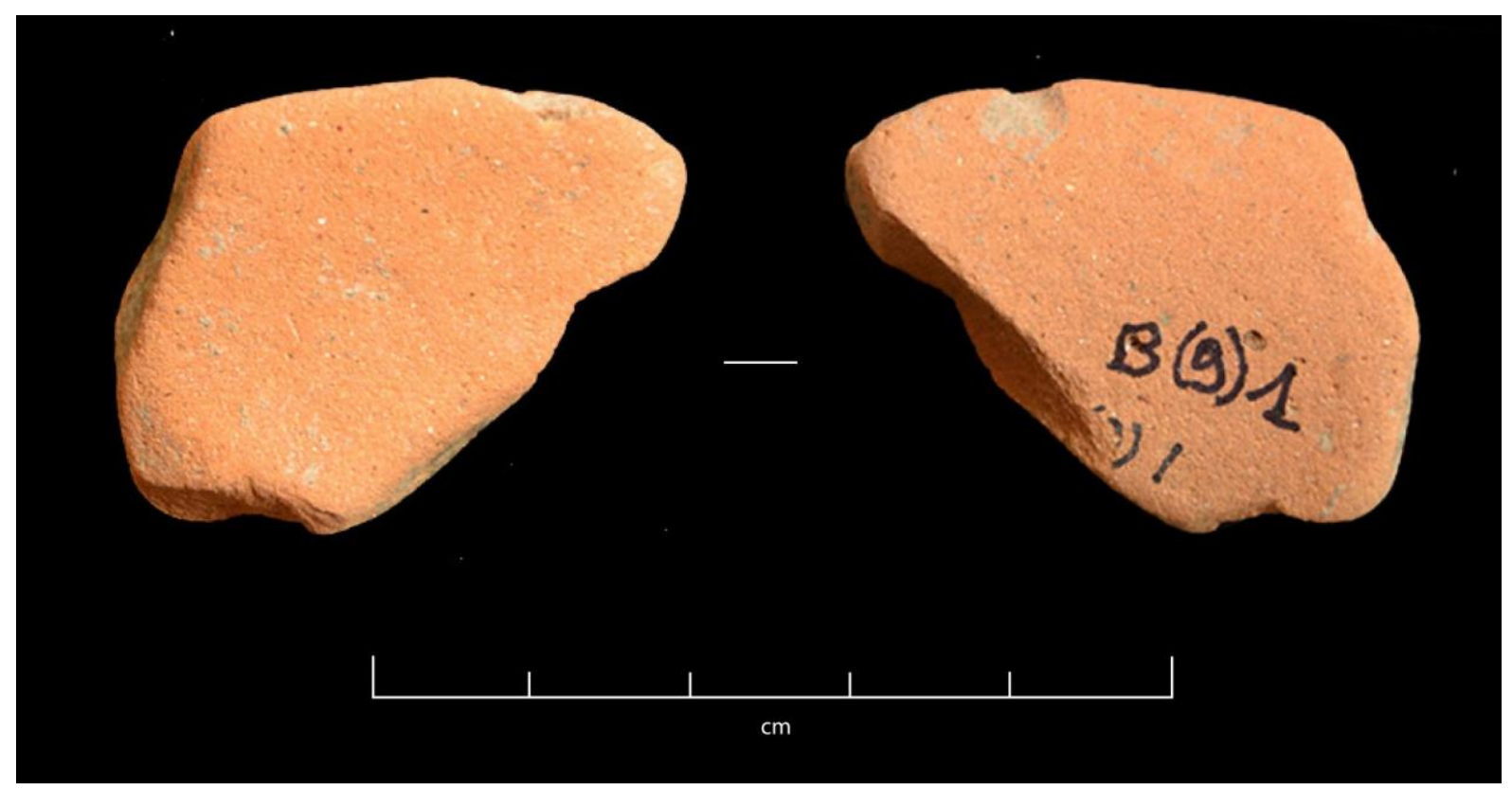

Figure 18: External and internal sides of rim, Class 4, MHR2002.B9.1-type 1. Image credit: Authors.

\subsection{Class 5}

This class is characterised by the high proportion of mica flakes and specks in both the paste and on the surfaces. The main Fabric Groups are 4 and 6 followed by Fabric Groups 5, 8, 18, 16 and (in a very low proportion) 13. All of these fabrics contain mica but differ both in texture, from medium to coarse, and in the presence of other inclusions. The wheel-coiled technique is the one most frequently used in the production of both unrestrictive and restrictive shapes. In both morphological categories, undulations are visible on the surfaces and in the joins of the large coil of the rim and the rest of the vessel. However, for globular pots, a mould might have been used to make the vessel base with coils added later. Few traces of the use of paddle and anvil have been observed in order to join both parts and to thin the sides. In all cases, a light smoothing has been applied on both sides of the vessels.

One of the main differences between Class 5 and Class 3 is that vessels of Class 3 have a micaceous slip applied to the surfaces, while in Class 5 mica flakes and specks are bigger in size, higher in concentration and present in the fabric. The variants of this class have been defined on the basis of differences in surface treatment (none, red slip or black slip), firing atmosphere, and the presence of mica (abundant or less abundant). Apart from Class 5 variant 4, all variants were fired in an oxidising atmosphere that has not been well controlled. Hence, the potsherds frequently show a darker brown core.

\section{Class 5 variant 1 ( $n=1067)$ (Figure 19)}

The main feature of this variant is the presence of mica flakes and specks in the paste and on both surfaces. Fabric Group 4 is predominant. Traces of reddish-brown slip (2.5YR-7/4 light reddish brown, 7.5YR-6/4 light brown, 5YR-6/2 pinkish gray, 10R-6/6 light red, 2.5YR-6/2 pale red, 7.5YR-5/2 brown, 2.5YR-5/4 reddish brown, 2.5YR-6/4 light reddish brown, 2.5YR-6/6 light red, 5YR-4/1 dark gray, 5YR-5/2 reddish gray) are visible on some potsherds. Yet in most instances it is washed out. For vessel forms, see Lefrancq and Hawkes (2019b, plates 11-16). 


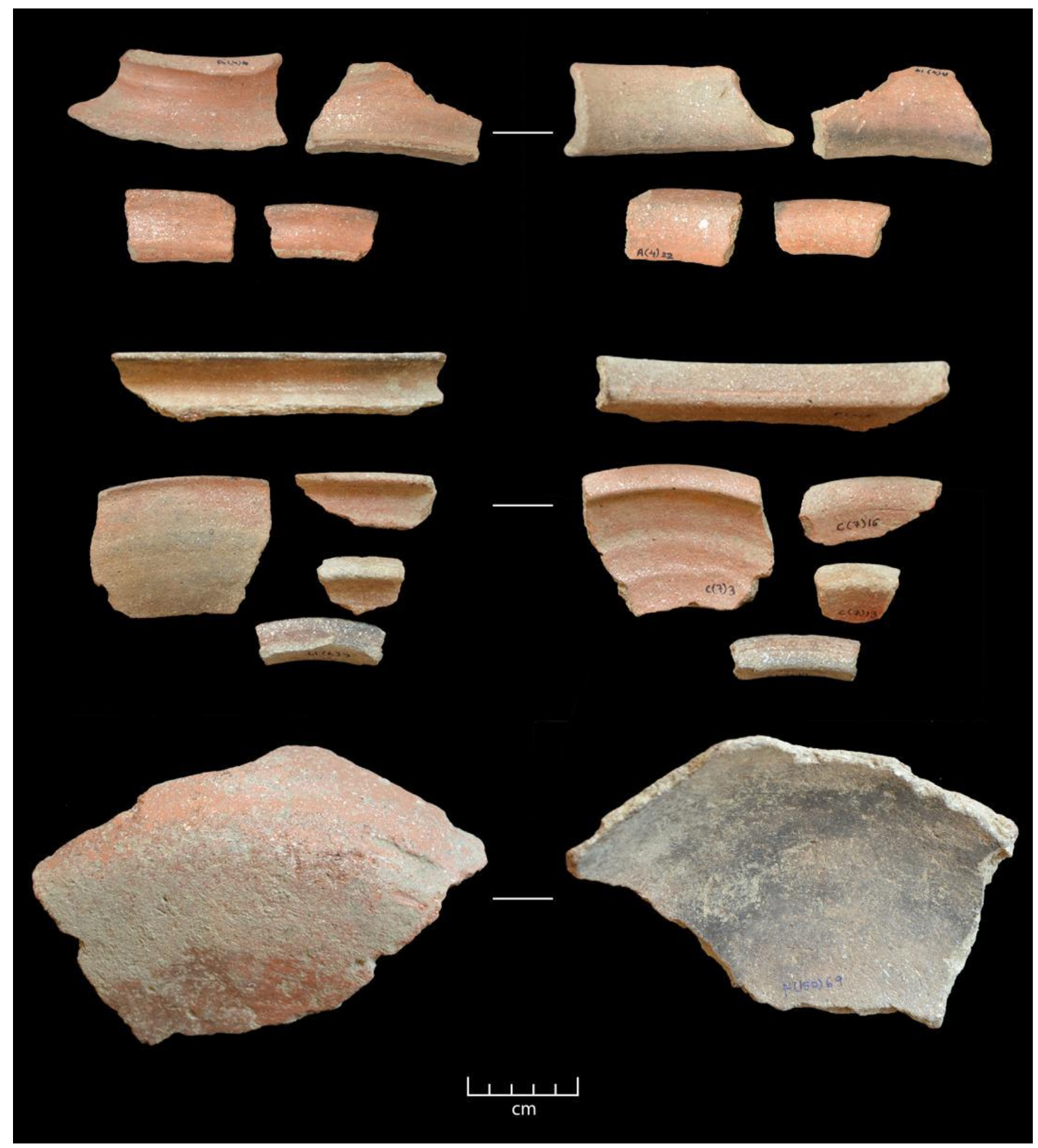

Figure 19: Above: external and internal sides of rims, Class 5 variant 1, MHR2002.A4-type 9; middle: external and internal sides of rims, Class 5 variant 1- mix of types, MHR2002.C7; below: external and internal sides of base, Class 5 variant 1-base type 1, MHR2002.F-NW.150.69. Image credit: Authors.

It can be difficult to differentiate between vessels belonging to Class 5 variant 1 and those belonging to Class 3 . The smoothing of surfaces can give the feeling that a micaceous slip was applied. The oxidising firing process was not well controlled, and it is often possible to observe 'firing traces' - colour variations within the same potsherd (5YR-5/4 reddish brown, 5YR-5/6 yellowish red, 5YR-6/4 light reddish brown). Vessel shapes are: bowls with an out-turned round rim, plates with out-turned flat rim, plates with a carination below the ribbed/bifoliate rim, jars with an out-turned and splayout rim, jars with an everted and elongated rim marked by an internal carination (most common shape), jars with neck and out-turned rim. 
Class 5 variant 2 vessels are most frequently made using Fabric Group 6, followed by Fabric Group 4. Mica flakes and specks are visible on both surfaces, though less than on those of Class 5 variant 1 . The colour of the slip shows a range of grey and reddish-brown colours (2.5YR-2.5/4 dark reddish brown, 2YR-3/4 dark reddish brown, 5Y-5/1 gray, 5YR-8/3 pink, 10YR-2/1 black) owing to a last reducing phase during the firing process. Shapes consist of bowls with straight rim, carinated pots with an out-turned and slightly elongated rim and jars with neck and complex out-turned rim. For vessel forms, see Lefrancq and Hawkes (2019b, plate 17).

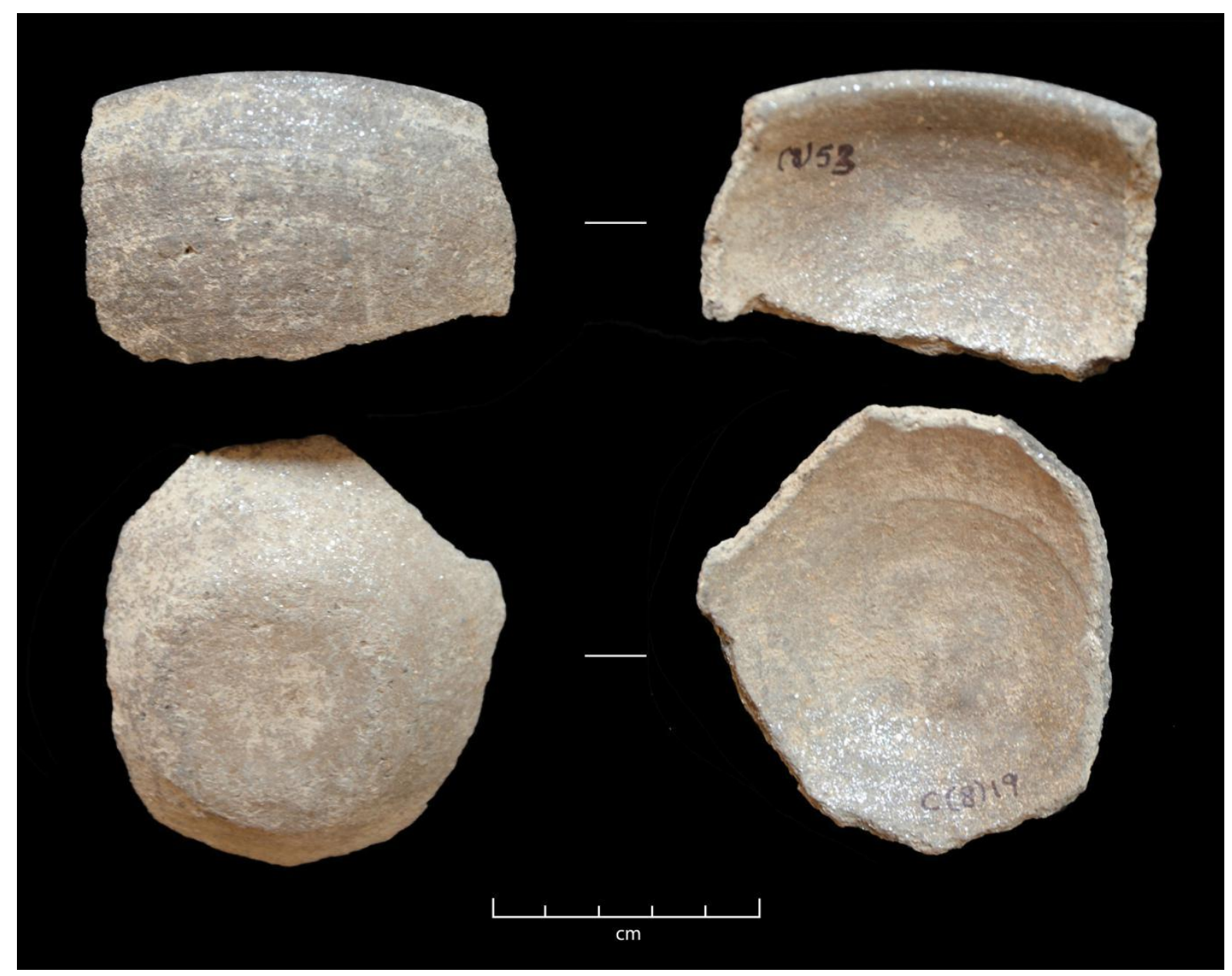

Figure 20: External and internal sides of bowl, Class 5 variant 2-type 2, MHR2002.C8.19-53. Image credit: Authors.

\section{Class 5 variant 3 ( $n=1559)$ (Figure 21)}

This variant presents a wider range of Fabric Groups $(4,6,5,8,18,16,13)$ and the clay is generally coarser. A red slip is applied on external or internal surfaces depending on the shape but, quite often, the red slip has turned black either because of a non-well controlled firing process or subsequent use (2.5YR-4/8 red, $2.5 \mathrm{YR}$ 4/6 red, 2.5YR-3/4 dark reddish brown, 7.5YR-5/1 gray, 7YR-4/3 brown, 10R-4/6 red, 10R-4/8 red, 10R-5/8 red, 10R-4/1 dark reddish gray, 10R-5/6 red). In such circumstances, both colours of slip are visible on the surface. Medium to high quantity of mica flakes and specks are visible on both surfaces. Besides the slip, 'flower' or 'sun' motifs are stamped on the upper part of the body of certain restrictive shapes. A type of basin with a very developed and complex rim displays another impressed decoration on the rim along with 'appliqué' decoration and ridges.

The range of vessels is wide, and includes basins with in-turned, very complex and decorated rim, a series of bowls with in-turned rim, plates with an elongated and carinated rim, jars with small neck and out-turned rim 
with an impressed/stamped ('flowers or suns') and/or incised decoration on the shoulder, jars with neck and out-turned rim. For vessel forms, see Lefrancq and Hawkes (2019b, plates 18-23).

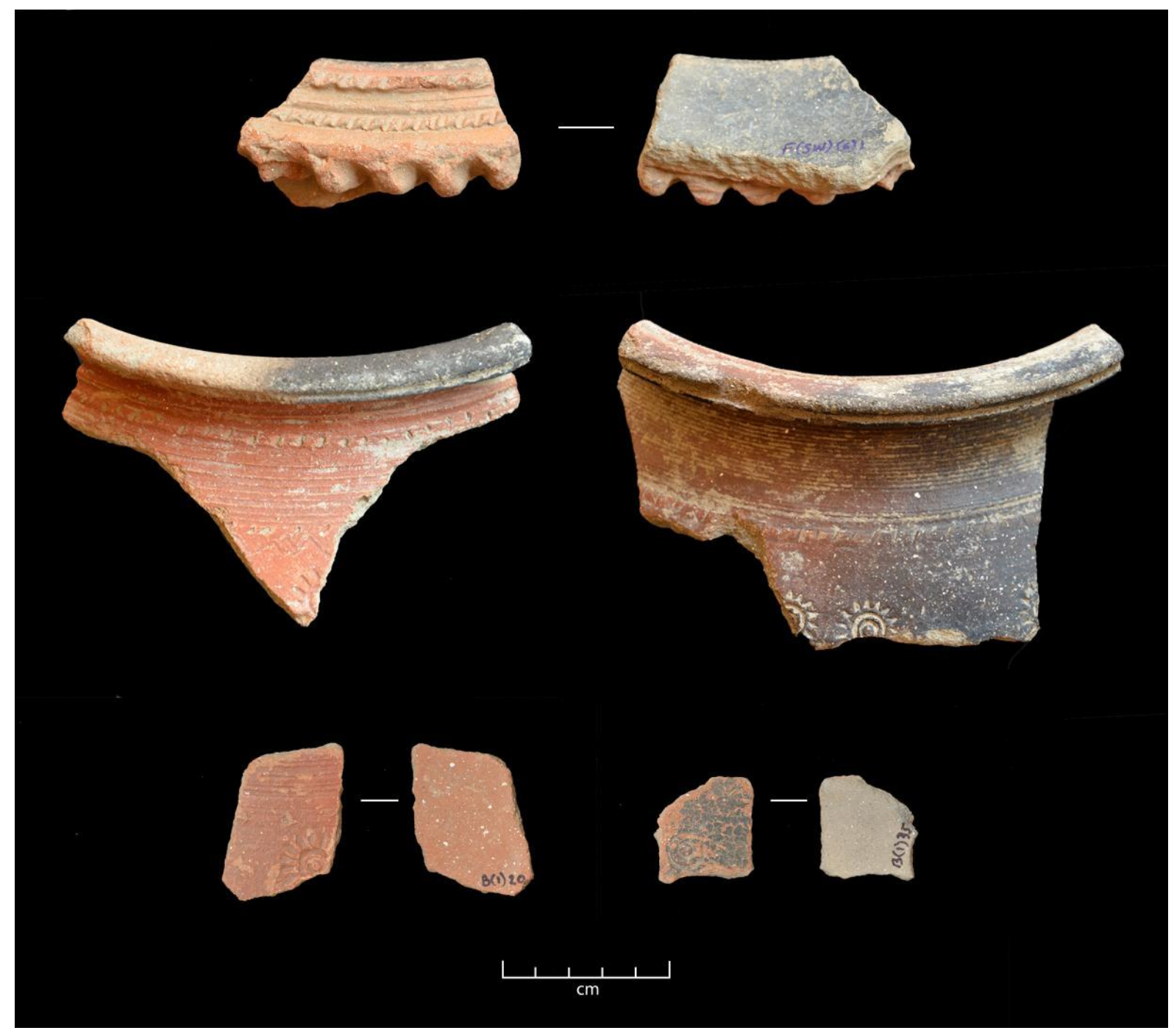

Figure 21: Above: external and internal sides of rim, Class 5 variant 3-type 2 variant 1, MHR2002.F-SW.6.1; middle left: external side of rim, Class 5 variant 3-type 8, MHR2002.F-NW.124.1; middle right: external side of rim, Class 5 variant 3type 8, MHR2002.F-NW.120.1; below: external and internal sides of bodysherds with incision and stamped decoration with 'sun-flower', Class 5 variant 3, MHR2002.B1.20/35. Image credit: Authors.

\section{Class 5 variant $4(n=170)$ (Figure 22)}

Vessels of this variant are most frequently made using Fabric Groups 16, 8, 13 and 4. The paste shows a low frequency of mica flakes and specks. However, the patches of mica are still very visible on both surfaces. Besides the variation in the quantity of mica in section, the most visible difference between this and other variants in this class is the presence of a black slip (10YR-2/1 black, 10YR-3/1 very dark gray, 2.5Y-2.5/1 black) on the external surfaces of restrictive shapes, and on the internal surfaces of unrestrictive shapes. The slip is smoothed and polished showing shiny reflections. Often, parallel lines are incised on the external surface of the neck or on the shoulder of restrictive shapes. Apart from the presence of mica in the fabric and surfaces, vessels of Class 5 variant 4 are similar to those of Class 6 variant 2 .

The range of shapes appears to be less developed than those of other variants. They include basins with inturned rim, shallow bowls, jars with neck and everted rim, pots with everted and out-turned rim. For vessel forms, see Lefrancq and Hawkes (2019b, plates 24-25). 


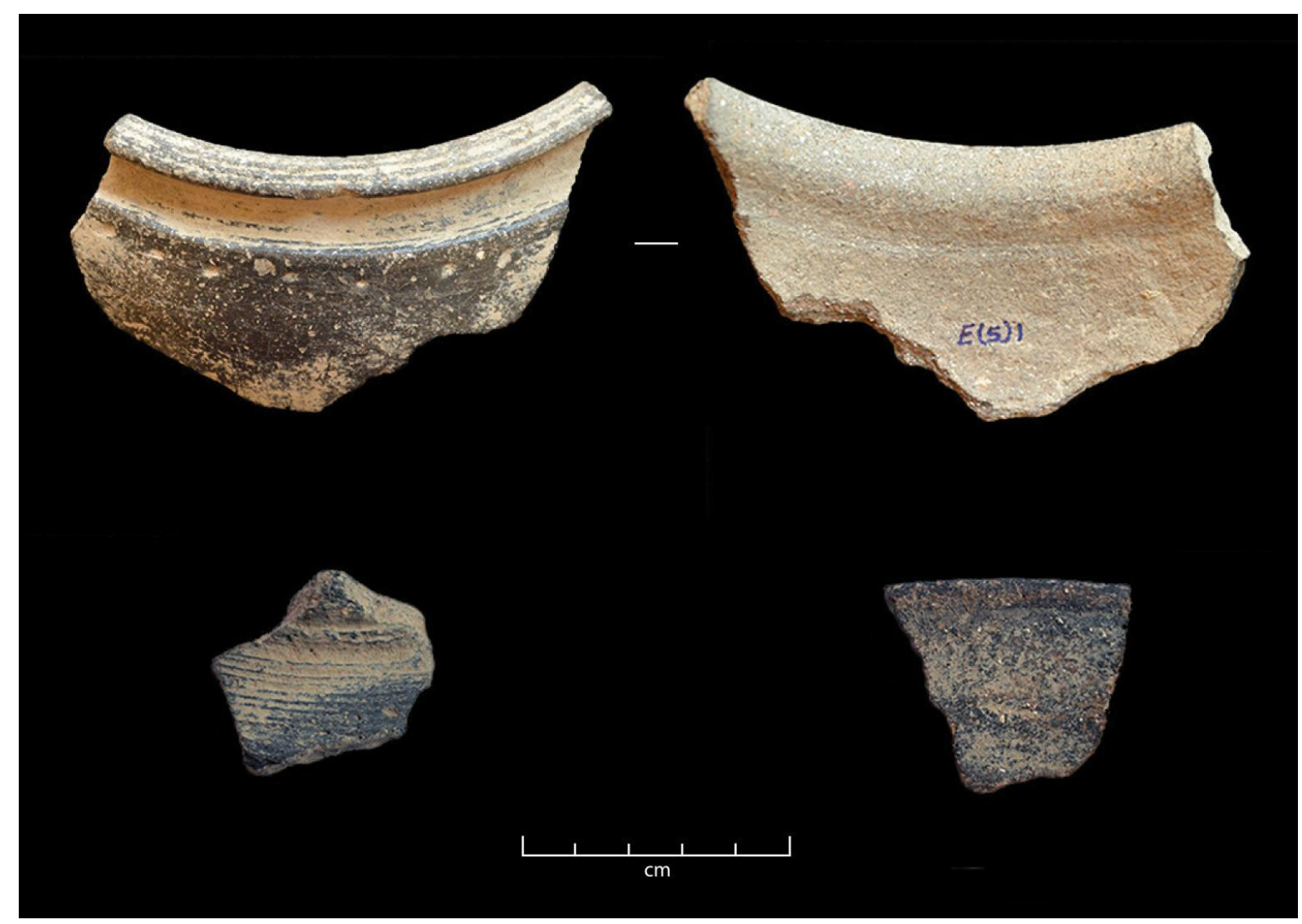

Figure 22: Above: external and internal sides of rim, Class 5 variant 4-type 4, MHR2002.E5.1; below: external side of a neck (left) and of a rim (right), Class 5 variant 4-type 2, MHR2002.D1.5/2. Image credit: Authors.

\subsection{Class 6}

This class is not associated with any specific fabric groups. The clay can be medium (as with Fabric Groups $2,1,7$, 10 ) as well as coarse (like Fabric Groups $13,8,17,14$ ). A few mica specks are visible in section but never on the surface. Owing to the small size of the surviving potsherds, it is difficult to identify the techniques used to fashion the pots. Notwithstanding these difficulties, it seems that they were all made using the wheel-coiled technique. The main distinguishing feature of this class is the presence of a red or black slip (depending on the firing atmosphere), which is then smoothed and usually polished. Three variants can be defined.

\section{Class 6 variant 1 ( $n=22)$ (Figure 23)}

This variant is made using fabrics with a medium texture without mica (i.e. Fabric Groups 1, 2, 7 and 10). Owing to the low quantity of potsherds in the assemblage ( 22 in total) and their small size, it is not possible to identify the shaping techniques. The only evidence is the regular surface thickness, which can be attributed to both wheelthrown and wheel-coiled techniques. A smoothed red slip (2.5YR-2.5/2 very dusky red, 2.5YR-4/6 red, 10R-4/6 red, 10R-5/6 red, 2.5YR-6/3 light reddish brown, 5YR-5/3 reddish brown) is applied. The firing atmosphere is oxidising, but a few potsherds exhibit variation in the colour of the surfaces resulting from an ill-controlled firing process. Only restrictive shapes (jars with neck and out-turned rim and pots with everted rims) have been discovered. For vessel forms, see Lefrancq and Hawkes (2019b, plate 26). 


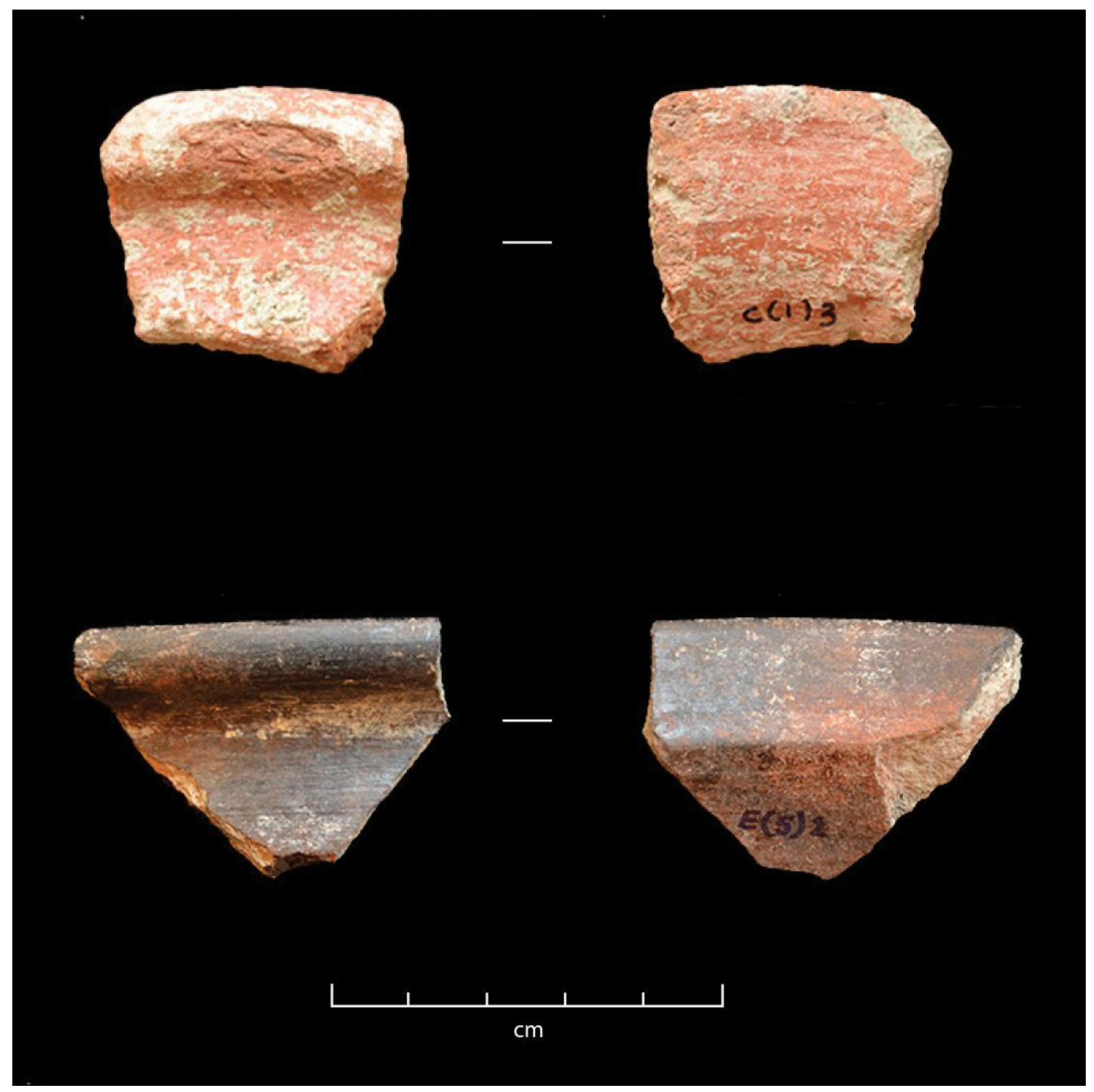

Figure 23: Above: external and internal sides of rim, Class 6 variant 1-type 2, MHR2002.C1.13; below: external and internal sides of rim, Class 6 variant 3-type 1, MHR2002.E5.2. Image credit: Authors.

\section{Class 6 variant 2 ( $n=56)$ (Figure 24)}

The paste of this variant is coarser than that of Class 6 variant 1 and belongs to Fabric Groups 13, 8, $17,14$. Depending on the fabric group, a few mica specks are present in the section but not on the surfaces. Potsherds display a black slip (2.5Y-2.5/1 black, 10YR-2/1 black, 5Y-2.5/1 black) that was smoothed and slightly polished. Shaping techniques are difficult to discern owing to the small size of potsherds. In contrast to variant 1 , pots of Class 6 variant 2 are fired in a reduced atmosphere, indicated by the grey colour of the paste and surfaces. They also exhibit a greater diversity of shapes. Unrestrictive shapes such as shallow bowls and bowls with in-turned rims are present, as well as restrictive shapes including pots with elongated and everted rim, pots with in-turned rim and jars with neck and out-turned rims. Ridges are sometimes present on the external surface of the rim, on the neck or shoulder of the vessel. Impressed decorations are evident on a basin with a complex rim - a vessel shape that is also evident in Class 5 variant 4. For vessel forms, see Lefrancq and Hawkes (2019b, plates 26-27). 


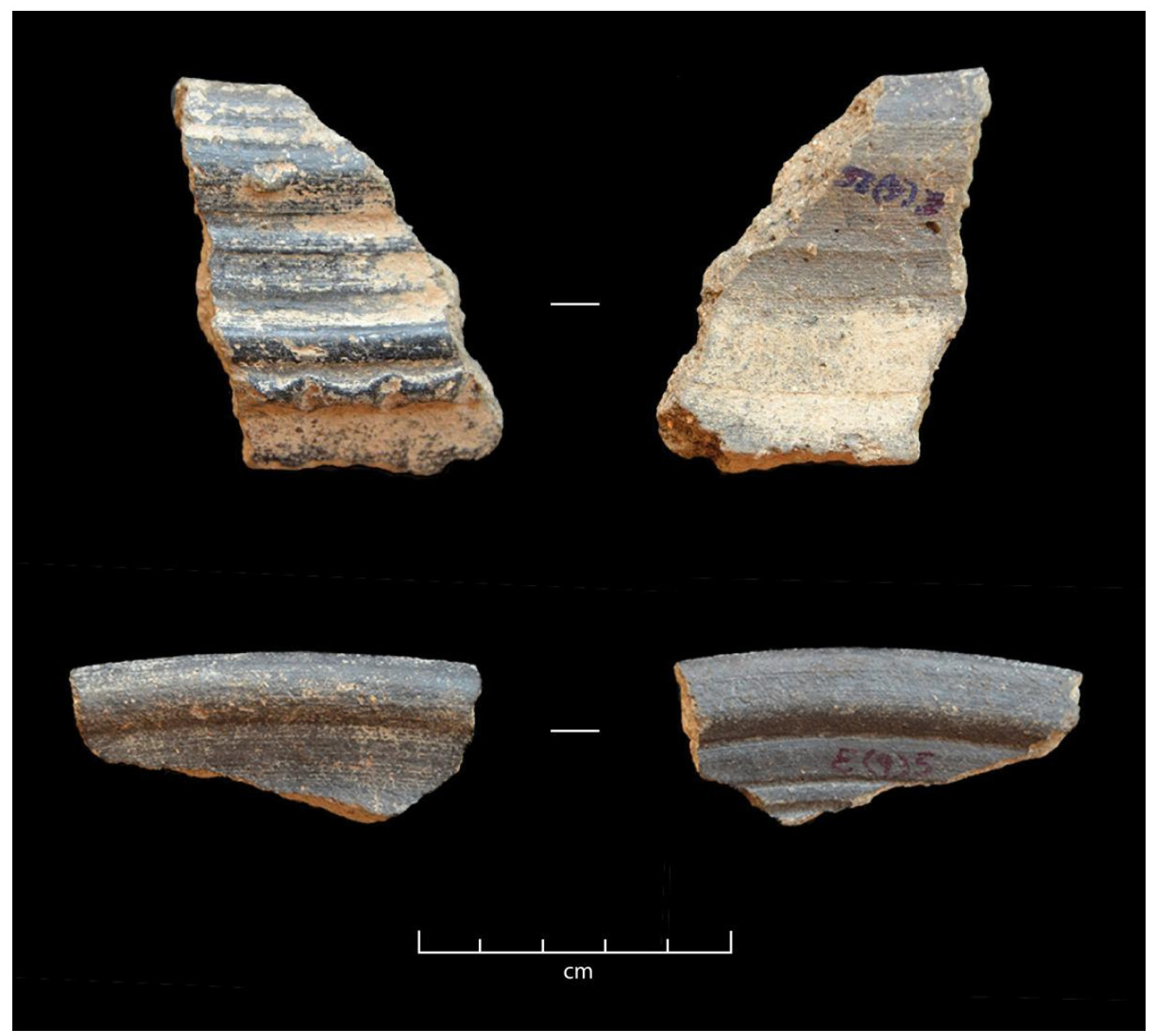

Figure 24: Above: external and internal sides of rim, Class 6 variant 2-type 9, MHR2002.E6.26; below: external and internal sides of rim, Class 6 variant 2-type 2, MHR2002.E9.5. Image credit: Authors.

\section{Class 6 variant 3 ( $n=15)$ (Figure 25)}

This variant brings together potsherds with a similar paste to those attributed to Class 6 variant 2 . However, the black slip indicative of that variant is not found in variant 3. Indeed, the grey colour of the surfaces (7.5YR $-5 / 1$ gray, 2.5YR-5/1 reddish gray, GLEY2-5/1 bluish gray) is instead the result of a final stage of firing in a reduced atmosphere. However, for some potsherds, it is difficult to say whether a black slip (characteristic of Class 6 variant 2) might have disappeared owing to post-depositional processes, or does not exist. Both surfaces of potsherds are smoothed and vessels are fired in a reducing atmosphere. Only one pot with an in-turned rim and a jar with neck and out-turned rim have been found. For vessel forms, see Lefrancq and Hawkes (2019b, plate 27). 


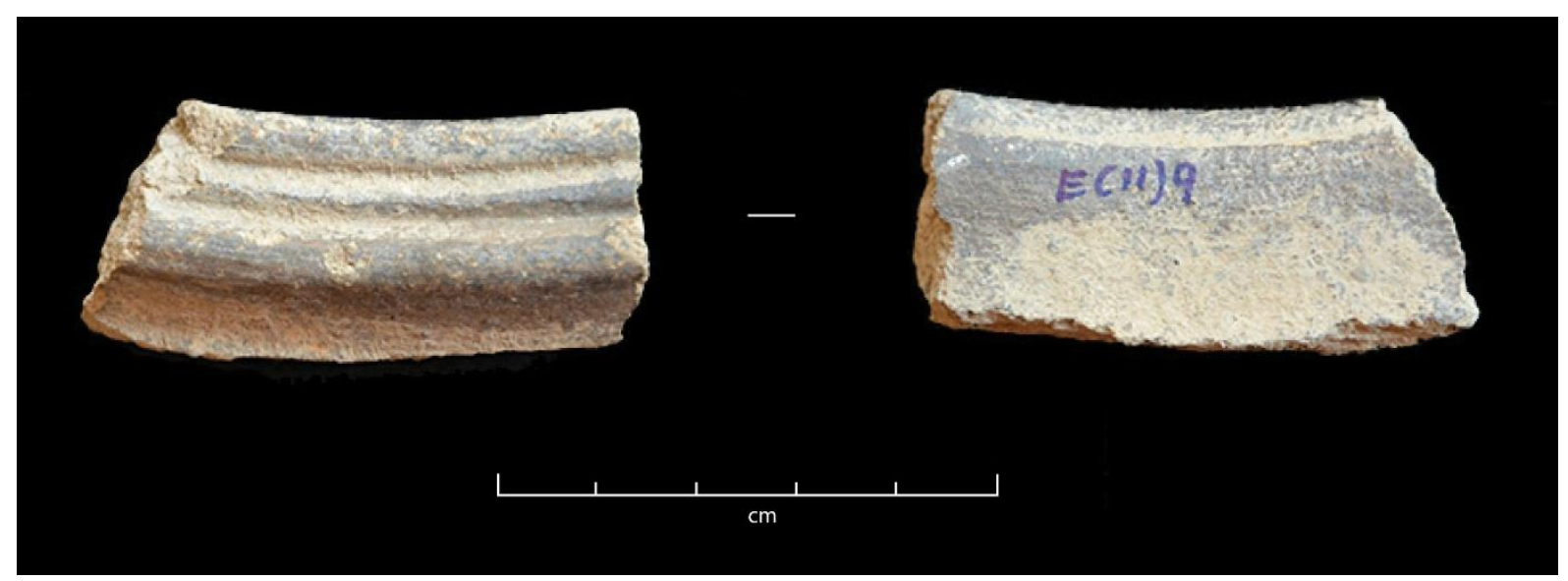

Figure 25: External and internal sides of rim, Class 6 variant 3-type 1, MHR2002.E11.9. Image credit: Authors.

\subsection{Class 7}

This class encompasses a wide range of Fabric Groups (i.e. Fabric Groups 2d, 8, 6, 13, 14, 10, 16). The texture of the paste is medium to coarse. This class is similar to Class 2 in terms of the fabrics that are used, though those that are used to produce these vessels is perhaps slightly coarser with the occasional addition of organic temper. However, two technical features enable us to define this as a separate class, namely the imprints of organic tempers visible in both surfaces (probably rice husks and plants) and the thickness of the potsherds, which varies between $1.5 \mathrm{~cm}$ and $3 \mathrm{~cm}$. In addition, and despite the small number of diagnostic potsherds in the assemblage, all examples (mostly big jars and basins) were made from hand-stretching plates of clay and coils. The surfaces are smoothed. Vessels are fired in an oxidising atmosphere, which was not always fully achieved owing to the thickness of the vessels and the presence of organic inclusions (2.5YR-6/6 light red, 5YR-7/4 pink, 5YR-7/6 reddish yellow, 5YR-8/4 pink, 7.5YR-7/4 pink). Two variants have been defined according to the decorative techniques: variant 1 without any specific decoration, and variant 2 with a red slip and/or mica on surfaces. Both variants are decorated with 'appliqué' - in this instance, an added coil with finger imprints - on the external surface.

\section{Class 7 variant $1(n=14)$ (Figure 26)}

This variant corresponds to the plain version of the class, which is decorated only with appliqué. A slight smoothing is visible on some potsherds. Only two very fragmented rims are identified, the rest are bodysherds belonging to a basin or big jar. For vessel forms, see Lefrancq and Hawkes (2019b, plate 28).

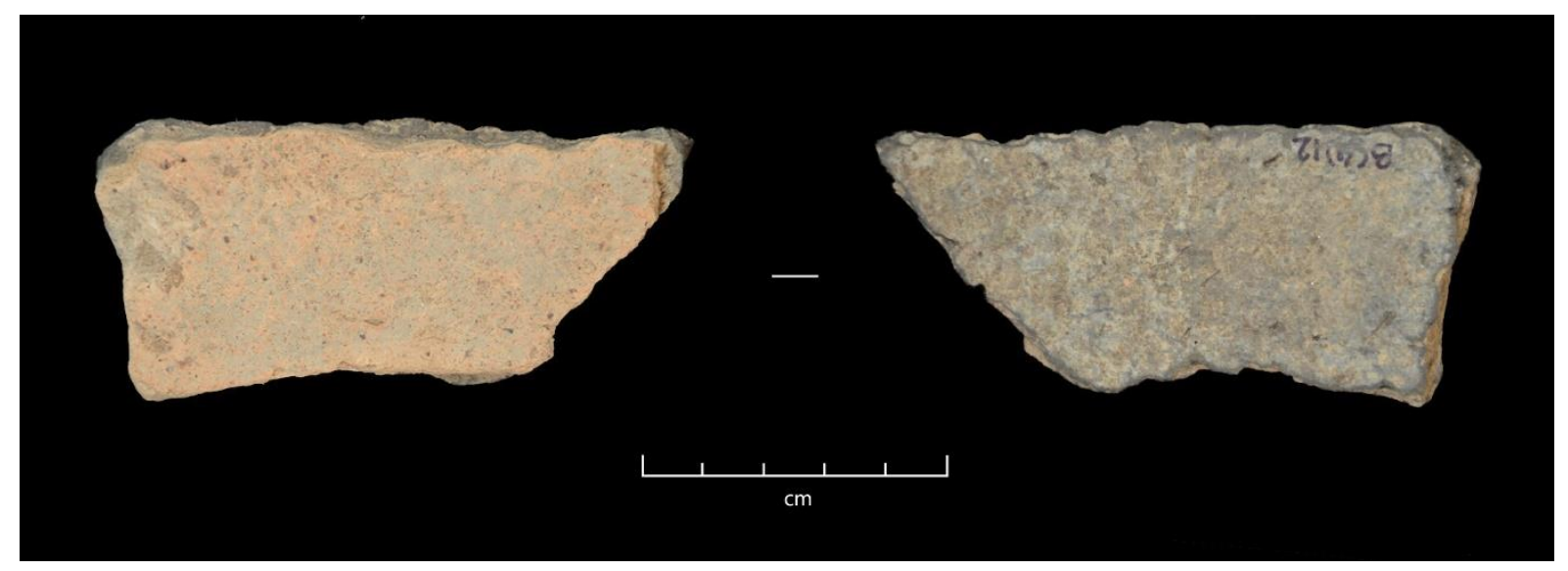

Figure 26: External and internal sides of bodysherd, Class 7 variant 1, MHR2002.B11.12. Image credit: Authors. 
This variant displays a red slip and/or a micaceous slip but the red slip is not always properly visible (2.5YR-4/6 red, 10R-6/2 pale red, 10R-6/3 pale red, 10R-5/6 red, 10R-5/8 red, 5YR-7/4 pink). Incised decorations can be observed on the external surface together with an appliqué decoration. Jars and basins are also the main vessel forms. For vessel forms, see Lefrancq and Hawkes (2019b, plate 28).

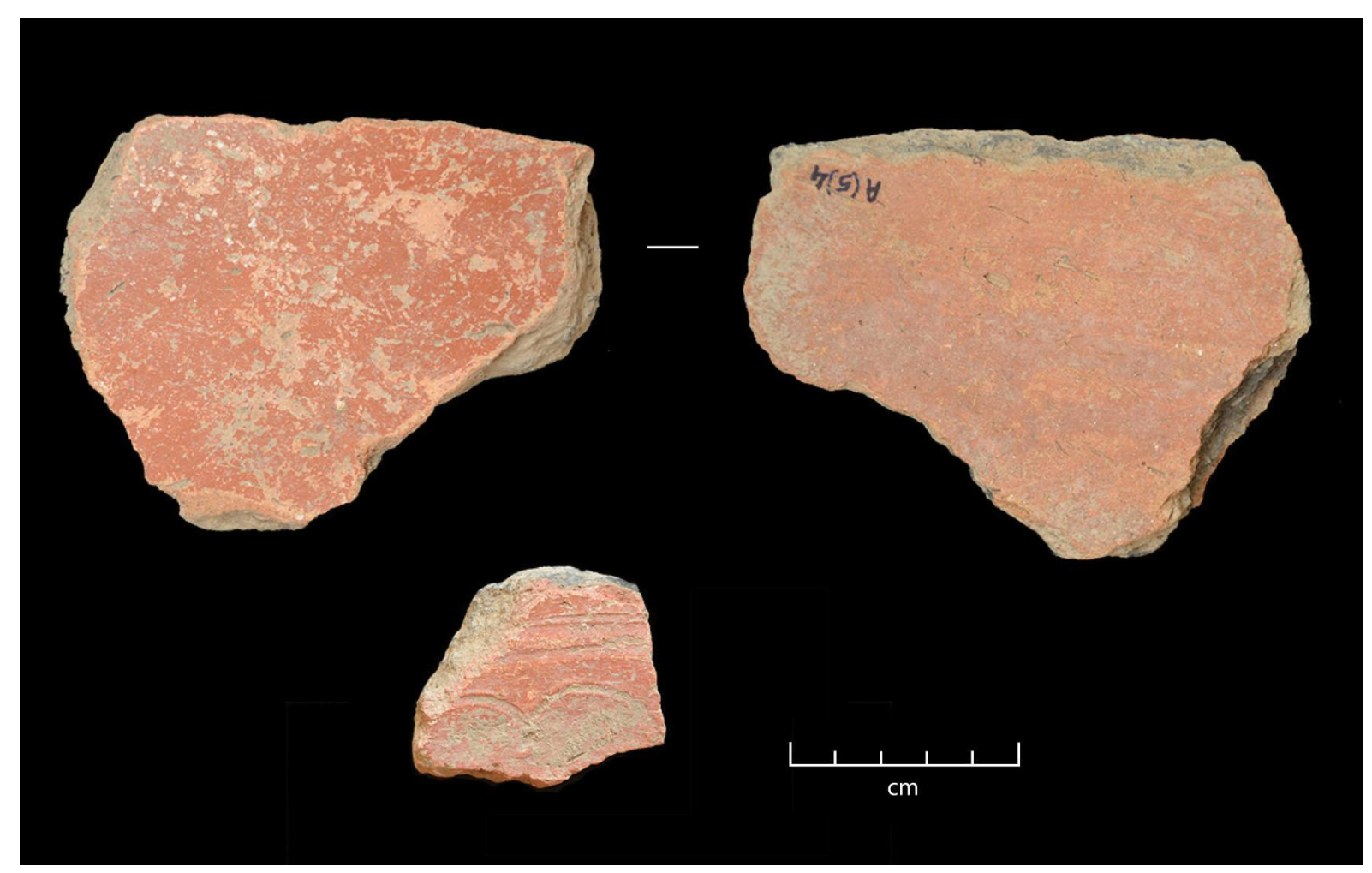

Figure 27: Above: external and internal sides of bodysherd with red slip, Class 7 variant 2, MHR2002.A5.4; below: external side of bodysherd with red slip and incision, Class 7 variant 2, MHR2002.A3.3. Image credit: Authors.

\subsection{Class $8(n=1)$}

This class comprises a single bodysherd (Figure 28), and will need to be better defined as more remains are excavated. The class is made using Fabric Group $2 \mathrm{~F}$, which is characterised by a compact paste that is fine in texture. The size of the bodysherd does not allow us to identify the precise fashioning technique used in its production, but it does not appear to have been wheel-thrown. The sherd is $1 \mathrm{~cm}$ thick. No slip is visible, and it appears not to have been slipped. The external surface has been smoothed (7.5YR-8/2 pinkish white) and is soft to the touch (7.5YR-5/1 gray). The internal surface shows traces of soot. It is difficult to say if this results from use (something that has burned within the receptacle) or if it is just because of the position of the pot during the firing process. 


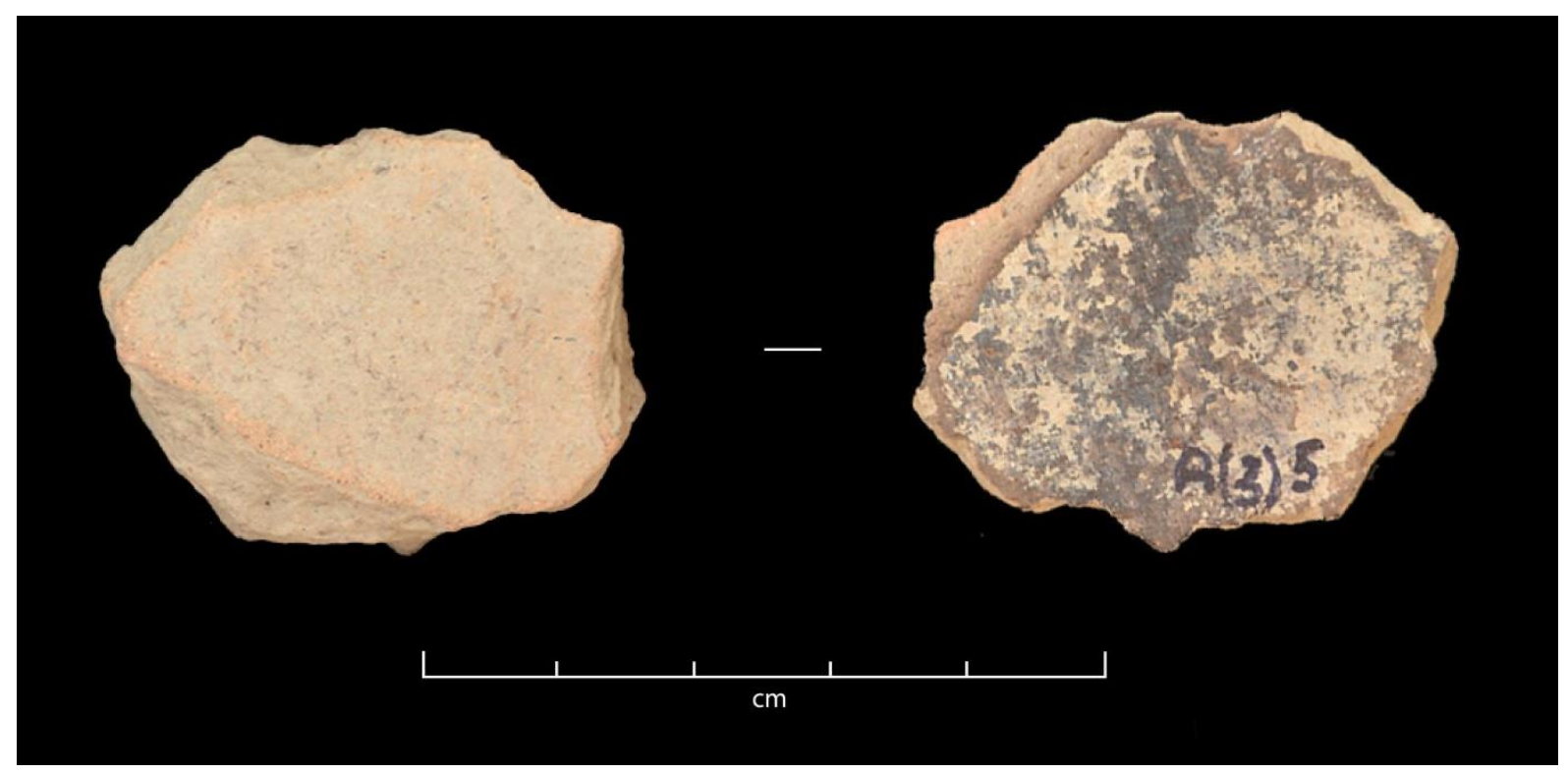

Figure 28: External and internal sides of bodysherd, Class 8, MHR2002.A3.5. Image credit: Authors.

\subsection{Class $9(n=36)$ (Figure 29)}

This class is made using Fabric Group 9, which is characterised by a very fine and compact clay. Inclusions are thus barely identifiable with $\mathrm{a} \times 10$ hand lens. If we look at the bodysherds alone, we would be tempted to say that these pots have been wheel-thrown because of the regularity of the sides. However, examination of the join between the rim and the upper part of the body of restrictive shapes reveals horizontal lines indicating the use of coiling techniques. As a result, we think that vessels of this class are wheel-coiled. Another characteristic is the thinness of the sides (3-4mm maximum). In terms of surface treatment, a red slip of good quality (2.5YR-3/6 dark red, 2.5YR-6/6 light red, 2.5YR-5/8 red, 10R-5/6 red) is applied on the external surface, which is smoothed and slightly polished becoming soft to touch (colour of surfaces: 2.5YR-6/8 light red, 2.5YR-6/4 light reddish brown, 2.5YR-6/6 light red, 5YR-6/3 light reddish brown, 10R-6/8 light red). Vessels are fired in an oxidising atmosphere. This is reflected by a uniform pinkish section. Only restrictive shapes have been found. These include a number of vessels with a neck that could be a variety of sprinkler. However, the majority of examples are bodysherds. For vessel forms, see Lefrancq and Hawkes (2019b, plate 29). 


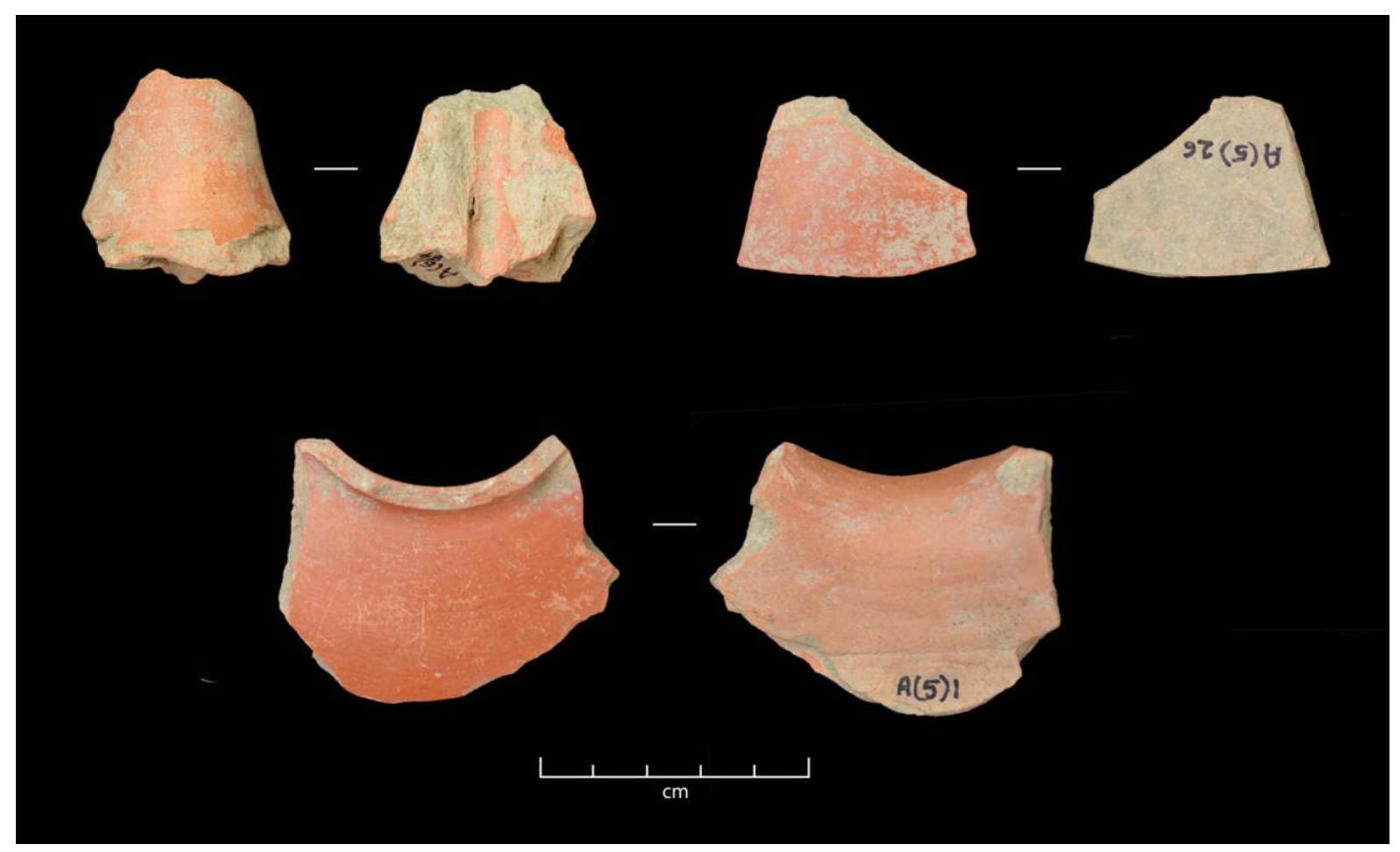

Figure 29: Upper left: external and internal sides of a neck, Class 9, MHR2002.A4.14; upper right and lower centre: external and internal sides of bodysherd, Class 9, MHR2002.A5. Image credit: Authors.

\subsection{Class 10}

This class is made using several Fabric Groups (mainly 2, 8, 1), which are medium to coarse in texture, with sand temper as noted in vessels of Class 1 , which are similar. Indeed, a whitish deposit is also present on many potsherds. Yet on vessels of Class 10 we also see organic temper and imprints visible on both surfaces. Vessels are shaped using a combination of coils and plates, followed by a process of smoothing probably on a slow wheel. Although smoothing traces are clearly noticeable, the general aspect looks coarser and we can feel small irregularities. All pots have been fired in an oxidising atmosphere (7.5YR-5/6 strong brown, 7.5YR-6/6 reddish yellow, 2.5YR-7/6 light red, 5YR-5/6 yellowish red). Two variants have been defined according to the decoration. The first one encompasses plain potsherds, while the second variant incorporates potsherds with a red and/or micaceous slip. Incised (horizontal lines) and impressed (small squares) decoration are noted on the external surface of both variants.

\section{Class 10 variant $1(n=48)$ (Figure 30$)$}

This variant comprises plain potsherds. Vessels with restrictive shapes (pots with in-turned rims and pots with outturned rims), as well as unrestrictive shapes (bowls) exist. On one rim-sherd, a line of small squares has been impressed at the junction between the shoulder and the rim. For vessel forms, see Lefrancq and Hawkes $(\underline{2019 b}$, plate 29). 


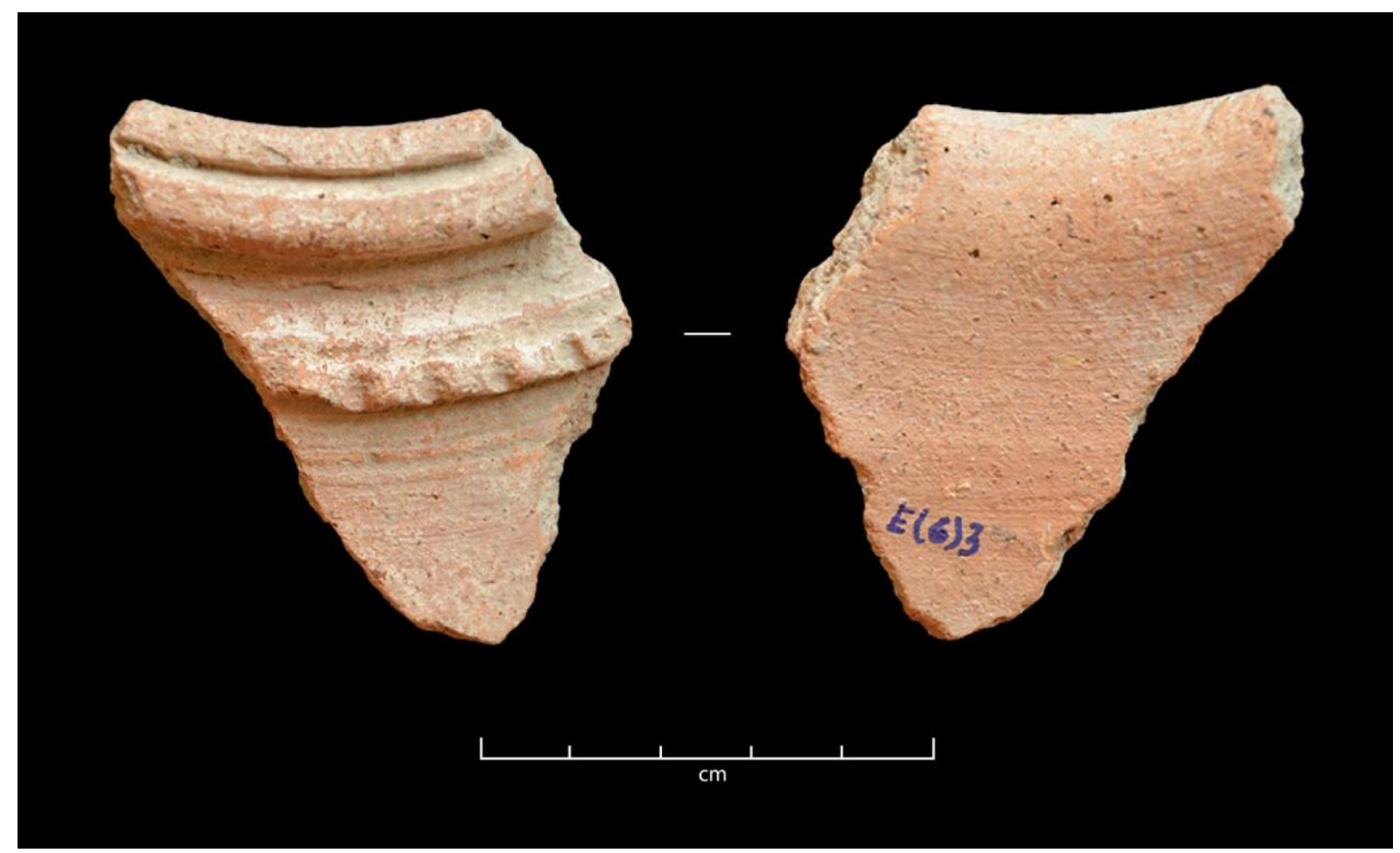

Figure 30: External and internal sides of rim with impressed decoration, Class 10 variant 1-type 3, MHR2002.E6.3. Image credit: Authors.

\section{Class 10 variant 2 ( $n=20)$ (Figure 31)}

This variant consists of potsherds displaying a micaceous slip, sometimes combined with a red slip (10R-4/6 red, $10 \mathrm{R}-4 / 8$ red, $10 \mathrm{R}-5 / 8 \mathrm{red})$. Compared with those of variant 1 , vessels with restrictive shapes are more numerous. We find shallow bowls and pots with out-turned rim such as jars with neck and everted rim. For vessel forms, see Lefrancq and Hawkes (2019b, plate 30).

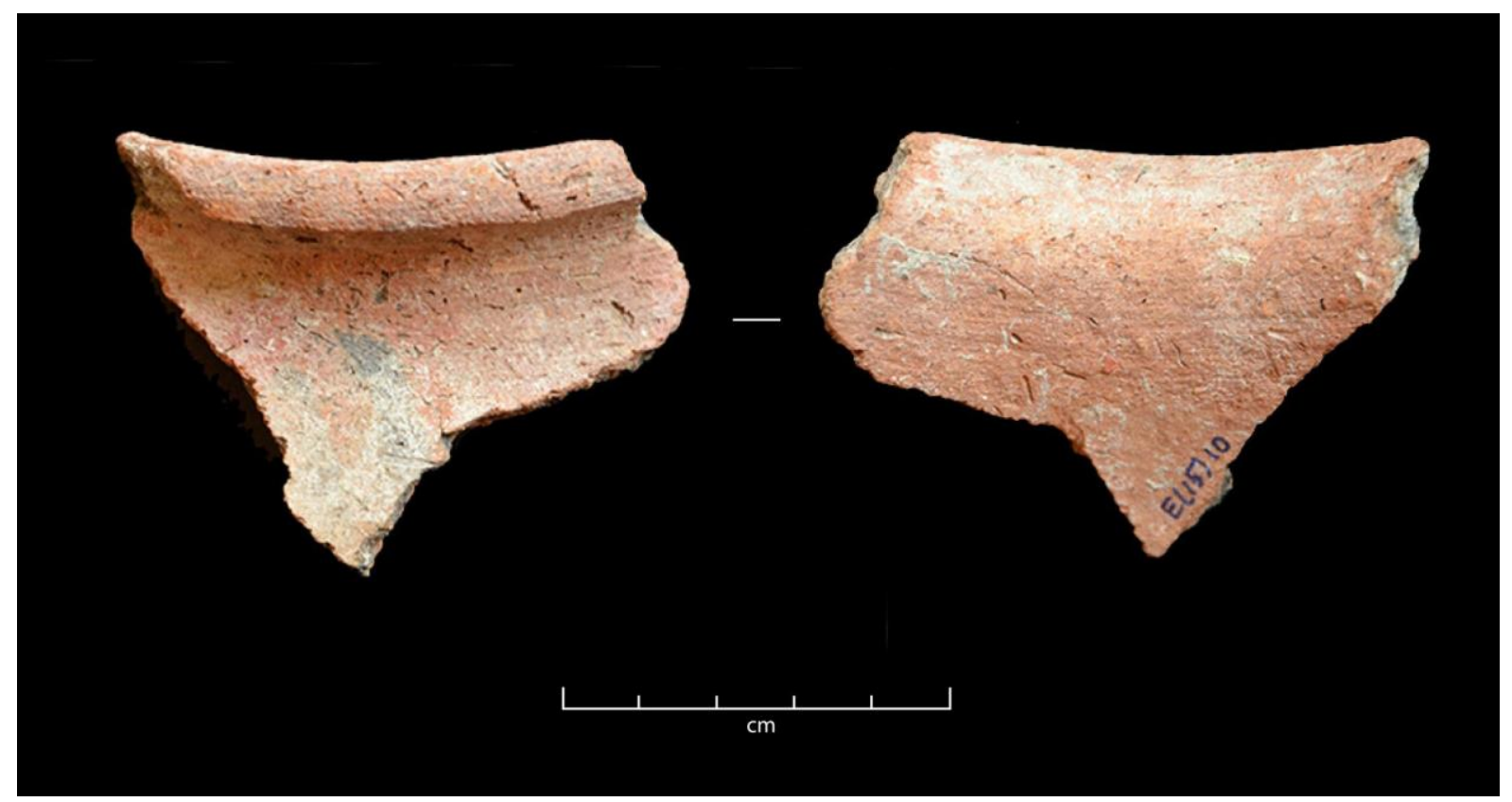

Figure 31: External and internal sides of rim, Class 10 variant 2-type 4, MHR2002.E15.10. Image credit: Authors. 


\subsection{Unidentified classes}

Within the assemblage, there are five potsherds whose technical features are so different from the others that they are grouped together and classified as 'unidentified' types. These may be non-local imports to the area, or local ceramics produced more recently that have found their way into the archaeological record.

\section{Unidentified 1 ( $n=1)$ (Figure 32)}

Only one bodysherd belongs to this group. It is characterised by a very fine, compact and hard paste. No information on the shaping of this vessel could be gleaned from this sherd. A kind of white slip (2.5Y/1-8.5 white) is applied to both surfaces.

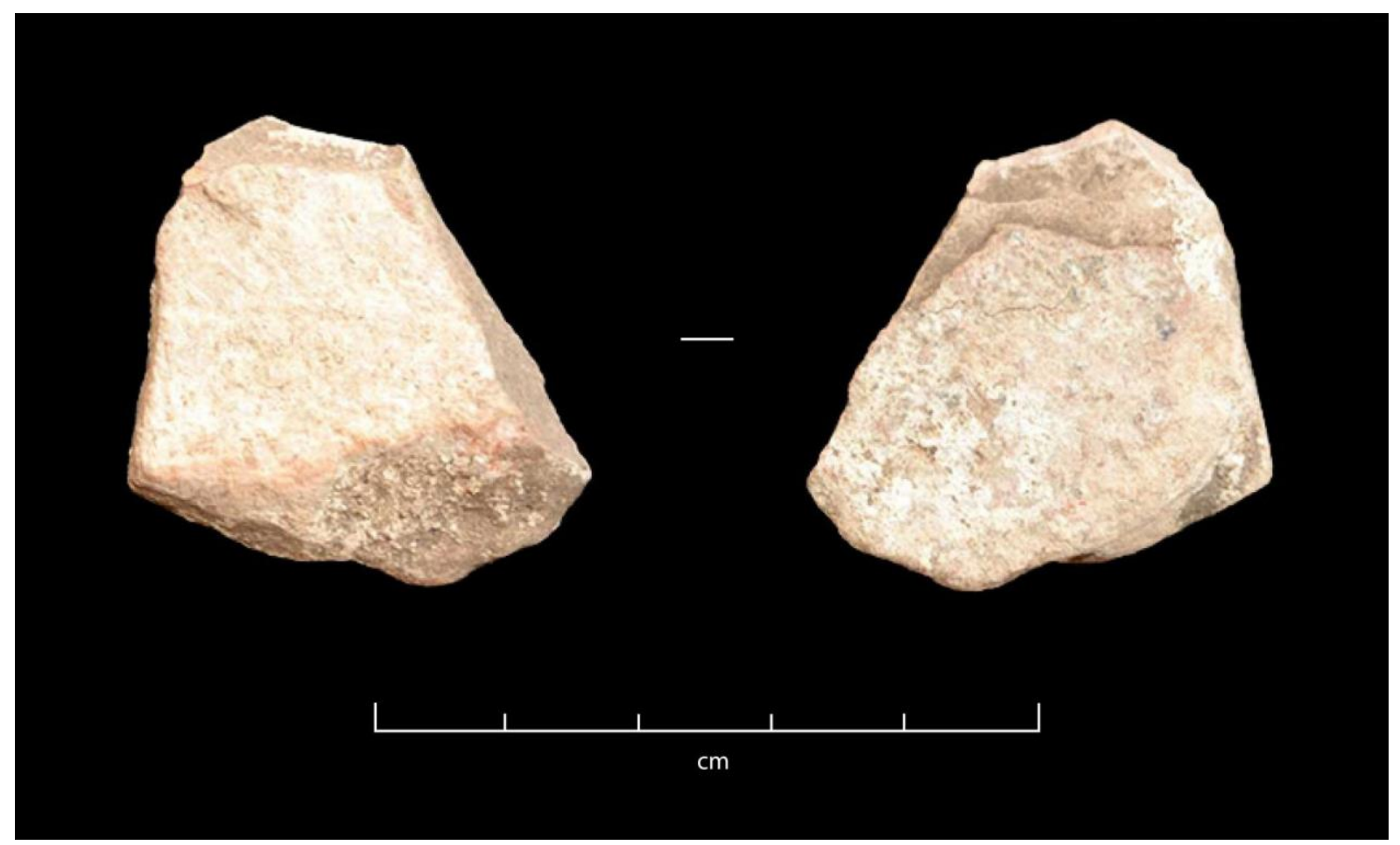

Figure 32: External and internal sides of bodysherd, Unidentified 1, MHR2002.D2.no number. Image credit: Authors.

\section{Unidentified 2 ( $n=3)$ (Figure 33)}

This group comprises potsherds characterised by the use of an alkaline clay decorated with a glaze. However, all three have different technical features in terms of type and colour of glaze and of decoration. One has a brownish-black glaze (5YR-3/3 dark reddish brown, 5YR-3/2 dark reddish brown, 7.5YR-3/3 dark brown) on the external surface and a whitish glaze (7.5YR_/1-9.5 white) on the internal surface. The external decoration is a pattern in low relief that could be moulded, composed of pointed long leaves. The second potsherd, a fragment of body, displays an orange (7.5YR-7/8 reddish yellow) glaze on both surfaces while the third, a base fragment, has a buff-cream (10YR-8/6 yellow) glaze on both surfaces. In addition, this sherd has ridges on the external surface. 


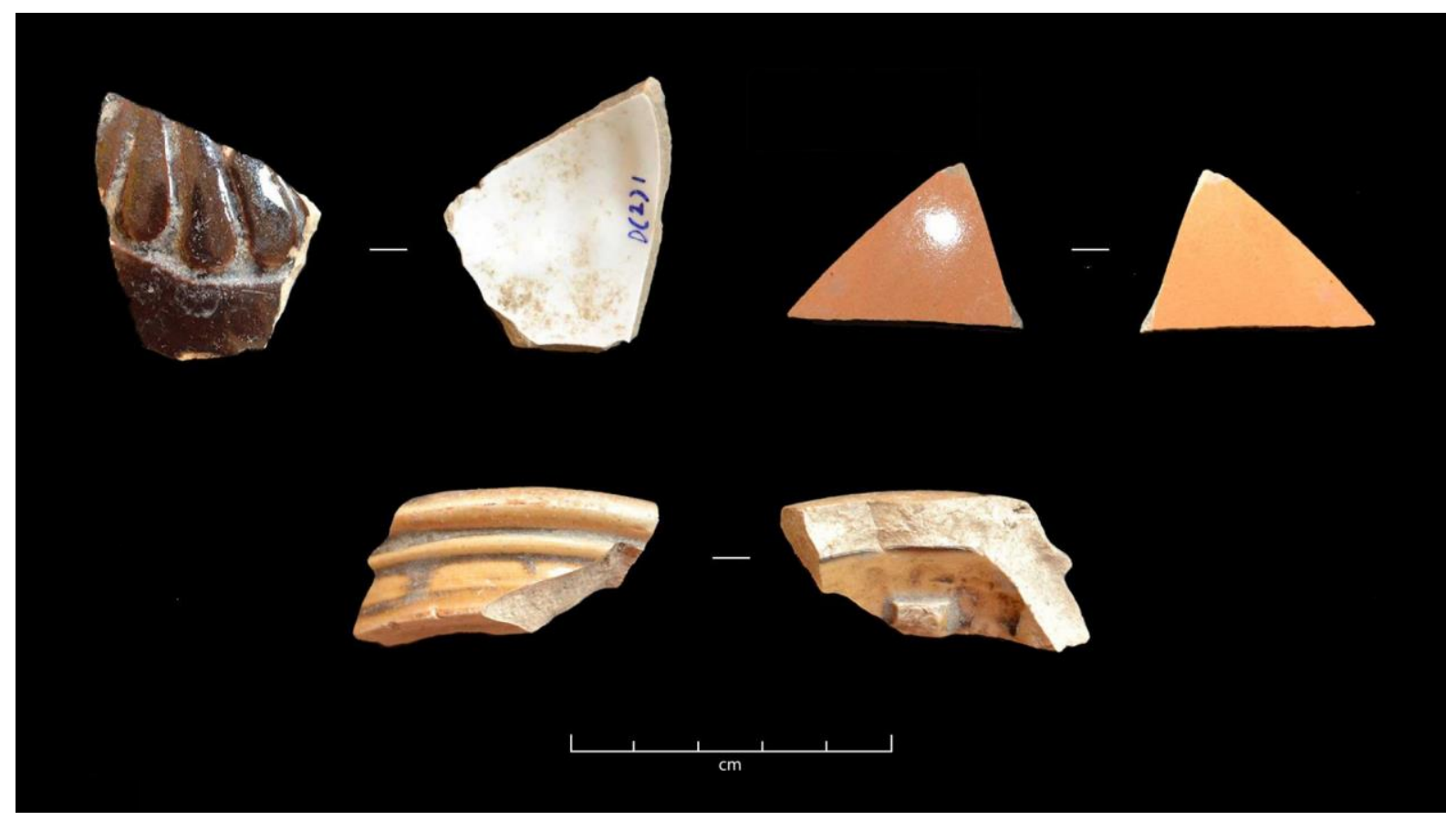

Figure 33: Upper left: external and internal sides of bodysherd, Unidentified 2, MHR2002.D2.1; upper right: external and internal sides of bodysherd, Unidentified 2, MHR2002.D12.20; lower centre: external and internal sides of bodysherd, Unidentified 2, MHR2002.E11.no number. Image credit: Authors.

These three potsherds could come from China or South-east Asia. Indeed, the first one is similar to examples from Dehua, Guangdong, and other Qing dynasty wares from China.

Unidentified 3 ( $n=1$ ) (Figure 34)

The last type of unidentified pottery is characterised by a very fine, compact, very hard to cut paste that is identified as Fabric Group 12. The bodysherd is too small to determine the shaping technique; however, the sides are extremely regular. Surfaces are soapy but still rough to the touch. It has been fired in an oxidising atmosphere (colour of surfaces 2.5YR-7/6 light red). The internal surface displays incised decorations: parallel lines combined with slightly oblique/vertical lines that are less marked. 


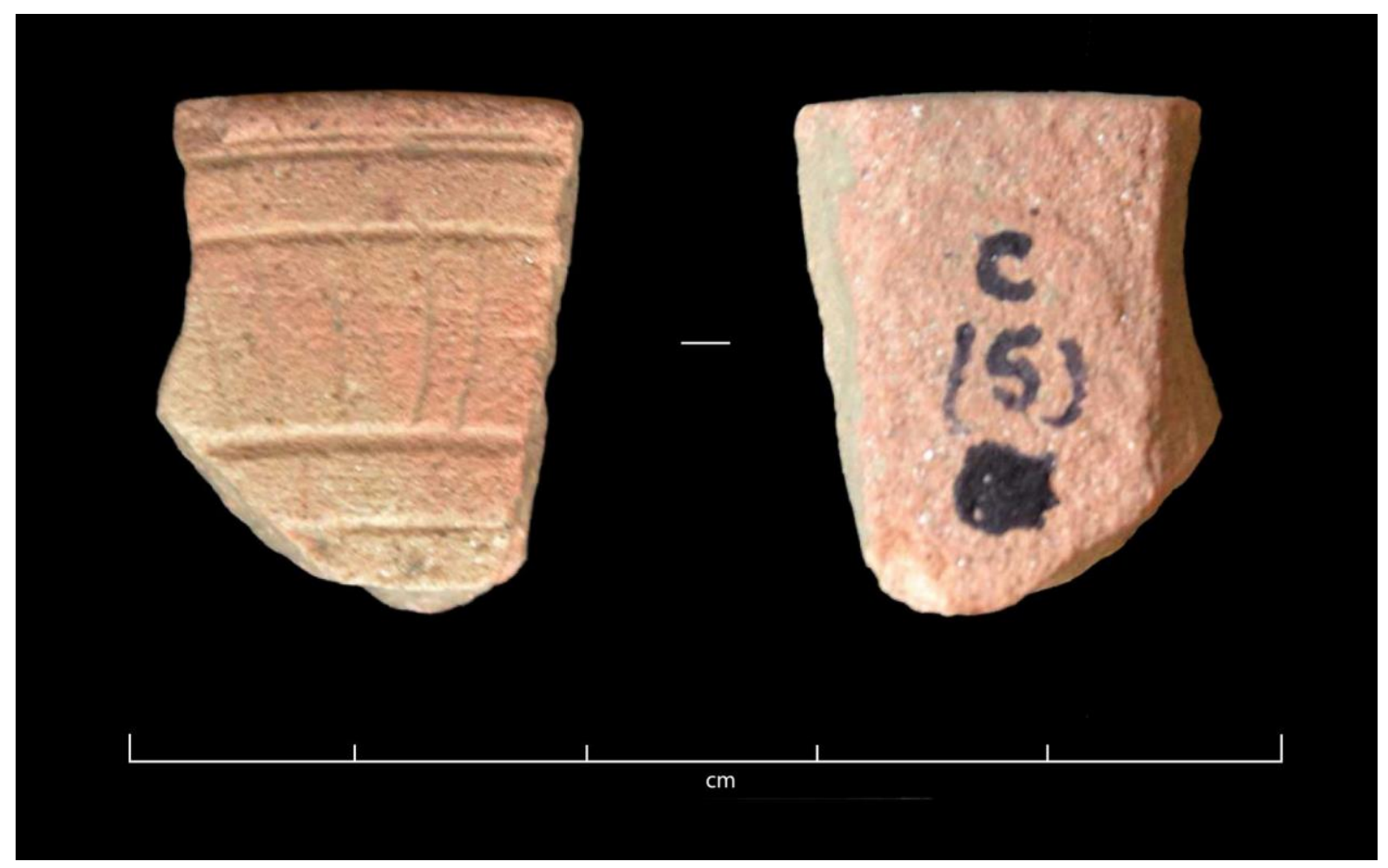

Figure 34: External and internal sides of bodysherd, Unidentified 3, MHR2002.C5. Image credit: Authors.

Table 3: Synthetic table illustrating the criteria used to define each class of pottery and its variants in the assemblage (as described in detail above)

\begin{tabular}{|c|c|c|c|c|}
\hline Class/variant & Paste & Shaping & $\begin{array}{c}\text { Surface treatment and } \\
\text { aspect }\end{array}$ & Firing \\
\hline Class 1 variant 1 & $\begin{array}{l}\text { medium } \\
\text { texture, sand as } \\
\text { temper }\end{array}$ & wheel? & white concretions & oxidised \\
\hline Class 1 variant 2 & $\begin{array}{l}\text { finer texture, } \\
\text { organic } \\
\text { temper? }\end{array}$ & wheel? & white concretions & oxidised \\
\hline Class 1 variant 3 & $\begin{array}{l}\text { medium } \\
\text { texture, sand as } \\
\text { temper }\end{array}$ & wheel? & $\begin{array}{l}\text { whitish slip, incised } \\
\text { decoration }\end{array}$ & oxidised \\
\hline Class 2 variant 1 & $\begin{array}{l}\text { fine to medium } \\
\text { texture }\end{array}$ & $\begin{array}{l}\text { combined techniques } \\
\text { (coils, slow wheel, } \\
\text { convex mould?) }\end{array}$ & $\begin{array}{l}\text { red slip of good quality, } \\
\text { smoothing-burnishing }\end{array}$ & oxidised \\
\hline
\end{tabular}




\begin{tabular}{|c|c|c|c|c|}
\hline Class 2 variant 2 & $\begin{array}{l}\text { fine to medium } \\
\text { texture }\end{array}$ & $\begin{array}{l}\text { combined techniques } \\
\text { (coils, slow wheel, } \\
\text { convex mould?) }\end{array}$ & $\begin{array}{l}\text { red slip of medium to } \\
\text { poor quality, smoothing- } \\
\text { burnishing }\end{array}$ & oxidised \\
\hline Class 2 variant 3 & $\begin{array}{l}\text { fine to medium } \\
\text { texture }\end{array}$ & $\begin{array}{l}\text { combined techniques } \\
\text { (coils, slow wheel, } \\
\text { convex mould?) }\end{array}$ & $\begin{array}{l}\text { red slip of good to poor } \\
\text { quality, incised- } \\
\text { appliqué-impressed } \\
\text { decoration }\end{array}$ & oxidised \\
\hline Class 2 variant 4 & $\begin{array}{l}\text { fine to medium } \\
\text { texture }\end{array}$ & $\begin{array}{l}\text { combined techniques } \\
\text { (coils, slow wheel, } \\
\text { convex mould?) }\end{array}$ & $\begin{array}{l}\text { red slip of medium } \\
\text { quality mixed with mica } \\
\text { powder }\end{array}$ & oxidised \\
\hline Class 2 variant 5 & $\begin{array}{l}\text { fine to medium } \\
\text { texture }\end{array}$ & $\begin{array}{l}\text { combined techniques } \\
\text { (coils, slow wheel, } \\
\text { convex mould?) }\end{array}$ & impressed decoration & oxidised \\
\hline Class 2 variant 6 & $\begin{array}{l}\text { fine to medium } \\
\text { texture }\end{array}$ & $\begin{array}{l}\text { combined techniques } \\
\text { (coils, slow wheel, } \\
\text { convex mould?) }\end{array}$ & $\begin{array}{l}\text { mud slip mixed with } \\
\text { mica powder }\end{array}$ & oxidised \\
\hline Class 3 variant 1 & $\begin{array}{l}\text { fine to medium } \\
\text { texture, } \\
\text { compact }\end{array}$ & $\begin{array}{l}\text { wheel? And combined } \\
\text { techniques (wheel- } \\
\text { coiled) }\end{array}$ & $\begin{array}{l}\text { micaceous slip with } \\
\text { mostly specks, } \\
\text { smoothing }\end{array}$ & oxidised \\
\hline Class 3 variant 2 & $\begin{array}{l}\text { fine to medium } \\
\text { texture, less } \\
\text { compact }\end{array}$ & $\begin{array}{l}\text { wheel? And combined } \\
\text { techniques (wheel- } \\
\text { coiled) }\end{array}$ & $\begin{array}{l}\text { micaceous slip with } \\
\text { mostly specks, } \\
\text { smoothing }\end{array}$ & oxidised \\
\hline Class 4 & $\begin{array}{l}\text { very fine sandy } \\
\text { texture, } \\
\text { compact, } \\
\text { specks of mica }\end{array}$ & undetermined & soapy & oxidised \\
\hline Class 5 variant 1 & $\begin{array}{l}\text { mica flakes as } \\
\text { temper, } \\
\text { medium to } \\
\text { coarse texture }\end{array}$ & $\begin{array}{l}\text { combined techniques } \\
\text { (wheel-coiled, mould, } \\
\text { paddle and anvil) }\end{array}$ & $\begin{array}{l}\text { mica flakes and specks } \\
\text { visible in surfaces, } \\
\text { reddish-brown slip, } \\
\text { smoothing }\end{array}$ & oxidised \\
\hline Class 5 variant 2 & $\begin{array}{l}\text { mica flakes as } \\
\text { temper, } \\
\text { medium to } \\
\text { coarse texture }\end{array}$ & $\begin{array}{l}\text { combined techniques } \\
\text { (wheel-coiled, mould, } \\
\text { paddle and anvil) }\end{array}$ & $\begin{array}{l}\text { less mica flakes and } \\
\text { specks visible in } \\
\text { surfaces, grey and } \\
\text { reddish-brown slip, } \\
\text { smoothing }\end{array}$ & oxido-reduced? \\
\hline Class 5 variant 3 & $\begin{array}{l}\text { mica flakes as } \\
\text { temper, } \\
\text { medium to } \\
\text { coarse texture }\end{array}$ & $\begin{array}{l}\text { combined techniques } \\
\text { (wheel-coiled, mould, } \\
\text { paddle and anvil) }\end{array}$ & $\begin{array}{l}\text { mica flakes and specks } \\
\text { visible in surfaces, red to } \\
\text { black slip, impressed } \\
\text { decoration ('flower' or } \\
\text { 'sun') }\end{array}$ & oxidised \\
\hline
\end{tabular}




\begin{tabular}{|c|c|c|c|c|}
\hline Class 5 variant 4 & $\begin{array}{l}\text { fewer mica } \\
\text { flakes as } \\
\text { temper, } \\
\text { medium to } \\
\text { coarse texture }\end{array}$ & $\begin{array}{l}\text { combined techniques } \\
\text { (wheel-coiled, mould, } \\
\text { paddle and anvil) }\end{array}$ & $\begin{array}{l}\text { fewer mica flakes and } \\
\text { specks visible in } \\
\text { surfaces, black slip, } \\
\text { smoothing, incised } \\
\text { decoration (lines) }\end{array}$ & reduced \\
\hline Class 6 variant 1 & $\begin{array}{l}\text { medium to } \\
\text { coarse texture }\end{array}$ & $\begin{array}{l}\text { wheel and/or combined } \\
\text { techniques (wheel- } \\
\text { coiled?) }\end{array}$ & red slip, smoothing & oxidised \\
\hline Class 6 variant 2 & coarse texture & $\begin{array}{l}\text { wheel and/or combined } \\
\text { techniques (wheel- } \\
\text { coiled?) }\end{array}$ & black slip, smoothing & reduced \\
\hline Class 6 variant 3 & coarse texture & $\begin{array}{l}\text { wheel and/or combined } \\
\text { techniques (wheel- } \\
\text { coiled?) }\end{array}$ & $\begin{array}{l}\text { grey surfaces (black slip } \\
\text { disappeared?), } \\
\text { smoothing }\end{array}$ & reduced \\
\hline Class 7 variant 1 & $\begin{array}{l}\text { medium to } \\
\text { coarse texture, } \\
\text { organic temper }\end{array}$ & $\begin{array}{l}\text { combined techniques } \\
\text { (hand-stretching plates, } \\
\text { coils, others?) }\end{array}$ & thick sides, smoothing & oxidised \\
\hline Class 7 variant 2 & $\begin{array}{l}\text { medium to } \\
\text { coarse texture, } \\
\text { organic temper }\end{array}$ & $\begin{array}{l}\text { combined techniques } \\
\text { (hand-stretching plates, } \\
\text { coils, others?) }\end{array}$ & $\begin{array}{l}\text { thick sides, red slip } \\
\text { sometimes mixed with } \\
\text { mica powder, } \\
\text { smoothing, applique } \\
\text { decoration }\end{array}$ & oxidised \\
\hline Class 8 & $\begin{array}{l}\text { fine texture, } \\
\text { compact }\end{array}$ & undetermined & smoothing & oxidised \\
\hline Class 9 & $\begin{array}{l}\text { very fine } \\
\text { texture, } \\
\text { compact }\end{array}$ & $\begin{array}{l}\text { combined techniques } \\
\text { (wheel-coiled) }\end{array}$ & $\begin{array}{l}\text { thin sides, red slip of } \\
\text { good quality, } \\
\text { smoothing-polishing }\end{array}$ & oxidised \\
\hline Class 10 variant 1 & $\begin{array}{l}\text { medium to } \\
\text { coarse texture, } \\
\text { sand and } \\
\text { organic as } \\
\text { tempers }\end{array}$ & $\begin{array}{l}\text { combined techniques } \\
\text { (wheel-coiled, plates, } \\
\text { other?) }\end{array}$ & $\begin{array}{l}\text { smoothing, incised and } \\
\text { impressed decoration }\end{array}$ & oxidised \\
\hline Class 10 variant 2 & $\begin{array}{l}\text { medium to } \\
\text { coarse texture, } \\
\text { sand and } \\
\text { organic as } \\
\text { tempers }\end{array}$ & $\begin{array}{l}\text { combined techniques } \\
\text { (wheel-coiled, plates, } \\
\text { other?) }\end{array}$ & $\begin{array}{l}\text { red slip and/or mica slip } \\
\text { made with mica powder, } \\
\text { smoothing, incised and } \\
\text { impressed decoration }\end{array}$ & oxidised \\
\hline UnID 1 & $\begin{array}{l}\text { very fine } \\
\text { texture, } \\
\text { compact }\end{array}$ & undetermined & white slip & oxidised \\
\hline
\end{tabular}




\begin{tabular}{|l|l|l|l|l|}
\hline UnID 2 & alkaline clay & wheel? & $\begin{array}{l}\text { glaze, moulded } \\
\text { decoration? }\end{array}$ & $\begin{array}{l}\text { oxidised and } \\
\text { oxido-reduced? }\end{array}$ \\
\hline UnID 3 & $\begin{array}{l}\text { very fine } \\
\text { texture, } \\
\text { compact }\end{array}$ & undetermined (wheel?) & incised decoration & oxidised \\
\hline
\end{tabular}

\section{Results: Stratigraphic Distribution and Seriation of the Ceramics}

Having described the classes and variants that we were able to identify within the assemblage, we now present the quantitative ratios of each class and its variants according to the chronological sequence of each trench. For reference, brief details of the stratigraphic layers and their depths as they were recorded during excavation are provided in Table 4. As mentioned earlier (see Methods), plotting the stratigraphic distribution of classes began with Trenches $C$ and F. As such, these results are presented first followed by their chronological phasing in relation to the radiocarbon dates for these trenches that have recently been obtained (Mohanty et al in press). These results are then followed by the stratigraphic distribution of ceramics in the remaining trenches $(A, B$ and $D)$, and their chronological phasing in comparison to the dated ceramics from Trenches $\mathrm{C}$ and $\mathrm{F}$. 


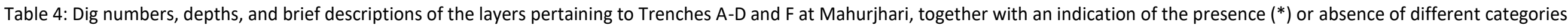
of archaeological material found during excavation.

PT=pottery, $\mathrm{BD}=$ bead, $\mathrm{BD}-\mathrm{d}=$ =bead debitage, $\mathrm{BR}=$ brick, $\mathrm{BN}=$ bone, $\mathrm{SH}=$ shell, $\mathrm{MT}=$ metal, $\mathrm{TC}=$ terracotta, $\mathrm{ST}=$ stone, and WS=worked stone

\begin{tabular}{|c|c|c|c|c|c|c|c|c|c|c|c|c|c|c|}
\hline TR & Layer & Digs & Depth $(\mathrm{cm})$ & Description & PT & BD & BD-d & BR & BN & SH & MT & TC & ST & WS \\
\hline & 1 & $1-3$ & $0-30$ & $\begin{array}{l}\text { Loose, greyish soil. } \\
\text { Disturbed through } \\
\text { modern ploughing } \\
\text { activity }\end{array}$ & $*$ & $*$ & $*$ & & & & & & & \\
\hline A & 2 & $4-6$ & $30-45$ & $\begin{array}{l}\text { Greyish soil, with } \\
\text { potsherds and brick } \\
\text { fragments throughout } \\
\text { the trench }\end{array}$ & $*$ & & $*$ & $*$ & $*$ & $*$ & & & & \\
\hline & 3 & $7-9$ & $45-80$ & Compact, light grey soil & $*$ & & $*$ & $*$ & $*$ & $*$ & $*$ & & & \\
\hline
\end{tabular}




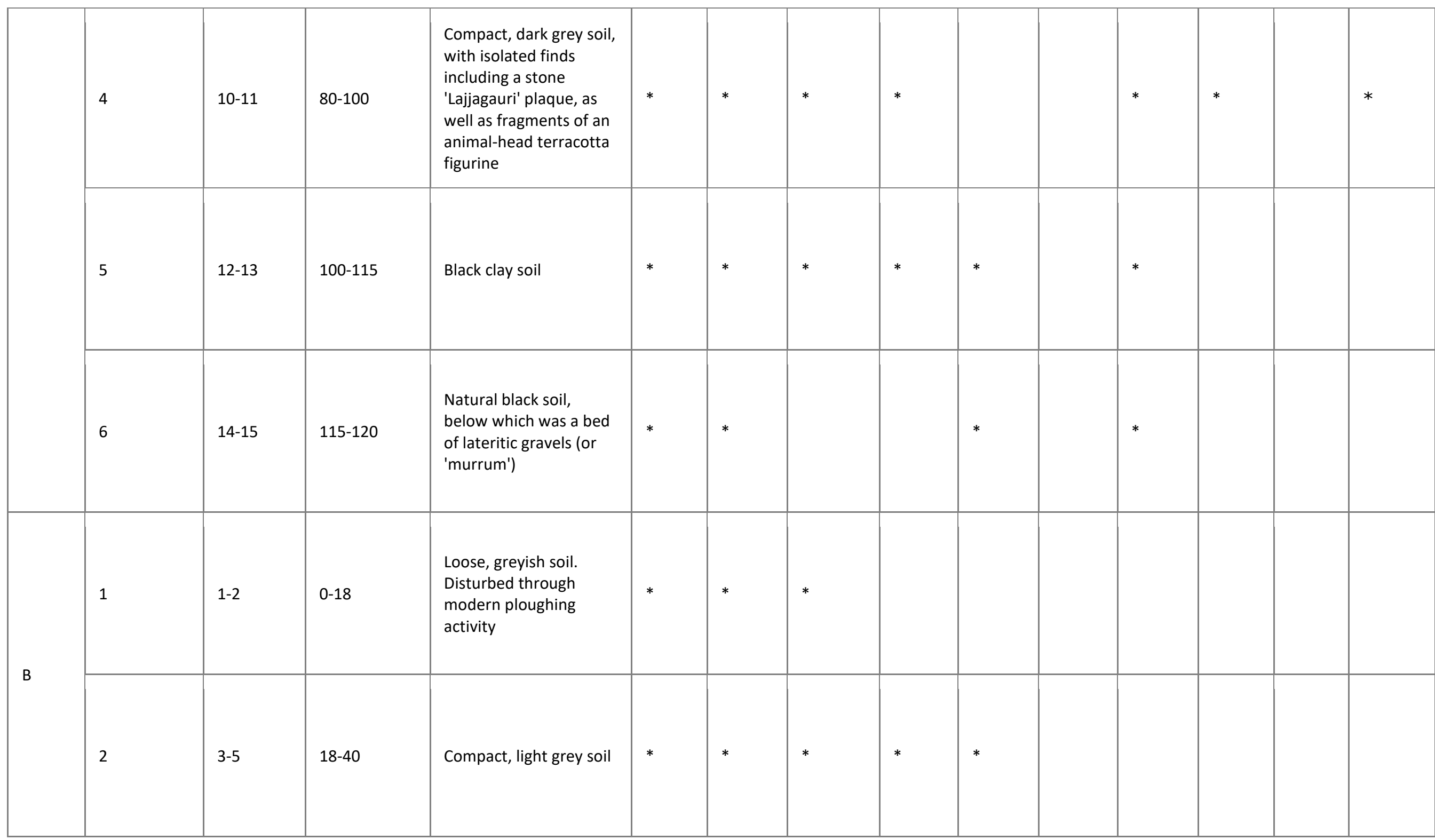




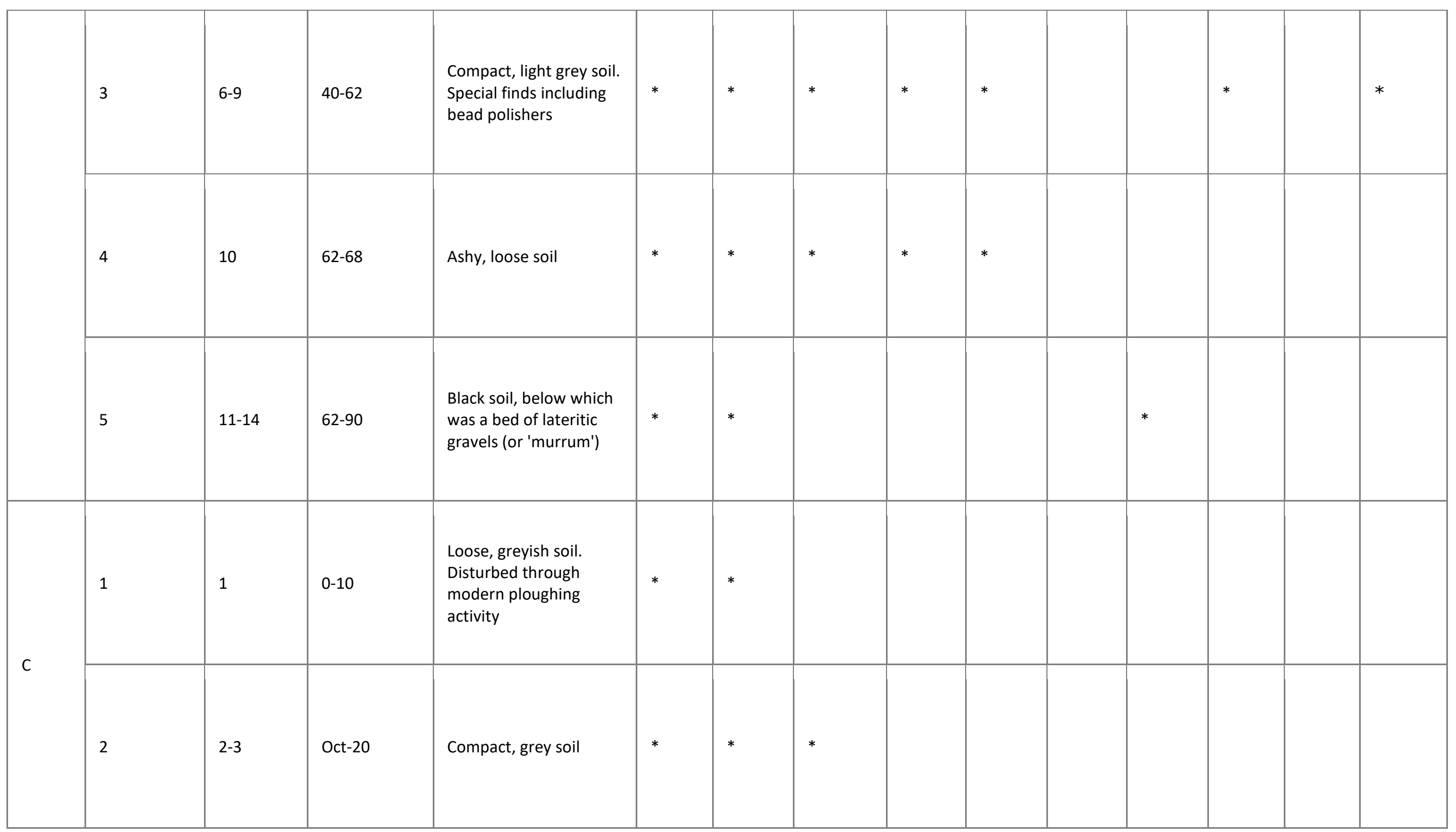




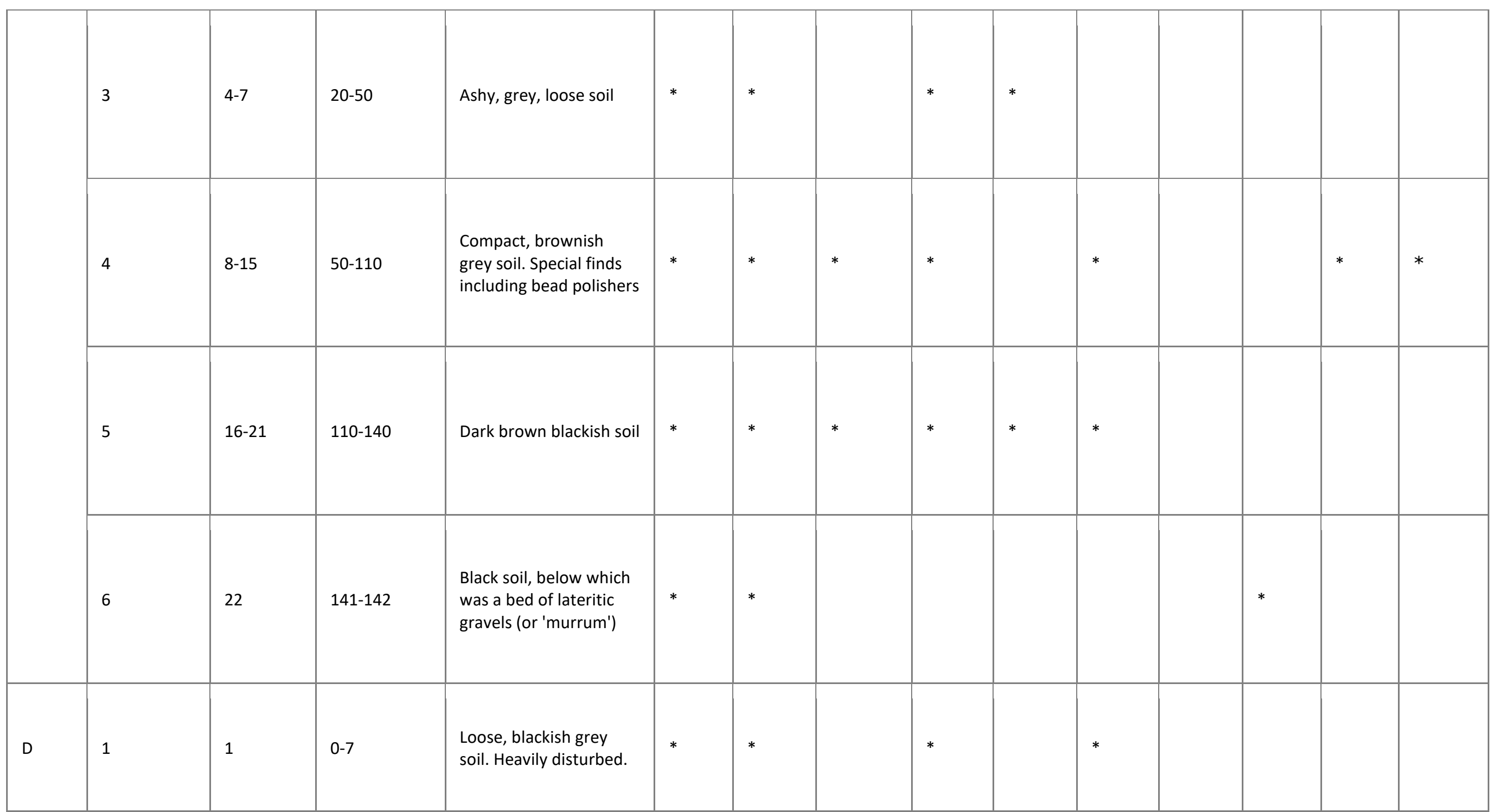




\begin{tabular}{|c|c|c|c|c|c|c|c|c|c|c|c|}
\hline & 2 & $2-9$ & Aug-60 & Compact, grey soil & $*$ & $*$ & $*$ & $*$ & $*$ & & $*$ \\
\hline & 3 & $10-12$ & $60-80$ & Light grey soil & $*$ & $*$ & & $*$ & & & \\
\hline & 4 & $13-14$ & 80- & $\begin{array}{l}\text { Thin layer defined by } \\
\text { alignments of stones, } \\
\text { indicating possible } \\
\text { structure or surface }\end{array}$ & * & $*$ & $*$ & & $*$ & $*$ & $*$ \\
\hline & 5 & $15-17$ & & $\begin{array}{l}\text { Natural black soil, } \\
\text { below which was a bed } \\
\text { of lateritic gravels (or } \\
\text { 'murrum') }\end{array}$ & $*$ & $*$ & & & $*$ & & \\
\hline & 1 & $1-6$ & $0-20$ & $\begin{array}{l}\text { Light grey, soft loose } \\
\text { soil; heavily disturbed } \\
\text { through modern } \\
\text { ploughing }\end{array}$ & $*$ & $*$ & & & & & $*$ \\
\hline & 2 & $7-14$ & $20-50$ & $\begin{array}{l}\text { Dark grey soil, } \\
\text { disturbed with animal } \\
\text { burrows }\end{array}$ & $*$ & & & $*$ & & & $*$ \\
\hline
\end{tabular}




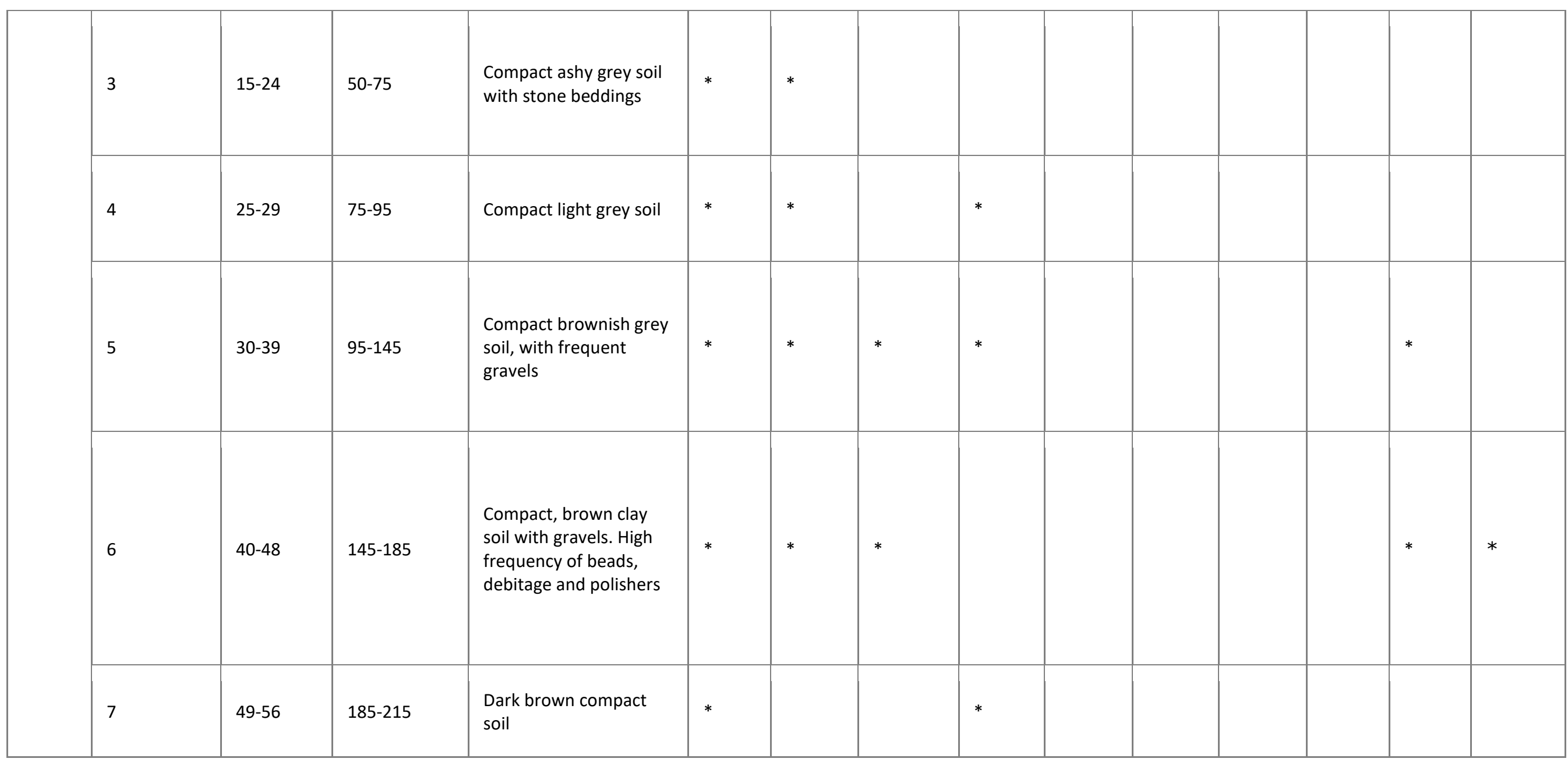




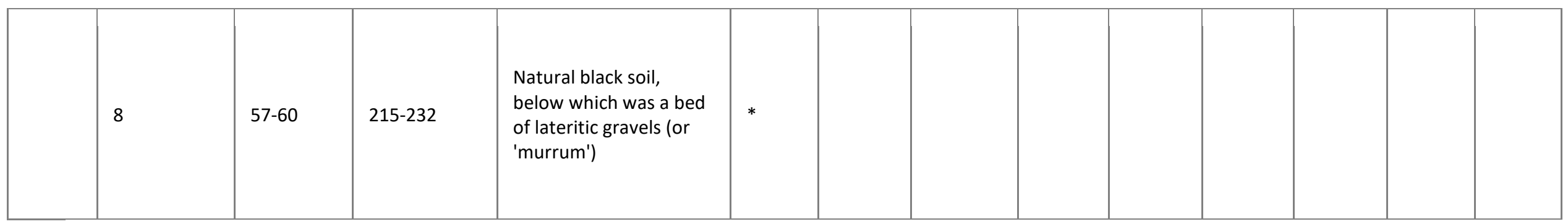




\subsection{Trenches $\mathrm{C}$ and $\mathrm{F}$}

The classes and variants identified in Trenches $\mathrm{C}$ and $\mathrm{F}$ were distributed throughout the stratigraphic sequence of each trench as shown in Tables 5-6 and Figures 35-36.

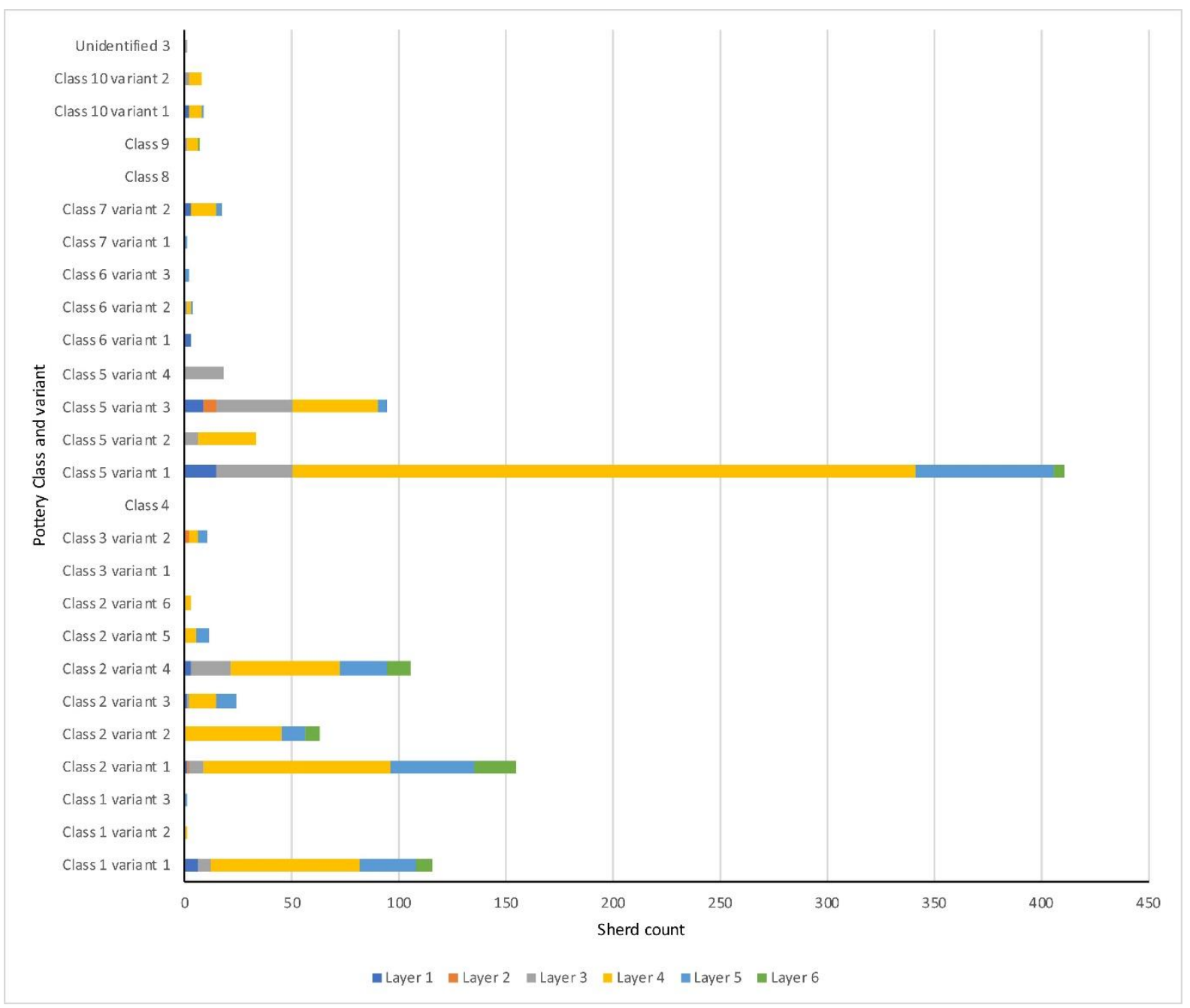

Figure 35: Chart illustrating the distribution of pottery classes and variants in Trench C, layers 1 to 6. Image credit: Authors.

Table 5: Number of sherds of each class/variant recorded in the archaeological layers of Trench C

\begin{tabular}{|l|l|l|l|l|l|l|l|}
\hline \multicolumn{1}{|c|}{ Class/variants } & Layer 1 & Layer 2 & Layer 3 & Layer 4 & Layer 5 & Layer 6 & Total \\
\hline Class 1 variant 1 & 6 & & 6 & 70 & 26 & 8 & 116 \\
\hline Class 1 variant 2 & & & & 1 & & 1 \\
\hline Class 1 variant 3 & & 1 & 7 & 87 & 39 & 20 & 1 \\
\hline Class 2 variant 1 & 1 & & & 45 & 11 & 7 \\
\hline Class 2 variant 2 & & & & & 63 \\
\hline
\end{tabular}




\begin{tabular}{|c|c|c|c|c|c|c|c|}
\hline Class 2 variant 3 & 1 & & 1 & 13 & 9 & & 24 \\
\hline Class 2 variant 4 & 3 & & 18 & 51 & 22 & 11 & 105 \\
\hline Class 2 variant 5 & & & & 5 & 6 & & 11 \\
\hline Class 2 variant 6 & & & & 3 & & & 3 \\
\hline \multicolumn{8}{|l|}{ Class 3 variant 1} \\
\hline Class 3 variant 2 & & 2 & & 4 & 4 & & 10 \\
\hline \multicolumn{8}{|l|}{ Class 4} \\
\hline Class 5 variant 1 & 15 & & 35 & 291 & 65 & 5 & 411 \\
\hline Class 5 variant 2 & & & 6 & 27 & & & 33 \\
\hline Class 5 variant 3 & 9 & 6 & 35 & 40 & 4 & & 94 \\
\hline Class 5 variant 4 & & & 18 & & & & 18 \\
\hline Class 6 variant 1 & 3 & & & & & & 3 \\
\hline Class 6 variant 2 & & & 1 & 2 & 1 & & 4 \\
\hline Class 6 variant 3 & & & & & 2 & & 2 \\
\hline Class 7 variant 1 & & & & & 1 & & 1 \\
\hline Class 7 variant 2 & 3 & & & 12 & 2 & & 17 \\
\hline \multicolumn{8}{|l|}{ Class 8} \\
\hline Class 9 & & & 1 & 5 & & 1 & 7 \\
\hline Class 10 variant 1 & 2 & & & 6 & 1 & & 9 \\
\hline Class 10 variant 2 & & & 2 & 6 & & & 8 \\
\hline Unidentified 3 & & & 1 & & & & 1 \\
\hline Total & 43 & 9 & 130 & 668 & 194 & 52 & 1097 \\
\hline
\end{tabular}




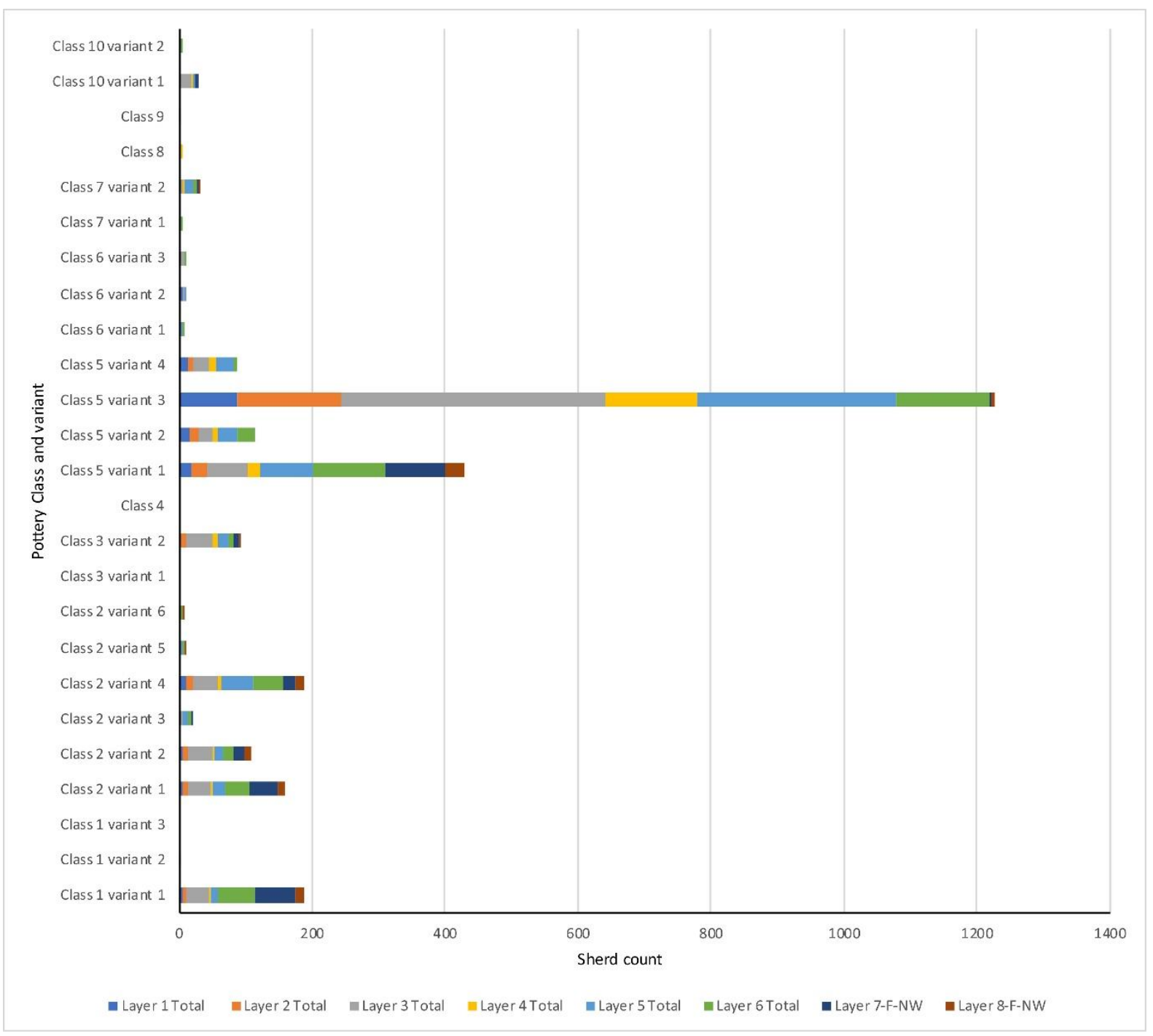

Figure 36: Chart illustrating the distribution of pottery classes and variants in Trench F, layers 1 to 8 . Image credit: Authors.

Table 6: Number of sherds of each class/variant recorded in the archaeological layers of Trench F

\begin{tabular}{|l|l|l|l|l|l|l|l|l|l|}
\hline \multicolumn{1}{|c|}{ Class/variants } & Layer 1 & Layer 2 & Layer 3 & Layer 4 & Layer 5 & Layer 6 & Layer 7 & Layer 8 & Total \\
\hline Class 1 variant 1 & 5 & 6 & 33 & 3 & 12 & 56 & 60 & 13 & 188 \\
\hline Class 1 variant 2 & & & & & 3 & & & 3 \\
\hline Class 1 variant 3 & & & & 33 & 3 & 18 & 39 & 40 & 12 \\
\hline Class 2 variant 1 & 6 & 8 & 9 & 36 & 2 & 15 & 16 & 16 & 9 \\
\hline Class 2 variant 2 & 5 & 9 & & & & & 108 \\
\hline
\end{tabular}




\begin{tabular}{|c|c|c|c|c|c|c|c|c|c|}
\hline Class 2 variant 3 & 1 & 1 & 4 & & 6 & 6 & 2 & & 20 \\
\hline Class 2 variant 4 & 11 & 9 & 38 & 5 & 49 & 44 & 19 & 13 & 188 \\
\hline Class 2 variant 5 & & & 2 & & 4 & 3 & & 1 & 10 \\
\hline Class 2 variant 6 & 1 & 1 & 1 & & & 1 & & 1 & 5 \\
\hline \multicolumn{10}{|l|}{ Class 3 variant 1} \\
\hline Class 3 variant 2 & 2 & 8 & 41 & 6 & 16 & 8 & 9 & 1 & 91 \\
\hline \multicolumn{10}{|l|}{ Class 4} \\
\hline Class 5 variant 1 & 19 & 22 & 61 & 19 & 79 & 109 & 92 & 28 & 429 \\
\hline Class 5 variant 2 & 15 & 13 & 21 & 9 & 28 & 29 & & & 115 \\
\hline Class 5 variant 3 & 86 & 158 & 398 & 137 & 299 & 140 & 4 & 6 & 1228 \\
\hline Class 5 variant 4 & 12 & 9 & 25 & 10 & 25 & 5 & & & 86 \\
\hline Class 6 variant 1 & 1 & 1 & 1 & & 2 & 1 & & & 6 \\
\hline Class 6 variant 2 & 4 & 2 & 1 & & 3 & & & & 10 \\
\hline Class 6 variant 3 & 1 & 2 & 5 & & 1 & 1 & & & 10 \\
\hline Class 7 variant 1 & & & 1 & & 1 & 1 & & & 3 \\
\hline Class 7 variant 2 & & 1 & 5 & 1 & 13 & 7 & 2 & 1 & 30 \\
\hline Class 8 & & & 2 & 1 & & & & & 3 \\
\hline Class 9 & & 1 & 2 & & & & & & 3 \\
\hline Class 10 variant 1 & & & 18 & 3 & 3 & & 5 & & 29 \\
\hline Class 10 variant 2 & & & 1 & & & 5 & & & 6 \\
\hline Total & 169 & 251 & 729 & 199 & 577 & 471 & 249 & 85 & 2730 \\
\hline
\end{tabular}

As mentioned above, a number of samples from Trenches $C$ and $F$ were subjected to AMS dating (two from Trench $\mathrm{C}$ and six from Trench F) (Mohanty et al in press). The resulting dates allow us to establish a tentative chronotypology from the 4th century to the 10th century CE (Table 7). 
Table 7: Reconstructed chronological sequence for Trenches $\mathrm{C}$ and $\mathrm{F}$, based on radiocarbon dates and relative dating (after Mohanty et al. in press)

\begin{tabular}{|c|c|c|c|}
\hline Trench & Layer & Radiocarbon date(s) & Date range \\
\hline \multirow{6}{*}{ C } & 1 & & 19 th to 20 th century \\
\hline & 2 & & $\begin{array}{l}10 \text { th or post } 10 \text { th } \\
\text { century }\end{array}$ \\
\hline & 3 & & $\begin{array}{l}\text { 10th or post 10th } \\
\text { century }\end{array}$ \\
\hline & 4 & $870-985$ & 8 th to 10 th century \\
\hline & 5 & $570-655$ & 6 th to 7 th century \\
\hline & 6 & & 4th to 5th century \\
\hline \multirow{7}{*}{$\mathrm{F}$} & 1 & & 19 th to 20 th century \\
\hline & 2 & & 17 th to 18 th century \\
\hline & 3 & $1719-1826$ & 17 th to 18 th century \\
\hline & 4 & & Post 10 th century \\
\hline & 5 & $1810-1924$ & 7 th to 10 th century? \\
\hline & 6 & $560-650 / 575-640$ & 6 th to 7 th century \\
\hline & 7 & $340-400 / 425-540$ & 4th to 6 th century \\
\hline
\end{tabular}




\begin{tabular}{|l|l|l|l|}
\hline & 8 & & Pre 4th century \\
\cline { 2 - 4 } & 9 & & Pre 4th century \\
\hline
\end{tabular}

The ease with which we can compare material from these trenches is constrained by the differing scale of excavations in each trench, varying quantities of ceramics in different contexts, and diverse degrees of certainty in the identification of archaeological layers between trenches. Notwithstanding these difficulties, it is possible to consolidate the ceramic counts for each of these trenches, and correlate the number of class-variants that were found to occur in the dated stratigraphic layers from those trenches. Doing so enables us to identify broad-scale distributions/concentrations of class variants by period, which can in turn be used as an indicator for the broad chronological phases that these class variants belong to (see Table 8). This leads us to propose a tentative chronological sequence for the entire assemblage.

Table 8: Distribution of classes and variants from dated layers in Trenches $C$ and $F$

\begin{tabular}{|c|c|c|c|c|c|}
\hline Class/variant & $\begin{array}{l}\text { 4th-6th } \\
\text { century }\end{array}$ & $\begin{array}{l}\text { 6th-7th } \\
\text { century }\end{array}$ & $\begin{array}{l}\text { 7th-10th } \\
\text { century? }\end{array}$ & $\begin{array}{l}\text { 8th-10th } \\
\text { century }\end{array}$ & $\begin{array}{l}\text { 17th-18th } \\
\text { century }\end{array}$ \\
\hline Class 1 var 1 & 35 & 25 & & 2 & \\
\hline Class 2 var 1 & 18 & 11 & 1 & 6 & 1 \\
\hline Class 2 var 2 & 4 & 8 & & & \\
\hline Class 2 var 3 & & 1 & 1 & 4 & \\
\hline Class 2 var 4 & 9 & 11 & 1 & 2 & \\
\hline Class 2 var 5 & & 4 & & & \\
\hline Class 3 var 2 & 3 & 2 & & & \\
\hline Class 5 var 1 & 44 & 34 & 7 & 16 & \\
\hline Class 5 var 2 & & & 1 & & 1 \\
\hline Class 5 var 3 & 1 & 23 & 21 & & 12 \\
\hline Class 5 var 4 & & 1 & 1 & & \\
\hline Class 7 var 2 & 1 & 1 & & 3 & \\
\hline Class 10 var 1 & & & & 2 & \\
\hline
\end{tabular}




\begin{tabular}{|l|l|l|l|l|l|}
\hline Grand total & 115 & 121 & 33 & 35 & 14 \\
\hline
\end{tabular}

\section{Phase 1: from the 4th to 6th-7th century CE}

During the phase of occupation dating from the 4th to the 6th or 7th century CE, we observe that Class 1 variant 1 , Class 2 variants $1,2,3,4,5$, and Class 5 variant 1 are dominant. In terms of vessel shapes, type 1 (the cup with thinned rim) is the most common type of Class 1 variant 1 . For Class 2, necked jars with everted rims are the main shapes (Class 2 variant 1-types 9, 10, 11, 13; Class 2 variant 2-types 5, 6, 7). Bodysherds with impressed decoration are also present (Class 2 variant 5). The main shapes of Class 5 variant 1 are pots with an everted rim marked by an internal careen (Class 5 variant 1-types 8, 9, 10,11). Pottery belonging to Class 9 is also present; however, this only amounts to a single potsherd. Potsherds belonging to Class 7 occur in all three dated phases, so it is difficult to use this class as a chronological marker.

Restrictive shapes are the most common vessel forms that occur across all classes and variants. Despite this, we also see a relatively high proportion of unrestrictive shapes in the form of a large number of cups made using pots belonging to Class 1 variant 1 .

\section{Phase 2: from the 7th to 8th century CE}

With the exception of vessels belonging to Class 9, which do not appear in layers belonging to this phase of occupation, the same classes and types from the previous phase continue to be dominant. In addition, Class 3 variant 2, Class 5 variants 2 and 3, and Class 10 also begin to appear in the assemblage. Interestingly, examples of Class 5 variant 2 occur in measurably lower frequencies than those of Class 5 variant 3.

In terms of vessel shapes, for Class 3 variant 2 pots with everted rims marked by an internal careen (e.g. Class 3 variant 2-type 5, similar to Class 5 variant 1-types 9, 10, and 11) are the most common forms. For Class 5 variant 3 , vessels of shape-type 3 variant 2 (a bowl with an in-turned rim) and 8 (a necked-jar with out-turned rim and very often with an impressed and/or incised decoration on the top of the rim and a stamped decoration on the shoulder of the jar) are the most common forms.

Phase 3: from the post-10th up to 17th-18th century CE

The number of Class 5 variant 3 vessels increases and this becomes the main ware in the assemblage, while instances of Class 1, Class 2 and Class 5 variant 1 decrease significantly. Examples of Class 10 continue during this phase. Class 5 variant 2 also continues to be present but do not increase in quantity and appear in the same proportion as those of Class 5 variant 4, which also appears during this phase. Class 6 (all variants) also appears during this phase. Regarding the morphological types, we notice a greater variety of vessel shapes among pots of Class 5 variant 3. Yet, the shape-types 3 variant 2, 6 (a plate with a 'bord à marli'), 8, 14 variant 3 (a necked-jar), 15 (a necked-jar), and 16 variant 2 (a necked-jar) are the most common forms. Predominant vessel shapes in each of these phases are illustrated in Figure 37. 

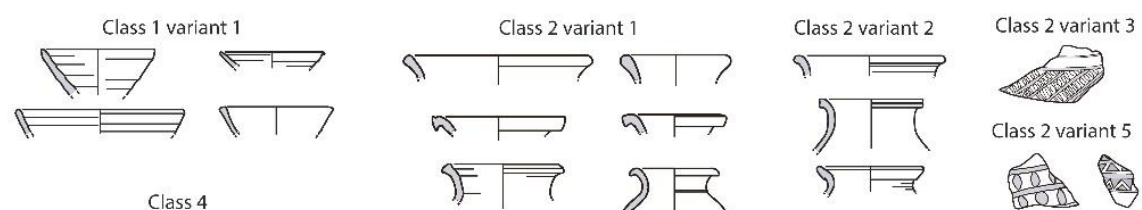

Phase 1

From the 4 th to 6 th $/ 7$ th c. CE

$$
\text { Class } 4
$$
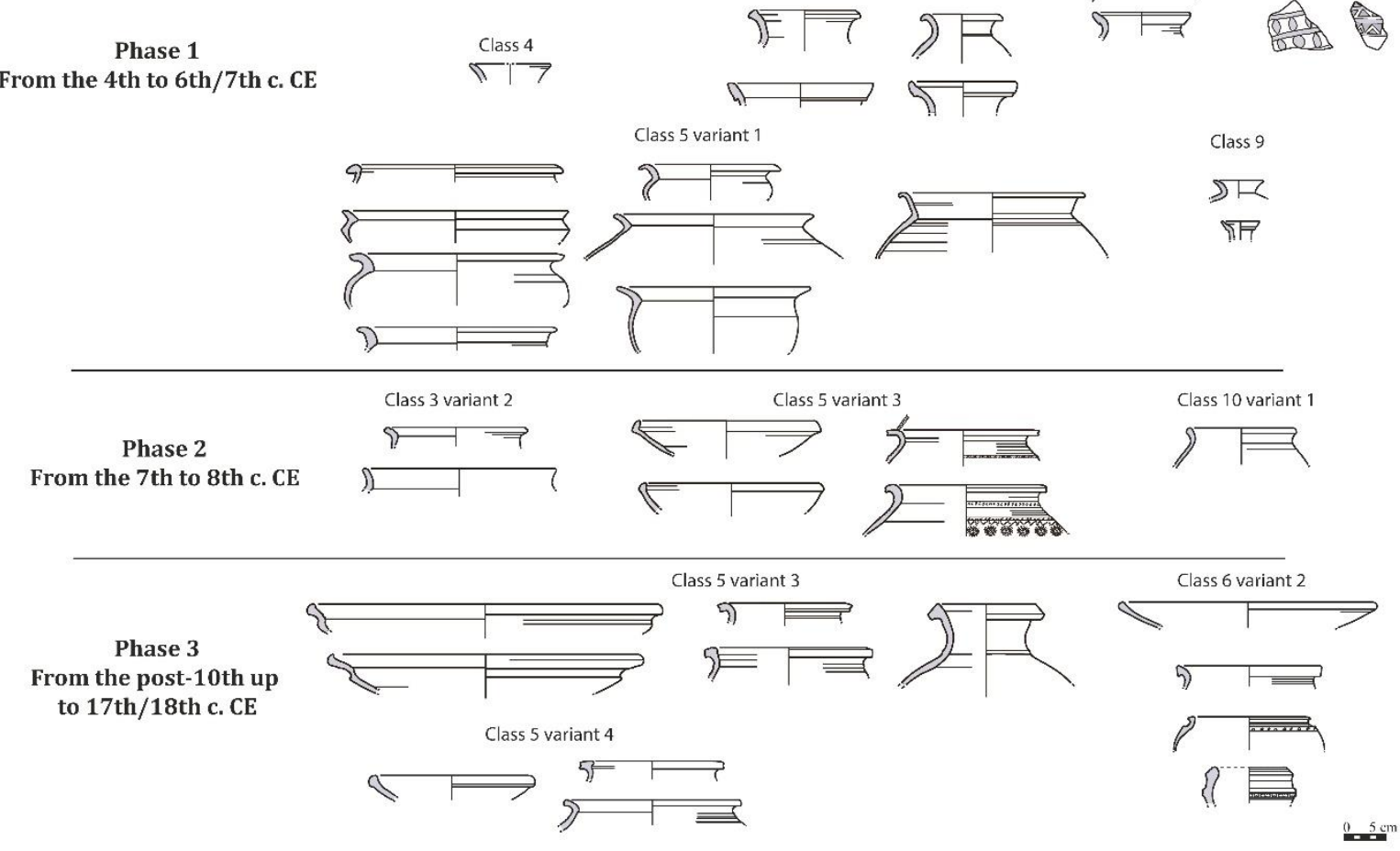

Figure 37: Common vessel shapes in each phase, Trenches C and F. Image credit: Authors.

Other classes that are present in the assemblage from the earliest phase of occupation do not exhibit any differences in their morphology. As such, we are in a situation where it is the presence or absence and the relative proportions of each class and its variants that provide the most reliable chronological indicators. Other than Class 5 variant 3 , we are unable to reconstruct an evolution of vessel forms within each class. The potsherds belonging to the Unidentified group have been discovered only in the upper layers of Trench C (dating to the post-10th century $\mathrm{CE}$ ). This is also true for pots belonging to Class 5 variant 3 , which can thus be considered chronological markers. The tentative chronological sequence made on the basis of the data from trenches $\mathrm{C}$ and $\mathrm{F}$ allows us to propose a relative dating for the layers of the other trenches.

\subsection{Trench A}

Now we turn to results from Trench A. Distribution of potsherds belonging to different classes and their variants are shown in Table 9 and Figure 38. 


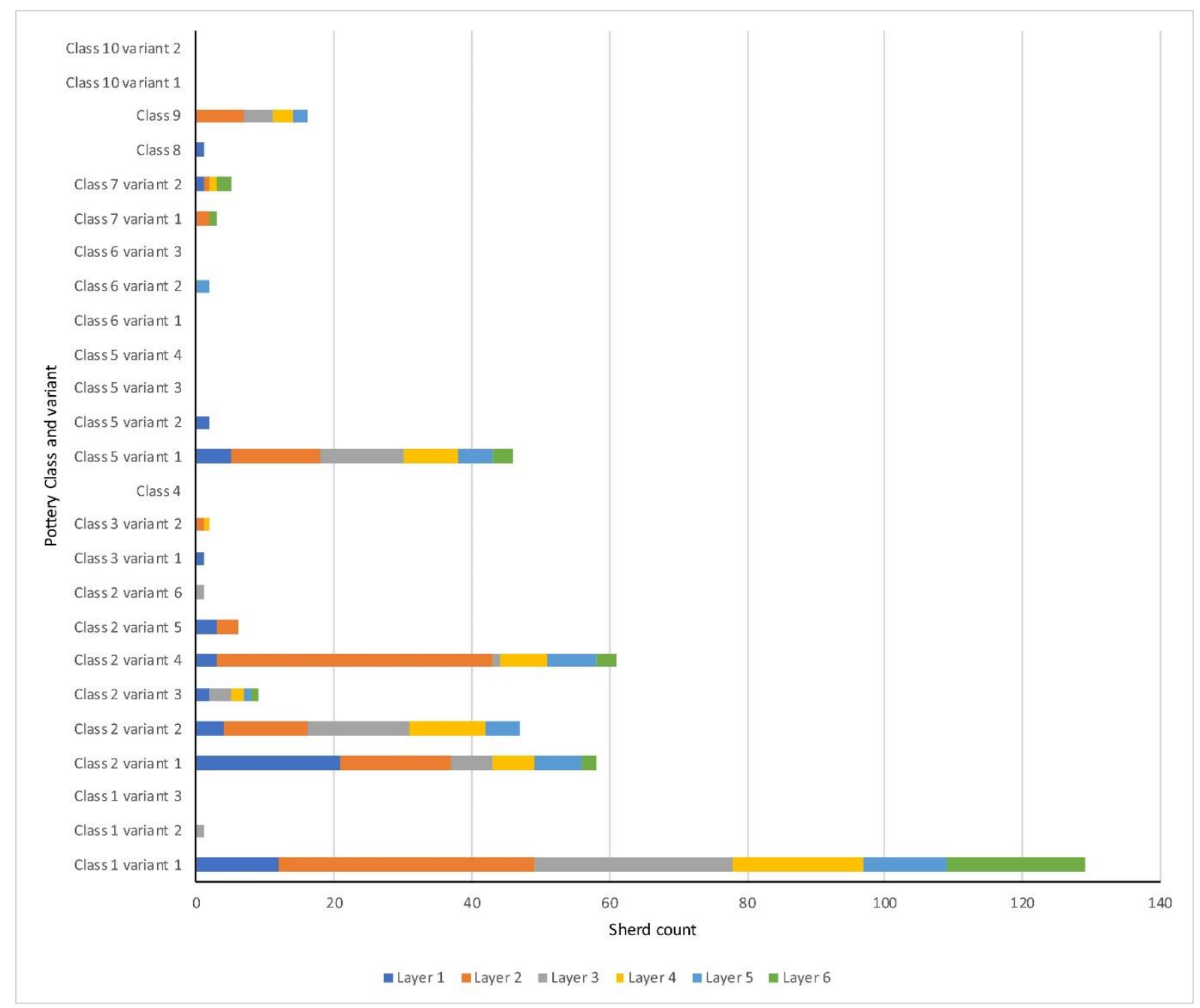

Figure 38: Chart illustrating the distribution of pottery classes and variants in Trench A, layers 1 to 6 . Image credit: Authors.

Table 9: Number of sherds of each class/variant recorded in the archaeological layers of Trench A

\begin{tabular}{|c|c|c|c|c|c|c|c|}
\hline Class/variant & Layer 1 & Layer 2 & Layer 3 & Layer 4 & Layer 5 & Layer 6 & Total \\
\hline Class 1 variant 1 & 12 & 37 & 29 & 19 & 12 & 20 & 129 \\
\hline Class 1 variant 2 & & & 1 & & & & 1 \\
\hline Class 1 variant 3 & & & & & & & 0 \\
\hline Class 2 variant 1 & 21 & 16 & 6 & 6 & 7 & 2 & 58 \\
\hline Class 2 variant 2 & 4 & 12 & 15 & 11 & 5 & & 47 \\
\hline Class 2 variant 3 & 2 & & 3 & 2 & 1 & 1 & 9 \\
\hline
\end{tabular}




\begin{tabular}{|c|c|c|c|c|c|c|c|}
\hline Class 2 variant 4 & 3 & 40 & 1 & 7 & 7 & 3 & 61 \\
\hline Class 2 variant 5 & 3 & 3 & & & & & 6 \\
\hline Class 2 variant 6 & & & 1 & & & & 1 \\
\hline Class 3 variant 1 & 1 & & & & & & 1 \\
\hline Class 3 variant 2 & & 1 & & 1 & & & 2 \\
\hline Class 4 & & & & & & & 0 \\
\hline Class 5 variant 1 & 5 & 13 & 12 & 8 & 5 & 3 & 46 \\
\hline Class 5 variant 2 & 2 & & & & & & 2 \\
\hline Class 5 variant 3 & & & & & & & 0 \\
\hline Class 5 variant 4 & & & & & & & 0 \\
\hline Class 6 variant 1 & & & & & & & 0 \\
\hline Class 6 variant 2 & & & & & 2 & & 2 \\
\hline Class 6 variant 3 & & & & & & & 0 \\
\hline Class 7 variant 1 & & 2 & & & & 1 & 3 \\
\hline Class 7 variant 2 & 1 & 1 & & 1 & & 2 & 5 \\
\hline Class 8 & 1 & & & & & & 1 \\
\hline Class 9 & & 7 & 4 & 3 & 2 & & 16 \\
\hline Class 10 variant 1 & & & & & & & 0 \\
\hline Class 10 variant 2 & & & & & & & 0 \\
\hline Total & 55 & 132 & 72 & 58 & 41 & 32 & 390 \\
\hline
\end{tabular}

Within all six layers of Trench A, we observe a predominance of: Class 1 variant 1-type 1; Class 2 variant 1-types 10, 11, 12, 13; Class 2 variant 2-types 5, 6, 7; Class 2 variant 4-type 10; and Class 5 variant 1-types 8, 9, 14. Class 9 is also present in almost all layers (2-5 inclusive). Only in layer 6 is Class 1 variant 1-type 1 the main pottery group. This absence of variation in the proportions of classes and related vessel forms raises a question regarding the chronology. Indeed, it seems that all layers could be ascribed to the same phase of occupation, which appears to correspond to the first phase identified in Trenches C and F dating to the 4th to 6th or 7th century CE (Table 10). 
Table 10: Reconstructed chronological sequence for Trench A, based on relative dating

\begin{tabular}{|l|l|}
\hline \multicolumn{1}{|l|}{ Layer } & \multicolumn{1}{c|}{ Date range } \\
\hline 1 & 4th to 6 th/7th century \\
\hline 2 & 4th to 6 th/7th century \\
\hline 3 & 4th to 6 th/7th century \\
\hline 4 & 4th to 6 th/7th century \\
\hline 5 & 4th to 6 th/7th century \\
\hline 6 & 4th to 5 th century \\
\hline
\end{tabular}

\subsection{Trench B}




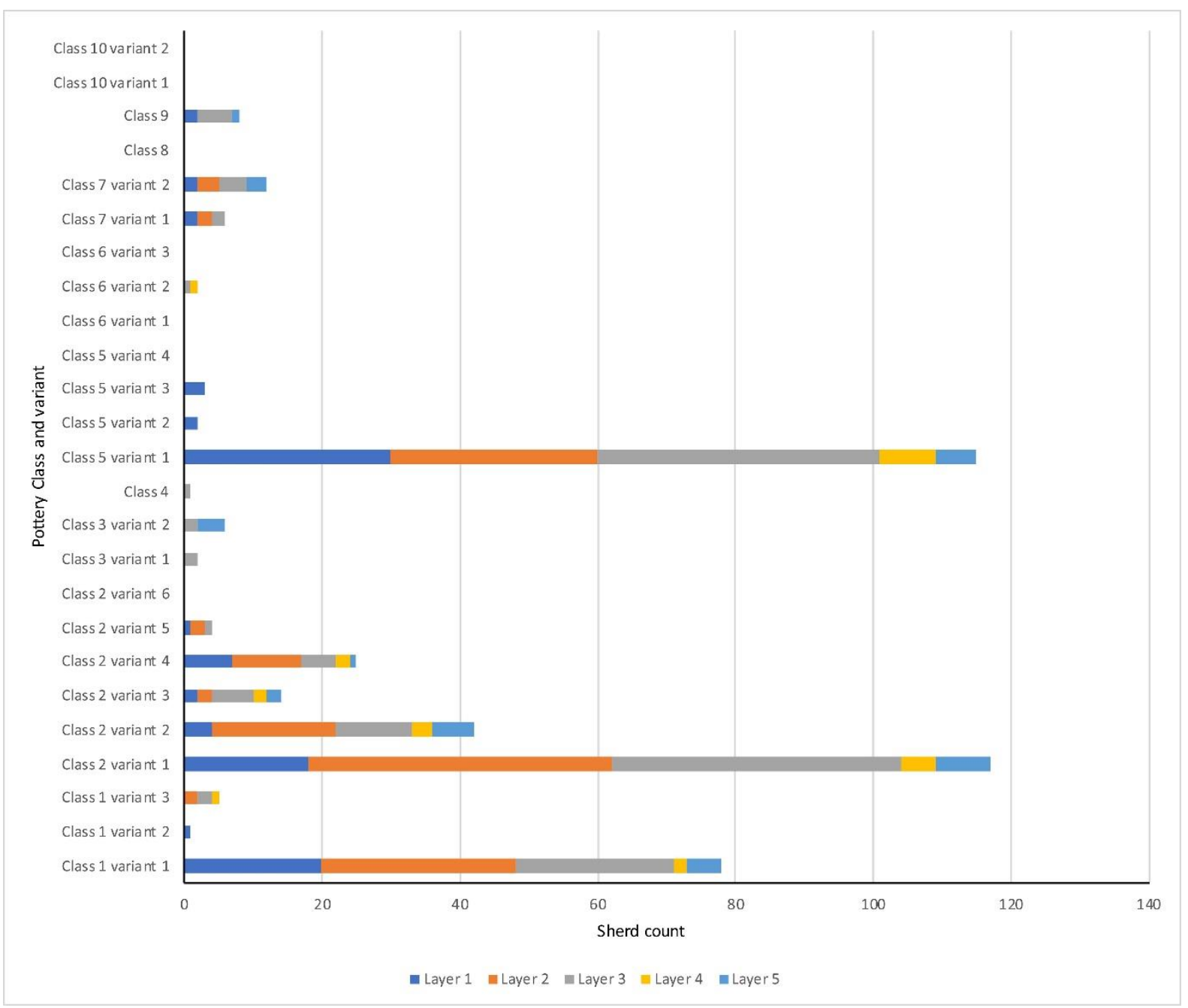

Figure 39: Chart illustrating the distribution of pottery classes and variants in Trench B, layers 1 to 5. Image credit: Authors.

Table 11: Number of sherds of each class/variant recorded in the archaeological layers of Trench B

\begin{tabular}{|l|l|l|l|l|l|l|}
\hline \multicolumn{1}{|c|}{ Class/variants } & \multicolumn{1}{|c|}{ Layer 1 } & Layer 2 & Layer 3 & Layer 4 & Layer 5 & Total \\
\hline Class 1 variant 1 & 20 & 28 & 23 & 2 & 5 & 78 \\
\hline Class 1 variant 2 & 1 & & 2 & 1 & 5 \\
\hline Class 1 variant 3 & 18 & 44 & 42 & 5 & 8 & 117 \\
\hline Class 2 variant 1 & 4 & 18 & 11 & 3 & 6 & 42 \\
\hline Class 2 variant 2 & 2 & 2 & 6 & 2 & 2 & 13 \\
\hline Class 2 variant 3 & 7 & 10 & 5 & 2 & 25 \\
\hline Class 2 variant 4 & 7 & 2 & & 5 \\
\hline
\end{tabular}




\begin{tabular}{|c|c|c|c|c|c|c|}
\hline Class 2 variant 5 & 1 & 2 & 1 & & & 4 \\
\hline Class 2 variant 6 & & & & & & 0 \\
\hline Class 3 variant 1 & & & 2 & & & 2 \\
\hline Class 3 variant 2 & & & 2 & & 4 & 6 \\
\hline Class 4 & & & 1 & & & 1 \\
\hline Class 5 variant 1 & 30 & 30 & 41 & 8 & 6 & 115 \\
\hline Class 5 variant 2 & 2 & & & & & 2 \\
\hline Class 5 variant 3 & 3 & & & & & 3 \\
\hline Class 5 variant 4 & & & & & & 0 \\
\hline Class 6 variant 1 & & & & & & 0 \\
\hline Class 6 variant 2 & & & 1 & 1 & & 2 \\
\hline Class 6 variant 3 & & & & & & 0 \\
\hline Class 7 variant 1 & 2 & 2 & 2 & & & 6 \\
\hline Class 7 variant 2 & 2 & 3 & 4 & & 3 & 12 \\
\hline Class 8 & & & & & & 0 \\
\hline Class 9 & 2 & & 5 & & 1 & 8 \\
\hline Class 10 variant 1 & & & & & & 0 \\
\hline Class 10 variant 2 & & & & & & 0 \\
\hline Total & 94 & 141 & 148 & 24 & 36 & 442 \\
\hline
\end{tabular}

In Trench B we observe the same stratigraphic distribution of the classes and variants as noted in Trench A (Table 11; Figure 39). The only exception to this trend is in layer 1, where examples of Class 5 variant 3 are far less frequent (only three potsherds). The majority of potsherds belong to: Class 1 variant 1; Class 2 variants 1, 2, 4; and Class 5 variant 1, while examples of Class 9 are not distributed as evenly throughout the sequence. Caution is needed when interpreting the distribution of pottery in layers 4 and 5 because the quantity of potsherds is noticeably lower (layer 4: 24 potsherds, layer 5: 36 potsherds) than in other layers (layer 1: 94, layer 2: 141, layer 3: 148). Nevertheless, the similarities to Trench $A$ enable us to propose a comparable date for the layers of Trench B, i.e. from the 4 th to the 6 th or 7 th century CE (Table 12). 
Table 12: Reconstructed chronological sequence for Trench B, based on relative dating

\begin{tabular}{|l|l|}
\hline \multicolumn{1}{|l|}{ Layer } & \multicolumn{1}{c|}{ Date range } \\
\hline 1 & 7 th to 8 th century \\
\hline 2 & 4th to 6 th/7th century \\
\hline 3 & 4th to 6 th/7th century \\
\hline 4 & 4th to 6 th/7th century \\
\hline 5 & 4th to 6 th/7th century \\
\hline
\end{tabular}

\subsection{Trench D}

A notable feature of the ceramic assemblage from Trench $D$ is the disparity between the quantities of potsherds in different layers (Table 13; Figure 40). Layer 2 contained a far greater quantity of potsherds than any of the others. This may indicate a difference in the nature of the activities that took place in that part of the site during a particular time (perhaps a period of more intense occupation, or alternatively a period of dumping or episode of backfilling). Equally, however, it may also reflect a different process of ceramic recovery and retention during excavation. Here, we continue to work on the premise that similar retention strategies were used across the site. 


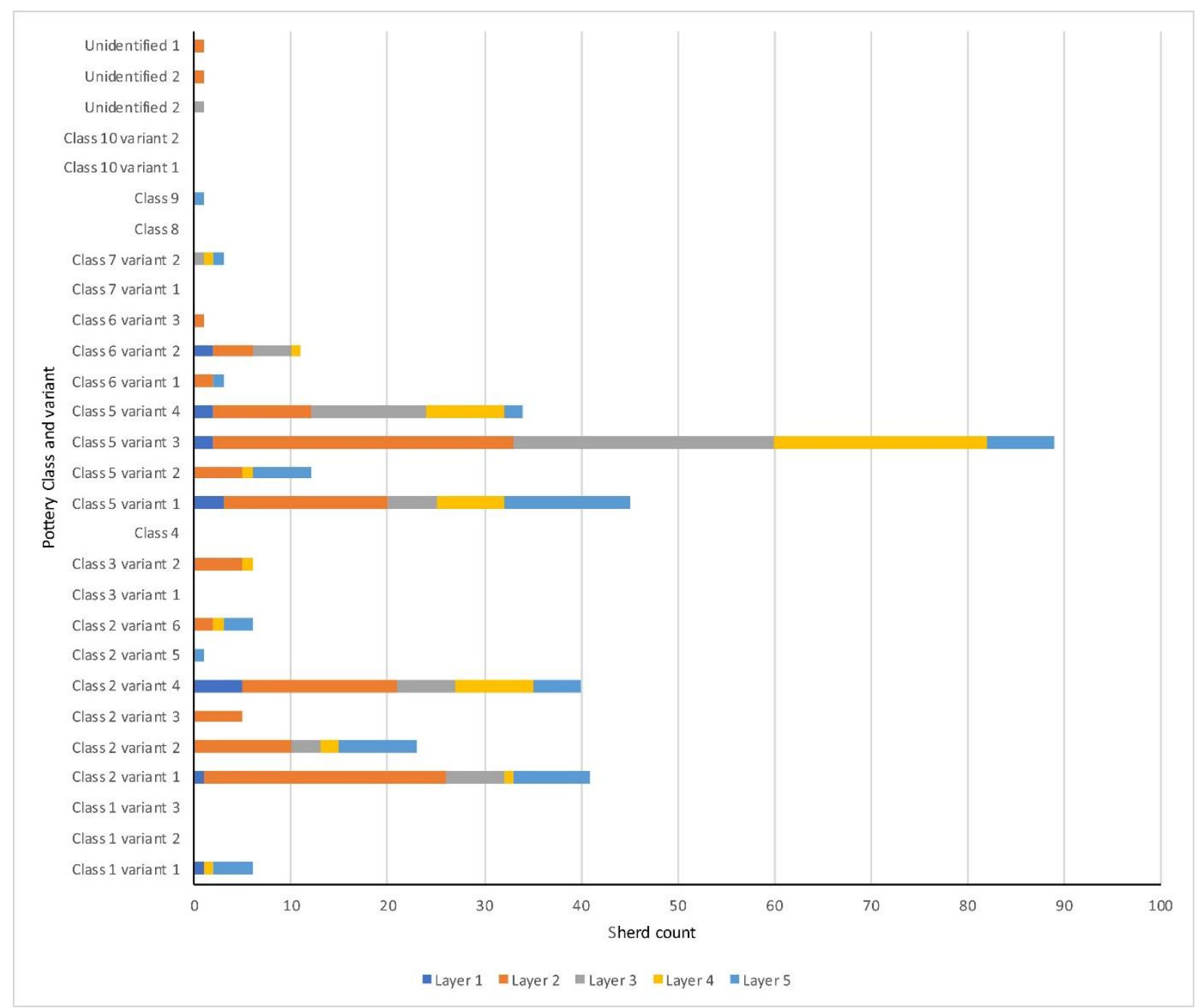

Figure 40: Chart illustrating the distribution of pottery classes and variants in Trench D, layers 1 to 5. Image credit: Authors.

Table 13: Number of sherds of each class/variant recorded in the archaeological layers of Trench D

\begin{tabular}{|l|l|l|l|l|l|l|}
\hline \multicolumn{1}{|c|}{ Class/variants } & Layer 1 & Layer 2 & Layer 3 & Layer 4 & Layer 5 & Total \\
\hline Class 1 variant 1 & 1 & & & 1 & 4 & 6 \\
\hline Class 1 variant 2 & & & & & & \\
\hline Class 1 variant 3 & 1 & 25 & 6 & 1 & 8 & 41 \\
\hline Class 2 variant 1 & & 10 & 3 & 2 & 8 & 23 \\
\hline Class 2 variant 2 & & 5 & 16 & 6 & 8 & 5 \\
\hline Class 2 variant 3 & 5 & & & & 40 \\
\hline Class 2 variant 4 & & & & & 5 \\
\hline
\end{tabular}




\begin{tabular}{|c|c|c|c|c|c|c|}
\hline Class 2 variant 5 & & & & & 1 & 1 \\
\hline Class 2 variant 6 & & 2 & & 1 & 3 & 6 \\
\hline \multicolumn{7}{|l|}{ Class 3 variant 1} \\
\hline Class 3 variant 2 & & 5 & & 1 & & 6 \\
\hline \multicolumn{7}{|l|}{ Class 4} \\
\hline Class 5 variant 1 & 3 & 17 & 5 & 7 & 13 & 45 \\
\hline Class 5 variant 2 & & 5 & & 1 & 6 & 12 \\
\hline Class 5 variant 3 & 2 & 31 & 27 & 22 & 7 & 89 \\
\hline Class 5 variant 4 & 2 & 10 & 12 & 8 & 2 & 34 \\
\hline Class 6 variant 1 & & 2 & & & 1 & 3 \\
\hline Class 6 variant 2 & 2 & 4 & 4 & 1 & & 11 \\
\hline Class 6 variant 3 & & 1 & & & & 1 \\
\hline \multicolumn{7}{|l|}{ Class 7 variant 1} \\
\hline Class 7 variant 2 & & & 1 & 1 & 1 & 3 \\
\hline \multicolumn{7}{|l|}{ Class 8} \\
\hline Class 9 & & & & & 1 & 1 \\
\hline \multicolumn{7}{|l|}{ Class 10 variant 1} \\
\hline \multicolumn{7}{|l|}{ Class 10 variant 2} \\
\hline Unidentified 2 & & & 1 & & & 1 \\
\hline Unidentified 2 & & 1 & & & & 1 \\
\hline Unidentified 1 & & 1 & & & & 1 \\
\hline Total & 16 & 135 & 64 & 54 & 60 & 330 \\
\hline
\end{tabular}

Despite differences in the relative quantity of ceramic remains between layers in Trench $D$, we notice the same distribution of classes and variants in layers 1 to 4 . Classes 1, 4, 7, 9 and 10 are almost absent from the 
assemblage. Class 2 is present along with Class 5 variant 1, but they are less frequent than those of Class 5 variants 3 and 4, which are clearly the predominant wares. Class 6 is also represented but accounts for a much smaller proportion of the overall assemblage. Another characteristic is the presence of glazed wares (Unidentified types). In layer 5 we can identify a change in this distribution. Here, we see an increase in the proportion of Class 2 and Class 5 variant 1, while the relative proportion of Class 5 variants 3 and 4 decreases.

On the basis of this analysis, we can assign layers 2 to 5 to the second phase of occupation identified in Trenches $C$ and $\mathrm{F}$, dating to the 7th and 8th centuries CE. Layer 1 can be dated to the third phase of occupation, which dates from the 10th century CE onwards (Table 14).

Table 14: Reconstructed chronological sequence for Trench D, based on relative dating

\begin{tabular}{|l|l|}
\hline \multicolumn{1}{|c|}{ Layer } & \multicolumn{1}{c|}{ Date range } \\
\hline 1 & Post 10th century \\
\hline 2 & 7 th to 8th century \\
\hline 3 & 7 th to 8th century \\
\hline 4 & 7 th to 8th century \\
\hline 5 & 7 th to 8th century \\
\hline
\end{tabular}

\section{Discussion and Conclusion}

We hope that this analysis of the ceramic assemblage from Mahurjhari has demonstrated that looking at pottery from a new perspective is both worthwhile and interesting. From the four vague and poorly understood wares that were identified during excavation (Red Ware, Red Micaceous Ware, Black Ware, and Black Micaceous Ware), we now have ten distinct classes of ceramics that contain at least twenty-three variants. Further, by applying an analytical framework that focuses on how pots were made, rather than simply what they look like, we have been able to move beyond a situation where archaeological ceramics are understood only as chronological markers, towards a situation that involves a more complex picture of these remains.

In approaching the ceramics in this way, we have tried to demonstrate that a systematic and descriptive approach must be used to establish pottery groups. In this case, we have based our analysis on the visual traces left by the manufacturing process. These are visible in the appearance, hardness and compositional matrix of the clay used to make the vessel, the shaping techniques, the finishing techniques, the decorative techniques and indications of the firing atmosphere. These characteristics have been compared and assembled in order to understand the variation that occurs within the assemblage and define pottery classes and variants. These have not been based only on one criterion, such as the colour of the surface, but on a combination of several diagnostic features.

In moving beyond 'fossil types', and with reference to radiocarbon determinations from the site (Mohanty et al in press), we have also been able to establish a pottery sequence with specific pottery groupings that can be used as chronological markers. We have also documented remarkable continuity in several ceramic classes and variants that challenges their use as clear-cut chronological markers. Classes 1, 2, 5 variant 1, and 9 are typical and indicative of the first phase of occupation at the site, which appears to date from the 4th to the 6th or 7th century CE. 
The second phase of occupation, dating to the 7th and 8th century, is marked by Class 3 variant 2 and Class 5 variants 2 and 3 . However, that is with the caveat that this phase is slightly more difficult to define owing to the continued use of earlier classes of pottery.

The third phase of occupation, which dates from the post-10th century, can be determined by the high proportion of Class 5 variant 3 ceramics, and the subsequent presence of those belonging to Class 5 variant 4 and Class 6 .

Through this analysis, we have been able to propose a relative date for the layers of each trench. Using these data and referring again to the distribution of excavation trenches across the site (Figure 4), we note that Trenches $C$ and $F$ exhibit evidence of continuous occupation from the 4th century CE to the post-10th century, while Trenches $A$ and $B$ (which both relate to the eastern edge of the habitation) appear to have been occupied from the 4th to the 7th century CE; and Trench D from the 7th to the post-10th century CE only.

Of course, the value of this approach extends far beyond simply identifying pots to use as chronological markers. By basing our typology on methods of manufacture, the ceramics themselves become markers of the people, processes, and practices that were involved in their manufacture and use. In this connection, we can begin to interpret the primary functions of the classes we have identified at Mahurjhari on the basis of their morphological types (see Lefrancq and Hawkes 2019b). Class 1 ceramics were almost all unrestrictive shapes, i.e. cups or bowls, and display few varieties of morphological types. We can thus presume that these vessels were used for serving and consuming food and drink. The reasonably high level of standardisation of production techniques and vessel forms that we were able to observe across ceramics belonging to this class could suggest that they were made in a workshop that specialised in the production of this class, presumably in response to a specific demand. Class 2 pots, with a predominance of restricted shapes such as necked jars, may have been used for the transport of liquids. Unrestricted shapes might have been used for the transport of food products or other commodities; the absence of firing traces and residues would appear to indicate that they were not used for culinary purposes. In contrast, Class 3 variant 2 and Class 5 variants 1 and 2 may have served a culinary function. This is indicated by the traces of post-firing burning on the surface of some pots, and the purposeful addition of mica to the fabric of Class 5 variant 1 pots. Further, the main shape for Class 5 variant 1 is a pot with an S-shaped profile, a round base and an everted and elongated rim. These features are significant because it is known that a more porous fabric, the addition of mica to the fabric, and the use of round bases all made pots more resistant to the thermal shock caused by repeated heating and cooling, and may thus be used as indicators of such usage (see Rye 1981, 26-27, for further discussion of the fact that both technical and sociocultural reasons affect the choices potters' make during manufacture see Spataro and Villing 2015).

Class 5 variants 3 and 4 may have fulfilled dual functions as both cooking and storage vessels. The variation in the colours on both surfaces of vessels belonging to Class 5 variant 3 is difficult to interpret. It may result from the firing process, or its possible use as a cooking pot. Similar uncertainties affect our interpretation of vessels belonging to Class 5 variant 4 and Class 6 variants 2 and 3, which both display a black slip and signature traces of having been fired in a reducing atmosphere. For those three pottery groups, we were unable to identify as many shapes and vessel types, though unrestricted shapes appear to have been the most prevalent. It is interesting to note that the shapes and types of Class 5 variant 4 and Class 6 variant 2 are often similar (e.g. Class 5 variant 4 type 2 and Class 6 variant 2-type 2, Class 5 variant 4-type 5 and Class 6 variant 2-type 8 for instance), indicating that pots serving the same function were made using different techniques, and (possibly) by different people or groups.

As mentioned earlier, Class 4 encompasses only one single potsherd that could be of non-local origin. All that we can say at this point is that its rim could belong to a small pot with an everted rim. In contrast, vessels belonging to Class 7 are all large basins and storage jars. Class 10 includes both unrestricted and restricted shapes that appear to have been dedicated to the preparation, storage and serving of food and/or liquids. Finally, vessels belonging to Class 9 were probably intended for carrying and serving liquids of special importance. This is indicated by the small diameter of the jars, the presence of narrow necks and the care used in the finishing of their surfaces.

Interestingly, there is no difference in the proportion of unrestricted and restricted shapes across all phases of occupation at the site - restricted shapes are always the most common forms. However, during the first and second phases, we do encounter more bowls/cups and fewer plates among the wider corpus of unrestricted shapes. During the third phase, bowls/cups become less frequent and plates (mainly those belonging to Class 5 
variants 3 and 4 and Class 6 variant 2) become more common. This may indicate a change in dietary habits or other social practices. As far as the scale of production is concerned, the degree of standardisation between groups of pottery and within individual groups is often used as an indicative criterion (see Sinopoli 1993; Roux 2003; Costin 2000; Miller 1985; Chakraborty 2018). However, the Mahurjhari assemblage is quite small and the shapes are not preserved well enough to enable us to draw a conclusion in this regard. What we can say is that certain classes, such as Class 2 and Class 5 exhibit a lot of variations in the kind of rims that were used, while their general shapes seem less diverse. This may be an indication of small familial workshops rather than large-scale highly regulated workshops (see Van der Leeuw 1976). On a broader scale, it is difficult at this stage to say if the appearance of new classes over time is linked to new social groups involved in the manufacture of pots, or if it is due to a chronological evolution of practices of the same potters and/or workshops.

All of these results are, of course, limited by a number of factors. The stratigraphic layers in which they were found were defined only very broadly, and were identified during an excavation that involved the 'dig' system, wherein horizontal spits of arbitrary depths are dug (usually by village labourers) until a distinct change in the composition of the soil or presence of artefacts within the matrix is noticed (usually by those observing the excavation from the side of the trench). The need for more stratigraphic control during these excavations has already been recognised (Mohanty et al. in press). In addition, the collection, discard and retention protocols that were employed on site have also negatively affected our ability to classify and analyse the distribution of wares across the site and throughout the stratigraphic sequence. Since most of the ceramics were initially classified during the excavation on the basis of their traditional ware attribution by different teams of people, and were then discarded on site, the full extent of our analyses suffers from a lack of information regarding the overall quantities of pottery. Indeed, we are unable to analyse the distribution of pottery classes as they have been defined here across space and time as well as we would have liked. Further, the fact that we can see that the four 'wares' first identified during excavation clearly encompass a great deal of variation means that we do not know whether other classes may have been missed altogether, having been discarded and forgotten about. Together, these different scales of resolution mean that we are unable to realise the full potential of such a detailed method of pottery analysis. As such, we suggest that if, on the one hand, we accept the value of looking at archaeological ceramics in this way and the clear contribution that these methods can make to our archaeological understanding, then this conceptual appreciation must be accompanied by the incorporation of new protocols in excavation strategies. In order to achieve high-quality results from the analysis of archaeological ceramics, it is essential to retain and analyse (even if only on the broadest of scales), all potsherds discovered during the excavations. Further, the ceramicist over-seeing the analyses should, in principle, be solely responsible for deciding what to keep and what to discard.

There are, then, clear signposts for future work, not only at this site but in this region in general which, as we mentioned earlier, does not yet have a diachronic regional pottery typology. In order to achieve this, we need to be attuned to the level of variation that we have demonstrated can exist within the range of pottery that was produced and used in the past. At the same time, we do not suggest for a moment that the method of approaching the analysis of pottery presented here is the definitive way that pottery should be recorded. There is no 'one size fits all' approach to the study of archaeological ceramics. The methods, techniques and questions that we can employ all depend on the time, resources and equipment available, as well as the level of previous work in the area. The process that we have used here was detailed and time-consuming - purposefully so. Because we are operating in an environment where there is no established regional pottery typology, we wanted to establish a solid basis for future approaches to their study.

Any perceived weakness of the analyses presented here are due to the limited size and range of ceramic assemblage that was retained following excavation. As discussed above, this made it impossible to apply a 'neat' text-book chaîne opératoire approach to their analyses, and our results are not necessarily indicative of the full range of ceramic variation that exists at the site. This is not to suggest that the approach outlined here (or something similarly detailed) should be applied on site in order to record every single sherd. It is far too timeintensive and requires slightly more skill and expertise than is realistically possible to provide at every excavation. It is (as would be the norm in many other parts of the world) much more suited to subsequent phases of postexcavation analyses. However, this is only possible if the majority of an assemblage is not discarded on site. With this in mind, we suggest that the application of any methods such as these must also be accompanied by changes in the standard excavation protocols employed in South Asia. Of course, entire pottery assemblages cannot always be retained ad infinitum, and we have no such expectations. However, there are still a number of potential solutions. We can identify at least four obvious alternative protocols and strategies. The first is to employ an 
alternative sorting strategy on site - one that is, at the very least, attuned to the range of variation that exists within any ceramic assemblage and does not seek to reduce it to crude differences in colour and texture. As we have demonstrated here, this masks a great deal of variation, which is irretrievably lost once sherds are discarded. Second, this strategy could be overseen by trained ceramic specialists as a matter of course. If the main impediment to implementing either of these approaches is the additional time it would take, then a third protocol could be to transport the entire assemblage back to the excavating institution where more time may be available to complete the initial sorting beyond the end of excavation and back-filling. Or fourth, and even more radically, we might reconsider the scale of planned excavations so as not to generate so much material. After all, if the artefacts themselves are not going to be examined in any great detail, what exactly is being gained from largescale exposures?

None of these suggestions are mutually exclusive, and all bring with them a number of additional considerations. Is there, for instance, sufficient capacity for the involvement of trained ceramic specialists? Are there storage facilities available and large enough to house the material for the time needed to achieve a minimum standard of preliminary sorting and recording? Are the corresponding budgets large enough to accommodate these? Full consideration of these issues is beyond the remit of this article. Yet what should by now be beyond doubt is that the practice of discarding the majority of an assemblage without having a grasp of a diachronic typology that can account for all of the variation that exists can no longer be excused.

We hope that future work on ceramics in this region can benefit from the approaches outlined here, and consider the various constraints and clear potential that we have highlighted. It will be interesting now to compare the ceramics from Mahurjhari to both surface material from the wider region and material from excavations as and when they take place. In this connection, the next stage of our research will be the analysis of material collected from surface surveys across the Vidarbha region (see Hawkes and Abbas 2016; Hawkes et al. 2016). The excavations conducted in Nagardhan since 2014-2015 by the Deccan College and the Maharashtra State Department of Archaeology and Museums (Sontakke et al. 2016) will also provide invaluable data when they are published. Indeed, by comparing the different local productions, we will be able to better understand the choices made by the potters in different areas, and the scale and organisation of the pottery manufacture and craft production (household, local and regional workshops, and so on). We will be able to analyse the results through the prism of the cultural exchanges (identification of local and imported materials or exchange of manufacturing techniques for instance) and the relationship between the people and their environment (use of specific temper or clay). By putting together the different scales of analysis, we will gradually be able to develop not only a robust diachronic regional typology, but also a far more nuanced archaeological understanding of the region's past.

\section{Appendix: Variables and Attribute States used in the Recording of Archaeological Ceramics for this Study}

\subsection{Introduction}

This appendix presents the attributes and variables that were recorded for each potsherd in the Mahurjhari assemblage during the ceramic recording and analysis process. The reasons for recording these features are outlined above. Here, we present the variables and attributes that were recorded, and details of how they were recorded. This includes the pre-defined qualitative and quantitative values that were assigned to certain variables or attributes, a corresponding account of the scales or visual references used to explain and justify the values that were used, as well as explanations regarding the ways in which certain measurements were taken and to what scale. These details are presented in exactly the same order used during the recording process. All records were entered into a spreadsheet (Microsoft Excel).

Note: the details presented in this appendix (or the text of this article) should by no means be taken as a complete guide to the recording of archaeological ceramics, for which a number of easily accessible resources exist (e.g. Orton et al. 1993; Orton and Hughes 2013).

\subsection{Potsherd ID}


The unique identifier applied to each potsherd. In our study, we used the following formula: Site code/Trench number/Layer or unit/sherd number. Thus, the first sherd to be recorded from site MHR02, Trench F, Unit 4 would be recorded as: MHR02/F/4/1.

\subsection{Context information}

The basic record of the context, locus or unit in which the potsherd was found, using the same nomenclature and numbering system that was used in the excavation.

Trench: The trench in which the sherd was found.

Square: The excavation square within the trench in which the sherd was found.

Context/Layer: The specific context, or layer number the sherd came from. Obviously, the terminology would be adjusted as necessary depending on how the site was excavated.

Feature: The feature the sherd was associated with (e.g. the ditch or pit in which it was found) if any.

\subsection{Fabric information}

This broad category includes details of all visually discernible aspects of the fabric of the potsherd. These were recorded in order to identify and define the initial stages of production used in the formulation of pottery classes. Information recorded in this category also formed the basis for our identification and definition of the Fabric Groups used in the production of ceramics in this assemblage (see Lefrancq and Hawkes 2019a).

All details were recorded from fresh breaks in the potsherd. Breaks were made manually using a pair of pliers on the edge of a sherd, in an area that was deemed to be most representative of that sherd. Where possible, this was on the body portion of a sherd and not the rim or base, as it was recognised that the thickness of the fabric in these parts may present different characteristics than those evident in the profile of the body of a vessel. In order to avoid making multiple breaks, they were made on parts of the sherd deemed to be of average thickness for that sherd.

\subsubsection{Fabric colour}

The first category of fabric information recorded was its colour, and any differences in colour that might be evident in the profile of the sherd (i.e. whether or not there is any variation in colour, whether the internal core differs in colour from its margins, and whether or not the transition between these colours is diffuse or clearly defined). This is an important indicator of the firing environment in which the pot was made. Wherever possible, sherds were examined and these data recorded in natural light to avoid any distortion of colours caused by artificial light. This was the same for all other recorded data.

The core

First, the colour of the core was recorded. We defined the core as the central portion of the profile of a sherd where that portion differed in colour from one or both margins. The colour of the core was recorded using the following variables:

Munsell Colour: The Munsell code of the colour, with reference to the Munsell soil chart.

Colour Description: The Munsell colour (in words), with reference to the Munsell soil chart.

Diffuse?: Whether or not the core exhibits a diffuse transition towards one or both margins or either the external or internal surface. Requires a yes/no answer.

Margins?: Whether or not there are margins to the fabric core (i.e. the fabric differs in colour towards the edges of the profile from the centre). Requires only a yes/no answer. If 'no' then we took the core colour to be the 
colour of the fabric as visible in the section. If 'yes' then we recorded details of the colours of the margin(s) (see below).

The margin(s)

Details of the colour and nature of the change of colour from the margin(s) to either the external or internal surface (if any). These details were recorded for as many margins as were visible in the section. Usually, there were only two margins (one external and one internal). In instances where there was no internal core between the two margins, only details for the margins were recorded. The absence of any details of core colour in the record would then indicate that exactly half of the profile was one colour, and the other half another colour. However, if the majority of the profile was one colour and there was only one margin, then the predominant colour would be recorded as the 'core', and the secondary colour as a 'margin' (either external or internal).

Munsell Colour: The Munsell code of the colour, with reference to the Munsell soil chart.

Colour Description: The Munsell colour (in words), with reference to the Munsell soil chart.

Diffuse?: Whether or not the core exhibits a diffuse transition towards either the external or internal surface of the pot. Requires only a yes/no answer.

The surface

Details of the colour of the surface(s) of the sherd where they are visible. In some instances, one or both of the original surfaces were completely obscured by surface treatment (i.e. a slip or slurry), in which case these details were left blank. Details of the surface colour were recorded for both the external and internal surfaces following the same principles as detailed below:

Munsell Colour: The Munsell code of the colour, with reference to the Munsell soil chart. In some instances, it may have been necessary to record more than one colour, for instance if the surface was patchy (see below).

Colour Description: The Munsell colour (in words), with reference to the Munsell soil chart. In some instances, it may have been necessary to record more than one colour, for instance if the surface was patchy (see below).

Patchy?: Whether or not the surface colour is patchy (i.e. not uniform). Requires only a yes/no answer.

Visible in section?: Whether the surface colour was visible in the profile of the sherd (i.e. it is the same colour as the fabric directly beneath the surface - either as part of the margin, or a thin layer that is a different colour from the margin. Requires only a yes/no answer.

\subsubsection{Fabric texture/feel}

The second category of fabric information was details of its texture and feel. This was recorded as an indicator of either the way the vessel was shaped and formed, and/or the conditions under which it was fired.

Hardness: Qualitative classification of the hardness of the fabric, assessed on the basis of how easy it was to make a fresh break of the sherd to reveal the section. This was recorded using pre-defined (subjective) values of 'soft', 'medium' or 'hard', so that the recorded value would be relative between all sherds in the assemblage.

Fracture: The nature of the fracture resulting from a fresh break. This was recorded using the following qualitative values: Conchoidal (where the fracture resembles that of struck flint or glass, with ripples); Smooth (similar to conchoidal but without visible ripples); Regular (where the fracture is neither smooth, nor irregular or hackly); Hackly (where the fracture is highly irregular and appears 'spikey'); Laminated (where the sherd fractures in layers).

Feel: How the natural surface of the sherd feels to the touch. In other words, its relative smoothness. Obviously, this can only be recorded if the natural (i.e. untreated) surface is visible. The same information is recorded (where 
possible) for both the exterior and interior surfaces, with reference to a pre-defined scale of relative values (with values for individual sherds defined in relation to each other): Very fine/Fine/Medium/Coarse/Very coarse.

Firing: An assessment (based on the hardness, fracture, colour, overall nature of the inclusions, and feel of the surface) as to how well the pot was fired. Recorded with reference to a pre-defined scale of values: Well fired/Under fired/Over fired.

\subsubsection{Inclusions}

The third category of fabric information relates to details of the inclusions visible in the section of the sherd. This was identified as diagnostic of how the paste was constituted and prepared in order to make the fabric of the pot, as well as indicating certain conditions relating to how the finished vessel was fired. Here, a number of variables and attributes pertaining to each identifiable inclusion visible in the profile of the sherd were recorded.

Inclusion type: The type of inclusion (i.e. its material). Note: a void or pocket where something used to be prior to firing was still counted as an inclusion. Values were entered according to pre-defined list of values:

Organic/Sand/Grit/Mica/Grog/Shell/Calcite/Voids/None Visible. It was recognised that this list does not encompass every type of inclusion that could exist. However, it was formed through our experience of examining a range of ceramics from various South Asian contexts, and includes all recurring types that we encountered and that are identifiable through visual inspection. Further types found during examination could be added to this list.

Inclusion colour: The colour of this inclusion, using a pre-defined set list of values: White/Red/Brown /Black/Grey/Silver/Gold/Mixed/No colour. A pre-defined list of values was preferred over a Munsell colour chart owing to the impracticalities of easily and accurately establishing the Munsell colour of small particles. The same set of values was recorded for every inclusion.

Inclusion size: Assessment of the approximate size of these inclusions, with reference to pre-defined values: Very fine $(<0.1 \mathrm{~mm}) /$ Very fine $(<0.1 \mathrm{~mm})$ to fine $(0.1-0.25 \mathrm{~mm}) /$ Fine $(0.1-0.25 \mathrm{~mm}) /$ Fine $(0.1-0.25 \mathrm{~mm})$ to medium $(0.25-$ $0.5 \mathrm{~mm}) /$ Medium $(0.25-0.5 \mathrm{~mm}) /$ Medium $(0.25-0.5 \mathrm{~mm})$ to Coarse $(0.5-1 \mathrm{~mm}) /$ Coarse $(0.5-1 \mathrm{~mm}) /$ Coarse $(0.5 \mathrm{~mm}$ $1 \mathrm{~mm})$ to very coarse $(>1 \mathrm{~mm}) /$ Very coarse $(>1 \mathrm{~mm})$.

Inclusion shape: Identification of shape of inclusion, with reference to Powers' scale of roundness (see Barraclough 1992): Angular/Sub angular/Rounded/Well rounded/Irregular/Elongated/Flat.

Inclusion sorting: Identification of how the inclusions been sorted, as they appear distributed throughout the fabric (as visible in the profile). In other words, whether they all cluster together in one very localised area (very poorly sorted), or are very evenly spread throughout the fabric (very well sorted). Values recorded with reference to existing scales of pebble sorting (see Barraclough 1992): Very poor/Poor/Fair/Well/Very well.

Inclusion frequency: How frequent is the occurrence of this inclusion in the fabric (as a proportion of the fabric). With reference to the percentage inclusion estimation chart (after Mathew et al. 1991): Very sparse $(<5 \%) /$ Sparse $(5-10 \%) /$ Moderate $(10-20 \%) /$ Frequent $(>20 \%)$.

\subsection{Surface treatment}

Following details of the fabric of a sherd, the second broad category of information that was recorded was the way in which its surface(s) had been finished. This encompassed both: (1) the surface finish, i.e. any additional coating that may have been applied to the vessel and how either that (or the uncoated surface of the pot) was treated; as well as (2) the decoration, being any decoration that might have been applied to this coating (or bare surface). The same details were recorded for both the external and internal surfaces of a potsherd.

\subsubsection{Surface finish}

Details of the following variables were recorded in order to record the surface finish of a sherd. 
Coating: Whether the surface of the sherd has been treated with any type of coating. Requires only a yes/no answer.

Coating type: If there are traces of a coating, then an assessment of the type of coating that has been applied to the surface. This was recorded with reference to a pre-defined list of values, based on treatments most commonly found in South Asian record: Wash/Slip/Self-slip/Slurry/Glaze/Bitumen.

Colour: The colour of the surface treatment, with reference to Munsell chart if possible. We recognised that the standard soil chart does not always represent the entire range of colours applied to the surfaces of pots.

Treatment?: Whether the surface of the sherd (either the natural surface of the fabric or the coating that has been applied to it) has been treated using a secondary process in any way. Requires only a yes/no answer.

Treatment type: A record of the type of treatment that has been used, with reference to a pre-defined list of values: Burnishing (horizontal)/Burnishing (vertical)/Burnishing (varied)/Smoothed/Wet smoothed/Shaved/Unidentified (abraded). Where two or more types of treatment are evident, this can be recorded in the 'Treatment description' field (below).

Treatment description: An extra field for any additional notes if required.

\subsubsection{Decoration}

Details of the following variables were recorded in order to record any decoration (defined as an additional process differing from a finish or treatment, such as a painted design, incision, or applique) that had been applied to the vessel and visible on the sherd.

Decoration?: Whether or not the exterior surface been decorated in any way. Requires only a yes/no answer.

Decoration type: If yes, a record of how it has been decorated? For more than one type of decoration, additional columns can be added as necessary.

Decoration description: A description of that type of decoration.

\subsection{Vessel morphology and metrics}

The third broad category of information that was recorded related to the form of the vessel, the way it was shaped, and the various dimensions of its (identifiable) elements.

\subsubsection{Vessel description}

First, we recorded information relating to the type of vessel indicated by the sherd and how it appeared to have been formed.

Sherd type: The type of sherd as defined by the part of the vessel it was from (see Figure 41). Recorded with reference to a pre-defined list: Rim/Base/Body/Neck/Shoulder/Spout/Handle/Complete profile/Complete vessel. Where more than one element of the profile could be identified (e.g. rim and neck), the most diagnostic feature takes precedence.

Vessel form: Vessel form as an indicator of the vessel's primary function (assumed on the basis of its shape), with reference to a pre-defined list of vessel 'types' familiar to those working in the South Asian context: Amphora/Bowl/Dish/Globular Pot/Jar/Lid/Miniature vessel/Necked vessel/Spouted vessel/Storage Jar/Unidentified.

Manufacturing technique: What type of technique(s) was used to make this vessel? Wheel/Slow wheel Hand/Hand-formed and wheel finished/Moulded/Unidentified. 


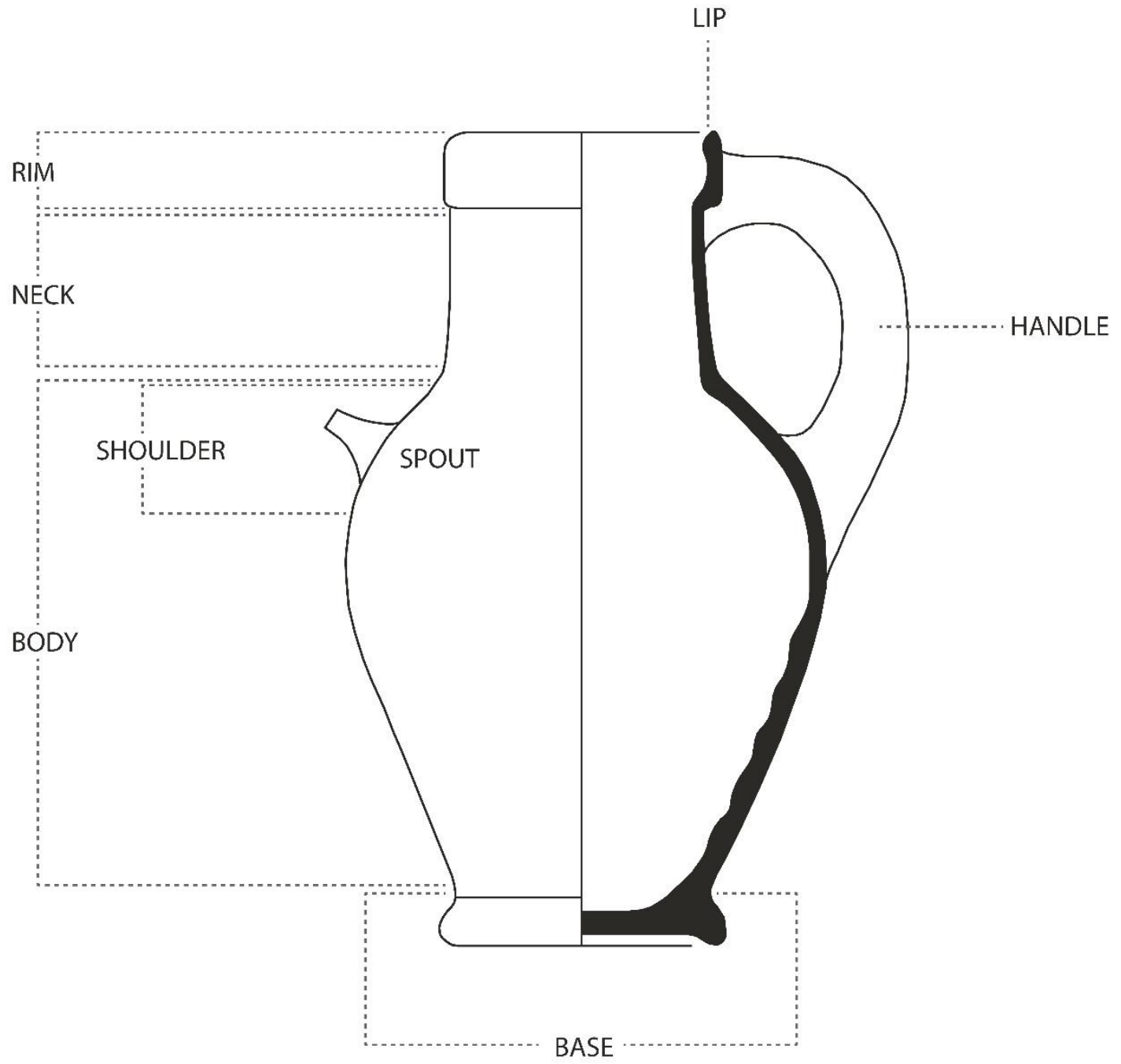

Figure 41: Diagram illustrating the different vessel parts as discussed in this study. Image credit: Authors.

\subsubsection{Sherd metrics}

The shape and size of a sherd, with all measurements taken using digital callipers, accurate to one millimetre.

Rim type: The type of rim profile defined and recorded with reference to a pre-defined (but by no means exhaustive) descriptive list of rim types (see Figure 42): Vertical/Flaring/Horizontally flaring/Outturned/Incurved/Overhanging/Carinated flaring/Carinated out-turned/Carinated incurved.

Rim shape: The precise shape of the rim lip, recorded with reference to a pre-defined list of terms: Plain/Thickened/Inward thickened/Outward thickened/Horizontally flattened/Horizontally flattened and thickened/Horizontally flattened and outwardly thickened/Horizontally flattened and inwardly thickened/Outward bevelled/Inward bevelled.

Rim diameter: In centimetres, using a rim chart.

$\%$ Surviving: The percentage of the original diameter of the rim that survives, rounded to the nearest $5 \%$, using a rim chart. 


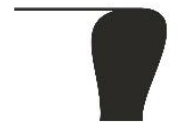

Thickened

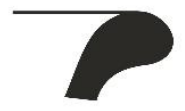

Outward thickened

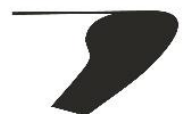

Inward thickened

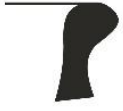

Vertical, outward thickened

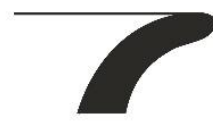

Outturned, plain

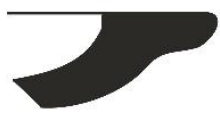

Carinated, flaring

Horizontally flattened, outward thickened

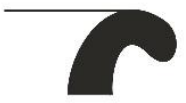

Overhanging

ertical, thickened horizontally flattened

Horizontally flattened, inward thickened

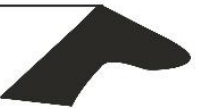

Overhanging outward bevelled

Figure 42: Diagram illustrating the different rim forms and their corresponding names as discussed in this study. Image credit: Authors.

Base type: The type of base that is evident, with reference to a pre-defined list of criteria: Round/Flat/Disc/Ring/Footed/String cut.

Base diameter: In centimetres, using a rim chart.

$\%$ Surviving: The percentage of the original diameter of the base that survives, rounded to nearest $5 \%$, using a rim chart.

\subsubsection{Sherd thickness, height and width}

A record of the thickness of each constituent part of the vessel (where more than one element of the profile is present). If only an unidentifiable bodysherd has survived, then only the body thickness need be recorded.

Body thickness: The thickness of the body of the vessel, taken from the widest point visible in section.

Rim thickness: The thickness of the widest part of the rim (perpendicular to the angle of curve).

Neck thickness: Thickness of neck of vessel (if visible and identifiable in profile), taken from the widest point visible in section. 
Shoulder thickness: Thickness of shoulder of vessel (if visible and identifiable in profile), taken from the widest point visible in section.

Base thickness: Thickness of base of vessel (if visible in profile). Measurement taken from as close to the centre of the base as possible.

Sherd height: Height of sherd (where it is possible to ascertain original orientation). If original orientation is not possible, the greatest length.

Sherd width: Width of sherd (perpendicular to height).

\section{Bibliography}

Balfet, H. 1965 'Ethnographical observations in North Africa and archaeological interpretation: the pottery of the Maghreb' in F.R. Matson (ed) Ceramics and Man, New York: Viking Fund Publication in Anthropology. 161-77.

Balfet, H. 1966 'La céramique comme document archéologique', Bulletin de la Société de Préhistoire Française 63(2), 279-310. https://doi.org/10.3406/bspf.1966.4071

Balfet, H., Fauvet-Berthelot, M.-F. and Monzon, S. 1983 Pour la normalisation de la description des poteries, Paris: Editions du Centre National de la Recherche Scientifique.

Barraclough, A. 1992 'Quaternary sediment analysis: a deductive approach at A-level', Teaching Geography 17(1), 15-18.

Ceccarelli, A. and Petrie, C.A. 2017 'Ceramic analysis and the Indus civilization. A review' in D. Frenez (ed) Walking with the Unicorn. Social Organization and Material Culture in Ancient South Asia, Jonathan Mark Kenoyer Felicitation Volume, Oxford: Archaeopress. 90-103.

Chakraborty, S. 2018 Ceramic Variability. An Ethnographic Perspective, New Delhi: Primus Book.

Choksi, A. 1998 'Pottery manufacturing techniques: the role of technical constraints and personal choices', Man and Environment 23(2), 107-18.

Costin, C.L. 2000 'The use of ethnoarchaeology for the archaeological study of ceramic production', Journal of Archaeological Method and Theory 7(4), 377-403. https://doi.org/10.1023/A:1026523023550

Degoy, L. 2005 'Variabilité technique et identité culturelle. Un cas d'étude ethnoarchéologique en Andhra Pradesh (Inde du sud)' in A. Livingstone Smith, D. Bosquet and R. Martineau (eds) Pottery Manufacturing Processes: Reconstitution and Interpretation, Actes du XIVème Congrès UISPP, Université de Liège, Belgique, 2-8 Septembre 2001, Oxford: Archaeopress. 49-56.

Deo, S.B. 1973 Mahurjhari Excavation (1970-1972), Nagpur: Nagpur University.

Gardin, J.C. 1976 Code pour l'analyse des formes de poteries, Paris: CNRS Editions.

Ghosh, A. (ed) 1964 Indian archaeology, 1961-62 - A review', Archaeological Survey of India, Government of India, New Delhi, 32-33.

http://nmma.nic.in/nmma/nmma doc/Indian\%20Archaeology\%20Review/Indian\%20Archaeology\%20196162\%20A\%20Review.pdf 
Gosselain, O.P. 2002 Poteries du Cameroun méridional. Styles techniques et rapports à l'identité, Paris: CNRS Editions.

Hawkes, J. and Abbas, R. 2016 'Copperplates in context: preliminary investigation of the study and archaeological settings of land grant inscriptions', Pratnatattva 22, 41-71.

Hawkes, J., Abbas, R. and Willis, M. 2016 'Report of the archaeological survey of Chamak and its surroundings, District Amaravati, Maharashtra', Ancient Asia 7, 1-7. https://doi.org/10.5334/aa.115

Hunter, G.A.P. 1933 'The antiquities of Mahurjhari' in K. Deshpande (ed) Śaradāśrama Varshika, Śake 1855, Yeotmal. 30-35.

Kramer, C. 1997 Pottery in Rajasthan. Ethnoarchaeology in two Indian Cities, Washington: Smithsonian Institution Press.

Lefrancq, C. and Hawkes, J. 2019a Archaeological Ceramics from Mahurjhari: The Fabric Groups https://doi.org/10.5281/zenodo.3548752

Lefrancq, C. and Hawkes, J. 2019b Archaeological Ceramics from Mahurjhari: The Vessel Forms https://doi.org/10.5281/zenodo.3548883

Lefrancq, C. and Hawkes, J. 2019c Archaeological Ceramics from Mahurjhari: Pottery Classes by Stratigraphic Layer https://doi.org/10.5281/zenodo.3548898

Lefrancq, C. and Hawkes, J. 2019d Archaeological Ceramics from Mahurjhari: Vessel Forms by Stratigraphic Layer https://doi.org/10.5281/zenodo.3548902

Lemonnier, P. 1993 Technological Choices. Transformation in Material Cultures since the Neolithic, London: Routledge.

Leroi-Gourhan, A. 1964 Le geste et la parole, Tome I: Technique et langage, Paris: Albin Michel.

Leroi-Gourhan, A. 1965 Le geste et la parole, Tome II, La mémoire et les rythmes, Paris: Albin Michel.

Leroi-Gourhan, A. 1971 L'homme et la matière, Paris: Albin Michel.

Livingstone Smith, A. 2001 Chaînes opératoire de la poterie. Références ethnographiques, analyses et reconstitution, Unpublished PhD thesis, Brussels: Université libre de Bruxelles.

Mahias, M.C. 1993 'Pottery techniques in India. Technical variants and social choice', in P. Lemonnier (ed) Technological Choices. Transformation in Material Cultures since the Neolithic, London: Routledge. 157-80.

Mahias, M.C. 2011 'Les potières Kota (Nilgiri). Savoir-faire techniques, distinction des genres et fabrique des dieux' in M.C. Mahias (ed) Construire les savoirs dans I'action. Apprentissages et enjeux sociaux en Asie du sud, Paris: Collection Purusartha. 159-204.

Matthew, A.J., Woods, A.J. and Oliver, C. 1991 'Spots before your eyes: new comparison charts for visual percentage estimation in archaeological material' in A.P. Middleton and I.C. Freestone (eds) Recent Developments in Ceramic Petrology, British Museum Occasional Paper 81, London: The British Museum. 211-63.

Miller, D. 1985 Artefacts as Categories: a Study of Ceramic Variability in Central India, Cambridge: Cambridge University Press.

Mohanty, R.K. 1999 'Significance of a bead manufacturing centre at Mahurjhari, District Nagpur, Maharashtra, India', Man and Environment 26(2), 79-89. 
Mohanty, R.K. 2003 'A preliminary report on the excavations at Mahurjhari, 2001-02: a Megalithic and early historic site in Vidarbha, Maharashtra', Pratnatattva 9, 41-48.

Mohanty, R.K. 2004 'Excavations at Mahurjhari and exploration in Vidarbha', Annual Report of the Deccan College Post Graduate and Research Institute 2003-04, 50-52.

Mohanty, R.K. 2005 'Some important observations: excavations at Mahurjhari (2001- 2004', Man and Environment 30(1), 106-7.

Mohanty, R.K. 2006 'Excavation at Mahurjhari and explorations in Vidarbha, Maharashtra', Annual Report of the Deccan College Post Graduate and Research Institute 2004-05, 76-80.

Mohanty, R.K. and Thakuria, T. 2014 'Peninsular India and South India' in D.K. Chakrabarti and M. Lal (eds) The Texts, Political History and Administration till c.200 BC, History of Ancient India III, New Delhi: Aryan. 343-78.

Mohanty, R.K., Hawkes, J., Lefrancq, C. and Abbas, R. in press 'Report on the dating of the Historical Period site at Mahurjhari, Vidarbha', Heritage, Journal of Interdisciplinary Studies in Archaeology 7.

Orton, C. and Hughes, M. 2013 Pottery in Archaeology, 2nd edition, Cambridge: Cambridge University Press. https://doi.org/10.1017/CBO9780511920066

Orton, C., Tyers, P. and Vince, A. 1993 Pottery in Archaeology, Cambridge: Cambridge University Press.

Parikh, D. and Petrie, C.A. 2015 'Urban-rural dynamics and Indus ceramic production in Northwest India: a preliminary analysis of the pottery from Masudpur I and Masudpur VII' in V. Lefevre, A. Didier and B. Mutin (eds) Man and environment in Prehistoric and Protohistoric South Asia: New Perspectives, South Asian Archaeology and Art 2012, Volume 1, Turnhout: Brepols. 221-41.

Rice, P.M. 1987 Pottery Analysis. A Sourcebook, Chicago: University of Chicago Press.

Rivett-Carnac, J.H. 1879 'Prehistoric remains in Central India', Journal of the Asiatic Society of Bengal 48(1), 1-16.

Roux, V. 2003 'Ceramic standardization and intensity of production: quantifying degrees of specialization', American Antiquity 68(4), 768-82. https://doi.org/10.2307/3557072

Roux, V. 2007 'Ethnoarchaeology: a non-historical science of reference necessary for interpreting the past', Journal of Archaeological Method and Theory 14 (2), 153-78. https://doi.org/10.1007/s10816-007-9030-8

Roux, V. 2011 'Anthropological interpretation of ceramic assemblages: foundations and implementations of technological analysis' in S. Scarcella (ed) Archaeological Ceramics: A Review of Current Research, Oxford: Archaeopress. 80-88.

Roux, V. and Courty, M.A. 2016 Des céramiques et des hommes. Décoder les assemblages archéologiques, Paris: Presses Universitaires de Paris Ouest.

Rückl, S. and Jacob, L. 2016 '“With a little help from my wheel”': wheel-coiled pottery in Protogeometric Greece', Hesperia: The Journal of the American School of Classical Studies at Athens 85(2), 297-321.

https://doi.org/10.2972/hesperia.85.2.0297

Rye, O.S. 1981 Pottery Technology: Principles and Reconstruction, Washington: Smithsonian Institute.

Rye, O.S. and Evans, C. 1976 Traditional Pottery Techniques of Pakistan, Washington: Smithsonian Institution Press. https://doi.org/10.5479/si.00810223.21.1

Saraswati, B. and Behura, N.K. 1966 Pottery Techniques in Peasant India, Calcutta: Government of India. 
Sawant, R. 2008-2009 'State formation process in the Vidarbha during the Vakataka period', Bulletin of the Deccan College 68-69, 137-62.

Sawant, R. 2010 'Review of archaeological investigations in the Protohistoric and historical archaeology of Vidarbha', Man and Environment 35(2), 45-65.

Sawant, R. 2012 Historical Archaeology of Vidarbha, Bhopal: Indira Gandhi Rashtriya Manav Sangrahalaya and New Delhi: Aryan Books International.

Sharma, S., Singh, P. and Das, M. 2017 'The past and the present of the craft of pottery in Assam' in S.G. Deo, A. Baptista and J. Joglekar (eds) Rethinking the Past: A Tribute to Professor V.N. Mishra, Pune: Indian Society for Prehistoric and Quaternary Studies. 330-42.

Shepard, A.O. 1965 Ceramics for the Archaeologist, Washington: Carnegie Institution of Washington.

Shete, G. and Kantikumar, P. 2017 'Pre-Iron Age and Iron Age pottery of Khopdi, District Nagpur, Maharashtra', Journal of Multidisciplinary Studies in Archaeology 5, 212-23.

Shete, G. 2018 'The Early Iron Age pottery of Vidarbha: a comparative study', Heritage: Journal of Multidisciplinary Studies in Archaeology 6, 333-43.

Sinopoli, C.M. 1991 Approaches to Archaeological Ceramics, New York-London: Plenum Press.

https://doi.org/10.1007/978-1-4757-9274-4

Sinopoli, C.M. 1993 Pots and Palaces. The Earthenware Ceramics of the Noblemen's Quarter of Vijayanagara, New Delhi: Manohar.

Sontakke, V., Vaidya, S., Ganvir, S. and Joglekar, P. 2016 'Excavation at Nagardhan, Nagpur District, Maharashtra (2015-2016)', History Today 17, 43-51.

Spataro, M. and Villing, A. (eds) 2015 Ceramics, Cuisine and Culture: The Archaeology and Science of Kitchen Pottery in the Ancient Mediterranean World, Oxford: Oxbow Books.

Thakuria, T. and Mohanty, R.K. 2009 'A stone bead manufacturing centre in Peninsular India: a preliminary study of manufacturing debitage from Trench F of Mahurjhari excavations, Maharashtra', Tamil Civilization 23, 15-38.

Vaidya, S. and Mohanty, R.K. 2015 'Antiquity of bead manufacturing at Mahurjhari and its relevance in Early Iron Age Megalithic culture of Vidarbha', Heritage: Journal of Multidisciplinary Studies in Archaeology 3, 400-9.

Van der Leeuw, S. 1976 Studies in the Technology of Ancient Pottery, Unpublished PhD Thesis, Amsterdam: Universiteit van Amsterdam.

Vokaer, A. 2011 La Brittle Ware en Syrie. Production et diffusion d'une céramique culinaire de l'époque hellénistique à l'époque omeyyade, Fouilles d'Apamée de Syrie 2, Brussels: Académie Royale de Bruxelles.

\section{Acknowledgements}

The research presented in this article was carried out in collaboration between the Deccan College Postgraduate and Research Institute (Deemed University), the Indian Numismatic, Historical and Cultural Research Foundation, the Institute Français de Pondichéry and The British Museum. It took place as part of the Asia Beyond Boundaries project, an ERC Synergy project funded by the European Research Council under the European Union's 7th Framework Programme (FP7/2007-2013)/ERC grant agreement no. 609823, awarded to Dr. Michael Willis. 